\title{
Prediction of Ductile Fracture in Metal Blanking
}




\section{CIP-DATA LIBRARY TECHNISCHE UNIVERSITEIT EINDHOVEN}

\section{Goijaerts, Ad.}

Prediction of Ductile Fracture in Metal Blanking / by Ad Goijaerts. - Eindhoven : Technische Universiteit Eindhoven, 1999.

Proefschrift. - ISBN 90-386-2751-3

NUGI 834

Trefwoorden: taaie breuk / experimentele karakterisatie / metalen / ponsen ; produktvorm / eindige-elementenmethode

Subject headings: ductile fracture / experimental characterisation / metals / blanking ; product shape / finite element method

This thesis was prepared with the $\mathrm{BT}_{\mathrm{E}} \mathrm{X} 2_{\varepsilon}$ documentation system.

Printed by University Press Facilities, Eindhoven, The Netherlands.

This research was financially supported by the Innovative Research Programme (IOP). 


\title{
Prediction of Ductile Fracture in Metal Blanking
}

\author{
PROEFSCHRIFT \\ ter verkrijging van de graad van doctor \\ aan de Technische Universiteit Eindhoven, \\ op gezag van de Rector Magnificus, prof.dr. M. Rem, \\ voor een commissie aangewezen door het College voor Promoties \\ in het openbaar te verdedigen op \\ woensdag 15 december 1999 om 16.00 uur
}

door

Adrianus Maria Goijaerts

geboren te Schijndel 
Dit proefschrift is goedgekeurd door de promotoren:

prof.dr.ir. F.PT. Baaijens

en

prof.dr.ir. H.E.H. Meijer

Copromotor:

dr.ir. L.E. Govaert 


\section{Contents}

Summary $\quad$ ix

Notation $\quad$ xi

1 Introduction 1

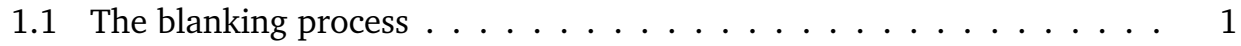

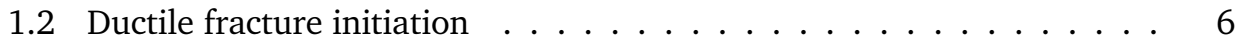

1.3 Objective of this thesis . . . . . . . . . . . . . . . . . 7

1.4 Scope of the study . . . . . . . . . . . . . . 8

1.5 Outline of the thesis ................. 8

2 Methods 11

2.1 Continuum mechanics ... . . . . . . . . . . . . 11

2.1.1 Constitutive model using the Von Mises flow rule . . . . . . . . 12

2.1.2 Constitutive model with Bodner-Partom viscosity . . . . . . . . 14

2.2 Material characterisation . . . . . . . . . . . . . . . . 15

2.2.1 Von Mises plasticity for large strains . . . . . . . . . . 15

2.2.2 Constitutive model with adapted Bodner-Partom viscosity . . . 17

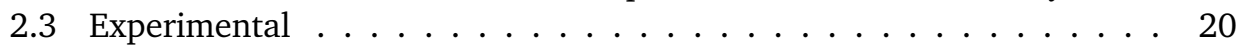

2.3.1 Planar blanking setup . . . . . . . . . . . . . . 20

2.3.2 Digital Image Correlation (DIC) . . . . . . . . . . . . . . . . . . 22

2.3.3 Axisymmetric blanking setup .................. 24

2.3.4 Measurements at the blanked edge . . . . . . . . . . . . . 26

2.4 Finite element model of the blanking process . . . . . . . . . . . 27

3 Experimental validation prior to fracture 31

3.1 Introduction . . . . . . . . . . . . . . . . . . . . . . . . . . . .

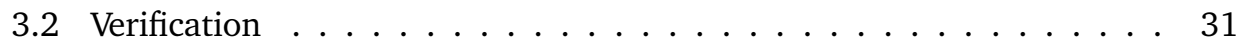

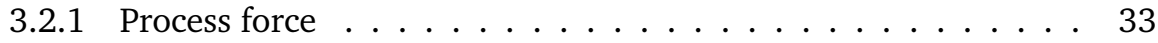

3.2 .2 Deformation field ....................... 33

3.2.3 Qualitative three-dimensional FEM-model . . . . . . . . . . . 37 
3.2 .4 Roll-over . . . . . . . . . . . . . . . . . . . . . . 38

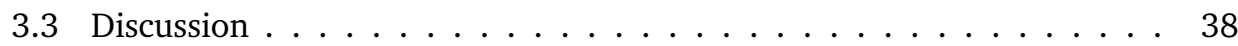

4 Prediction of ductile fracture in blanking for a stainless steel 41

4.1 Introduction . . . . . . . . . . . . . . . . . . . . 41

4.2 Blanking experiments . . . . . . . . . . . . . . . . . 42

4.3 Characterising ductile fracture in blanking . . . . . . . . . . . 44

4.3 .1 Strategy . . . . . . . . . . . . . . . . . . . . 44

4.3.2 Application of ductile fracture models . . . . . . . . . . . 44

4.4 Tensile tests under different hydrostatic pressures . . . . . . . . . . . 48

4.4 .1 Experimental results . . . . . . . . . . . . . . . . . . . 49

4.4 .2 FEM-simulation . . . . . . . . . . . . . . . 50

4.5 Characterising ductile fracture in tensile testing . . . . . . . . . 53

4.5 .1 Strategy . . . . . . . . . . . . . . . . 53

4.5.2 Application of ductile fracture models, using a tensile test . . . 54

4.5.3 A new ductile fracture model for both blanking and tensile testing 55

4.6 Discussion . . . . . . . . . . . . . . . . . . . 57

5 Influence of the blanking velocity 59

5.1 Introduction . . . . . . . . . . . . . . . . 59

5.2 Effect of punch speed on process force . . . . . . . . . . . 60

5.2.1 Comparison of experimental and numerical forces . . . . . . 60

5.2.2 Deviations due to thermal softening . . . . . . . . . . . 61

5.2 .3 Extrapolation to larger strain rates . . . . . . . . . . . 62

5.3 Effect of punch speed on ductile fracture initiation . . . . . . . . . 64

5.3 .1 Experimental results . . . . . . . . . . . . . . . 64

5.3 .2 Numerical predictions $\ldots \ldots \ldots \ldots \ldots 6$

5.4 Discussion . . . . . . . . . . . . . . . . . . . 66

6 Evaluation of fracture models for different metals in blanking $\quad 67$

6.1 Introduction . . . . . . . . . . . . . . . 67

6.2 Investigated metals . . . . . . . . . . . . . . . . 68

6.3 Results for different metals . . . . . . . . . . . . . . . . . . . . . . 69

6.3 .1 Material characterisation . . . . . . . . . . . . . . 69

6.3.2 Tensile testing . . . . . . . . . . . . . . . . . . . 71

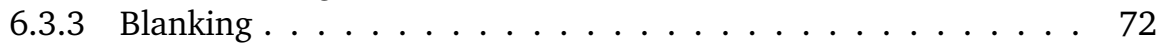

6.3.4 Application of criteria to both characterisation approaches . . . 74

6.4 Discussion . . . . . . . . . . . . . . . . . . . . . 75

7 Investigation of the blanking process for different grain sizes $\quad 77$

7.1 Introduction . . . . . . . . . . . . . 77

7.2 Recrystallisation procedures . . . . . . . . . . . . . 78

7.3 Results for different grain sizes $\ldots \ldots \ldots$. . . . . . . . . 79 
7.3.1 Process forces . . . . . . . . . . . . . . . . . . . 79

7.3.2 Deformation fields . . . . . . . . . . . . . . . . 83

7.3.3 Characteristics of blanked edges _. . . . . . . . . . . 83

7.4 Discussion . . . . . . . . . . . . . . . . . . . 84

8 Conclusions and recommendations $\quad 85$

8.1 Conclusions . . . . . . . . . . . . . . . . . . 85

8.2 Recommendations . . . . . . . . . . . . . . . . 87

$\begin{array}{lr}\text { Bibliography } & 89\end{array}$

$\begin{array}{lr}\text { Samenvatting } & 95\end{array}$

$\begin{array}{ll}\text { Dankwoord } & 97\end{array}$

$\begin{array}{lr}\text { Curriculum Vitae } & 99\end{array}$ 
viii Contents 


\section{Summary}

Metal blanking is a widely used technique in high volume production of metal components. General guidelines for this process exist but are not sufficient to overcome the trial and error situation in designing blanking processes, where requirements for cycle time and product dimensions become more demanding. Therefore, appropriate modelling and understanding of the blanking process could be beneficial to control the product shape of a blanked edge (involving roll-over zone, shear zone and fracture zone). Numerical tools using the Finite Element Method are applicable, but still one major issue needs to be solved to attain a useful model of the complete blanking process: the accurate prediction of ductile fracture.

This thesis focuses on the development of methods to accomplish a model of the blanking process that can accurately predict blanked edges. Prediction of the roll-over zone largely depends on the mechanical description of the material behaviour. Ductile fracture initiation marks the end of the shear zone and the start of the fracture zone. Thus, the reliability of the material description and the fracture criterion determine the predictive quality of the numerical model for the blanked edge.

An accurate model of the blanking process is developed for a ferritic stainless steel. Under the assumption of isotropy and isotropic hardening, an elasto-plastic model using Von Mises plasticity is employed. The material parameters are experimentally determined for equivalent logarithmic strains up to 3 by performing tensile tests on pre-rolled specimens. A planar blanking setup is used, which enables the in-situ measurement of both process forces and deformations (using a Digital Image Correlation technique). After implementation of the material description, the numerical model is validated up to the point of fracture initiation for different clearances and shows accurate predictions for the roll-over zone.

Ductile fracture is known to depend on the deformation and loading history. A general class of fracture criteria is used where ductile fracture is stated to initiate when an integral expression, which is a function of the deformation and loading history, reaches a critical value, given by the material parameter $C$. The experimental determination of this parameter $C$ is the key issue. In literature, no example has been found where the initiation of ductile fracture is accurately predicted for different loading situations with one critical parameter $C$. Generally, the experimental determination of 
$C$ is performed under loading conditions comparable to the loading conditions in the desired application.

In order to evaluate existing fracture models, an axisymmetric setup for the blanking process has been built that provides the verification data needed for five different clearances and different cutting radii of the tools. The first approach is to determine the critical $C$ in a blanking experiment for one clearance. When the criterion proposed by Rice \& Tracey is adapted, precise predictions for other clearances and different cutting radii can be obtained close to or within the experimental error. The second, more generally applicable and more straight forward, approach involves the determination of $C$ by using a standard tensile test. This requires, however, a criterion that is valid for both blanking and tensile testing, which is not the case for the modified Rice \& Tracey criterion. To this end, in this thesis, a new criterion is proposed and an extra evaluation for tensile tests under superposed pressures is performed. The results, finally obtained, deviate less than $7 \%$ for all five clearances and cutting radii, used for the stainless steel.

Next, the effect of the punch speed on the blanking process is investigated. To capture strain rate effects, an elasto-viscoplastic model is applied. Strain rate is shown, both experimentally and numerically, to have a significant influence on the maximum process force for industrial blanking speeds up to approximately $10[\mathrm{~mm} / \mathrm{s}]$. Within this range of blanking speeds no effect of the punch velocity on ductile fracture initiation is observed in the experiments, and the simulations confirm this. To correctly describe the blanking process for larger punch speeds, thermo-mechanical coupling in the numerical model is needed. This can be done.

The two approaches developed successfully for the stainless steel - characterisation of ductile fracture either in a relatively complex blanking experiment or in a tensile test - are, accordingly, evaluated for four other metals that are generally applied in blanking processes. The method, involving the blanking experiment, produces good results employing the adapted Rice \& Tracey criterion. The characterisation by using a tensile test only, making use of the newly proposed ductile fracture criterion, yields satisfactory results but provides a fast and cheap method, suitable for industrial application, to predict product shapes. Scientifically, and also from an engineering point of view, this is an important result, since, in contrast with all existing criteria, the newly proposed criterion is the only one that can correctly predict ductile fracture in both blanking and tensile testing under different superposed pressures. Its generality remains to be investigated, e.g. by checking whether it can also be applied in other forming processes.

Finally, a study is presented into the grain size effect on the blanking process. Experiments are performed with six and less grains over the thickness of the sheet. When single-crystals are considered, the orientation of the grain has a large influence on the deformation, and large deviations are observed. Due to the severely constraining boundary conditions, blanking products prove to be quite reproducible once the situation is reached that six or more grains over the thickness are present. 


\section{Notation}

\section{Quantities}

$\begin{array}{ll}\alpha, a, A & \text { Scalar } \\ \vec{a} & \text { Vector } \\ \boldsymbol{A} & \text { Second order tensor } \\ \boldsymbol{I} & \text { Second order unity tensor } \\ \mathbf{0} & \text { Second order zero tensor } \\ { }^{4} \mathrm{~A} & \text { Fourth order tensor } \\ { }^{4} \boldsymbol{I} & \text { Fourth order unity tensor }\end{array}$

\section{Operators}

$\begin{array}{ll}\vec{\nabla} & \text { Gradient operator } \\ A^{c} & \text { Conjugate } \\ A^{d} & \text { Deviatoric part } \\ \boldsymbol{A} \cdot \boldsymbol{B} & \text { Inner tensor product } \\ \boldsymbol{A}: \boldsymbol{B} & \text { Double inner product } \\ \vec{a} \vec{b} & \text { Dyadic product } \\ \operatorname{det}(\boldsymbol{A}) & \text { Determinant }\end{array}$


xii Notation 


\section{Chapter 1}

\section{Introduction}

During the past decade, two clear trends have been observed in the production of metal components. Firstly, time-to-market needs to be shortened in order to introduce new products competitively. Secondly, ongoing miniaturisation forces product dimensions to decrease.

Of all forming processes employed in high volume production, blanking is one of the most widely used separation techniques. Still, analysis of blanking is mainly based on phenomenological knowledge. Since, also in blanking processes, requirements concerning product dimensions are becoming more severe, empirical guidelines lead to more lengthy trial and error procedures in the development of the processes employed. One obvious way to tackle this problem, is to develop an appropriate numerical design tool, that can accurately predict the dimensions of a blanked product. One major problem in the modelling of the blanking process is the lack of an adequate description of ductile fracture, which greatly determines the blanked product shape. This thesis deals with the issue of the accurate prediction of blanked edges and will therefore focus on the development of an appropriate ductile fracture model.

In this introductory chapter the blanking process will be discussed in section 1.1. Next, the difficult issue of ductile fracture is given attention in section 1.2, followed by the objective of this study in section 1.3. In section 1.4 the scope of this research is formulated and finally, in section 1.5, an outline of the thesis is presented.

\subsection{The blanking process}

The blanking process, which is also referred to as shearing, or punching process, is illustrated in figure 1.1. A metal sheet is pressed on a die by a blankholder and perforated by a punch. It is of no principle concern whether the final blank or the perforated sheet is the product. Four characteristic dimensions can be distinguished 


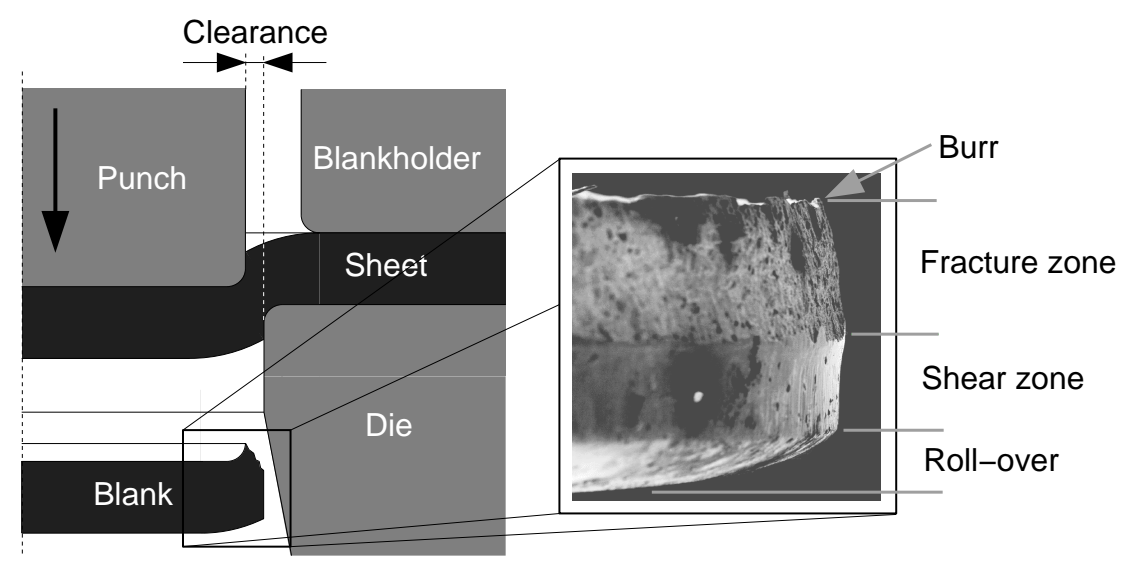

Figure 1.1: A schematic representation of the blanking process with an indication of the different zones determining the product shape.

on the blanked edge. Their formation can be explained from three different stages of the blanking process:

1. The bending stage. The (symmetric) punch and die can be considered to represent a four point (or two ring) bending setup. Here, the roll-over or draw-in starts to develop. Because the clearance between punch and die is much smaller than the sheet thickness, this bending stage is small and will generally merge into the shearing stage, at a punch displacement in the order of $5-10 \%$ of the sheet thickness.

2. The shearing stage. At the beginning of this stage the material starts to yield locally at the cutting radius of the punch and the main mode of deformation is shear along a band from the punch to the die. As long as the punch force is increasing due to strain hardening of the material, the 'roll-over' will also increase. The material that slides along the punch will eventually form the smooth shear zone which is approximately perpendicular to the plane of the sheet.

3. The fracture stage. During the shearing stage the material is deformed with extremely large and local strains, as the high pressure in the material postpones fracture. At a certain point, fracture will initiate and will grow from the punch to the die, or vice versa, along a localised band of large strains. The resulting fracture zone can be recognised by a rough surface that generally evolves 
obliquely to the shear zone, depending on the clearance (figure 1.1). Fracture may initiate next to the punch or die, which results in a burr.

The different zones determine the quality of the blanked edge. Some examples of how these zones may vary are given in figure 1.2 for two different clearances for stainless steel and aluminium. From this figure it is clear that the roll-over zone is larger for stainless steel, which is related to the stronger strain hardening of this metal. The fracture zone is larger for aluminium due to the fact that this metal is more brittle and fractures at an earlier stage of the process. The influence of the clearance is also evident: a wider clearance results in a larger roll-over because the deformation zone is wider; furthermore, a smaller clearance results in a larger shear zone due to the higher pressure in the metal, which postpones fracture.

For most industrial applications the quality of the product is related to the shape of the blanked edge. Some examples of sophisticated blanked products are presented in figure 1.3:

- Links from a chain of a transmission belt in a CVT (Continuously Variable Trans-

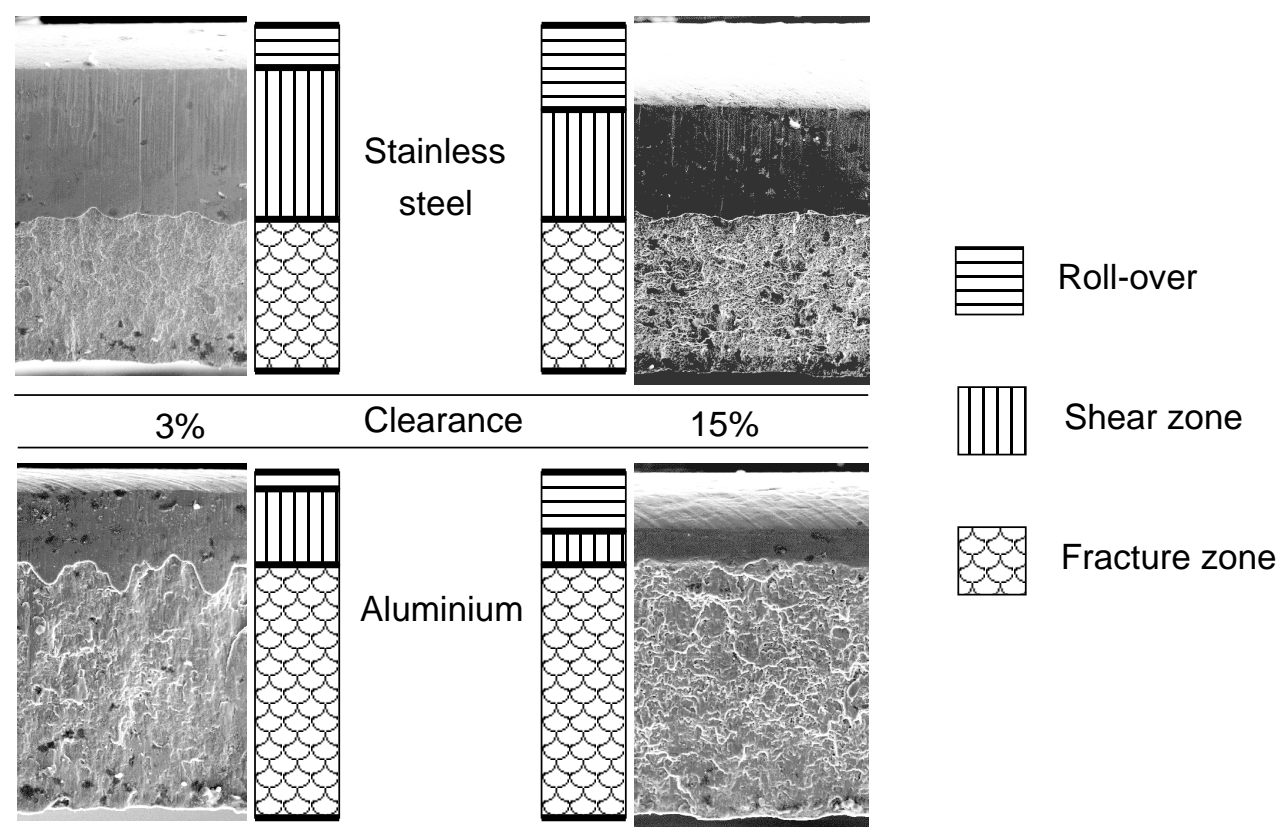

Figure 1.2: Examples of different blanked edges for a stainless steel and an aluminium, blanked with two different clearances (expressed as a percentage of the sheet thickness). 

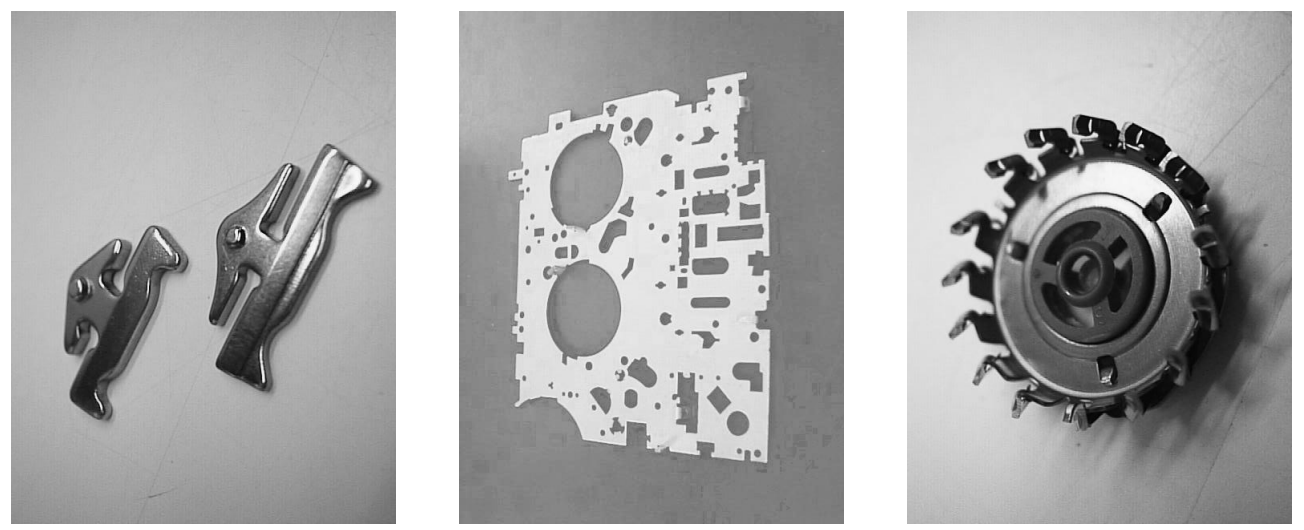

Figure 1.3: Some examples of blanked products: links from the chain of a CVT transmission belt (left); mounting plate for a car cassette player (centre); rotating knives of an electric razor (right).

mission) automatic gear box. Since the blanked edges transfer the transmission load, the shape tolerances are narrow and a fracture zone is not allowed.

- Mounting plate for a car cassette player. A smooth blanked edge is required for some holes to facilitate the connection of mechanical parts that need accurate positioning.

- Rotating knives of an electric razor. For haircutting applications the blanked edges must meet tight specifications. The part displayed is an assembly of a number of high accuracy blanked and formed parts.

These examples represent just a small selection of the wide range of products in which the blanking process is an important, or even critical, step in the manufacturing process.

Current realisations of blanking are mainly based on empirical knowledge. Chang \& Swift (1950) and Chang (1951) performed both plane strain and axisymmetric experiments for different materials and they recommended optimum clearances for a 'clean fracture' and 'least work' for different materials. Tilsley \& Howard (1958) investigated also the effect of punch speed on the blanking process. Noble \& Oxley (1963) performed and analysed blanking experiments with different cutting radii of the tools. Although the emphasis of the research in that time was mainly on reducing the process energy required, they also took into consideration the quality and the appearance of the blanked edge. An extensive review of all parameters that influence 
the blanking process was presented by Johnson \& Slater (1967). Balendra \& Travis (1969) investigated variations in the blanking process due to materials with the same composition but with different heat treatments, using speeds as high as $100[\mathrm{~m} / \mathrm{s}]$.

Ductile fracture initiation is a determining aspect of the blanking process concerning the resulting product shape. It marks the end of the shear zone and the beginning of the fracture zone. It is known that ductile fracture initiation can be postponed by increasing the pressure in the material. As an application thereof, a prime example in the problems considered is the so-called fine-blanking process (Nakagawa \& Maeda, 1968; Johnston et al., 1968), in which a V-ring and a counterpunch are applied to increase the internal pressure of the material. Apart from this solution, several other suggestions have been made to change the geometry of the blanking tools in order to postpone ductile fracture initiation and thus increase the shear zone (e.g. Fukui et al., 1971; Kondo \& Suzuki, 1996).

All experimental data collected on blanking processes have resulted in rules of thumb (Hilbert, 1972; Spur \& Stöferle, 1985; Iliescu, 1990) or tabular information with general guidelines and trends (e.g. Walsh, 1994, chapter 9). For the prediction of blanked edges this phenomenological information will suffice as long as the accuracy required is not limited. Since both, materials and specified product shapes, are increasingly becoming more non-standard, empirical approaches, like these, nowadays often fail for high accuracy specifications. The number of experiments, needed to establish the appropriate blanking settings, is exploding and valuable time and resources are spent during trial and error. Moreover, even after setting the 'optimal' process conditions, problems frequently arise during production of high quality blanked products, when tool wear or variation in material properties causes uncontrollable variations in product dimensions, leading to intolerably high reject rates.

Problems in process design for production practice are generally caused by lack of fundamental understanding of the phenomena governing the blanking process. An accurate model of the blanking process, which is able to predict product shapes, represents in essence the design tool that is currently missing. Analytical models are available (Noble \& Oxley, 1963; Zhou \& Wierzbicki, 1996), but in engineering practice their use is limited to determining estimates of the more global quantities (e.g. maximum punch force). This is mainly due to the fact that the blanking process is principally too complex for an analytical treatment. Finite element modelling appears to provide an appropriate tool to model complex processes, like the blanking process (Brokken, 1995; Brokken et al., 1996; Jeong et al., 1996; Post \& Voncken, 1996; Taupin et al., 1996; Brokken et al., 1997, 1998; Faura et al., 1998; Klocke \& Sweeney, 1998; Samuel, 1998; Brokken, 1999). However, one major difficulty in this numerical approach is the description of ductile fracture initiation, which is essential for a quantitatively correct prediction of the blanked edge. Therefore, this thesis applies the numerical tools, currently available, but will, however, focus on the most important missing link: the quantitative prediction of ductile fracture for metals. 


\subsection{Ductile fracture initiation}

The physical background for ductile fracture initiation in metals is pretty well understood from the sequential mechanisms of initiation, growth and coalescence of voids, as is shown in figure 1.4 (Broek, 1971; Dodd \& Bai, 1987; Bolt, 1989). Voids can initiate by dislocation pile-ups at grain boundaries, secondary phase particles or inclusions. Initiation, growth and coalescence of voids are driven by plastic deformation and largely influenced by the hydrostatic pressure (Bolt, 1989; Habraken, 1996). Considering this, it seems evident to incorporate the deformation and loading history in a ductile fracture initiation model.

Both Linear Elastic Fracture Mechanics and Elastic Plastic Fracture Mechanics (an extensive overview is provided by Atkins \& Mai, 1985; Kanninen \& Popelar, 1985; Broek, 1989; Gdoutos, 1993; Anderson, 1995) do not incorporate the deformation and loading history in the description of fracture initiation. Moreover, both approaches can not cope with large plastic deformations. Besides, in Fracture Mechanics theory a crack is assumed to be present to start with and the analysis only focuses on the question whether this initial fracture will grow or will not. Crack initiation is not an issue. All this is, obviously, not compatible with the fracture phenomena occurring in the blanking process.

'Forming Limit Diagrams' describe the ultimate strains to which a material can be deformed prior to failure (Keeler, 1965; Goodwin, 1968). These diagrams are extensively used to define the onset of plastic instability in sheet metal working processes that exhibit a plane state of stress (e.g. Boudeau \& Gelin, 1992; Gronostajski \& Zimniak, 1995; Atkins, 1996). A combination of major and minor principal strains is assumed to determine whether the material will be plastically stable or unstable. However, 'Forming Limit Diagrams' are not generally valid for bulk forming processes,

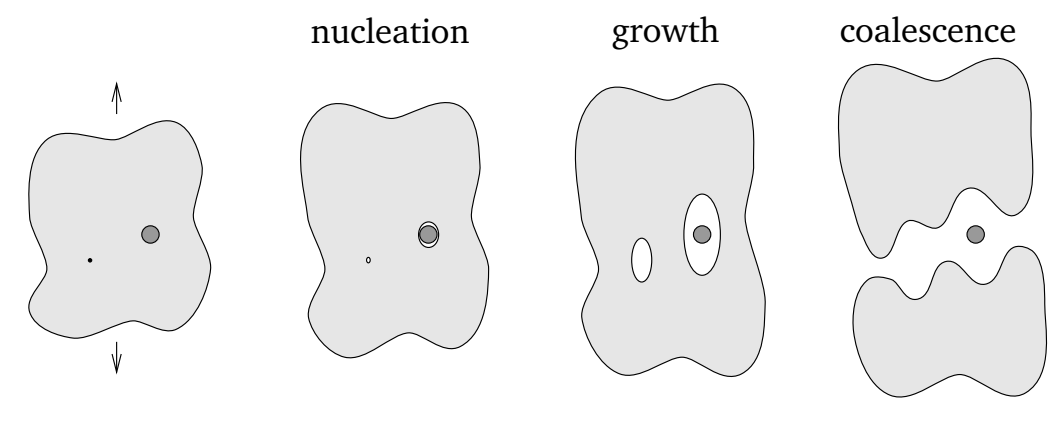

Figure 1.4: Schematic representation of the nucleation, growth and coalescence of voids. Voids can initiate by dislocation pile-ups at grain boundaries, secondary phase particles or inclusions. 
like blanking, in which the state of stress is triaxial. Furthermore - and more importantly - these methods do not incorporate the deformation and loading history.

To include the decisive deformation and loading history in the description of ductile fracture initiation, a local state variable has to be used that is updated constantly. Two principally different approaches are possible; the state variable (damage or fracture parameter) either influences the material behaviour or it does not.

The first class of models are - generally - based on Continuum Damage Mechanics (see e.g. Kachanov, 1986; Lemaitre, 1996), that defines a local damage parameter which evolves from 0 (undamaged state) to 1 (completely damaged). This parameter influences the constitutive behaviour, usually by reduction of the yield stress. Yield functions that are dominated by a void volume fraction (Gurson, 1977; Tvergaard, 1990; Needleman et al., 1992) also decrease the yield stress with ongoing deformation. It should be noticed, however, that the experimental determination and validation of evolution laws for these history dependent state variables (damage parameter, void volume fraction) is difficult. Moreover, in the application of all these models that degenerate the material behaviour, special care has to be taken to avoid problems concerning mesh dependency and energy dissipation. Many solutions, called regularisation techniques, have been proposed to overcome these localisation difficulties (de Borst et al., 1994). However, mesh independent solutions for the issue of ductile fracture initiation, embodying extremely large plastic strains as in blanking, have, to the authors' knowledge, not been presented yet.

The second class of models does not suffer from the restrictions mentioned above and, in this thesis, the explicit choice is made to employ ductile fracture criteria that do incorporate the stress and strain history but do not influence the constitutive behaviour. An extensive review of this class of criteria is provided by Hartley et al. (1989), Clift et al. (1990) and Gouveia et al. (1996). Some well-known examples are proposed by McClintock (1968), Cockroft \& Latham (1968), Rice \& Tracey (1969), Hancock \& MacKenzie (1975) and Oyane et al. (1980). In a general expression of criteria in this class, an integral over plastic strain up to fracture of a certain function of the actual stress state is formulated. Taking into consideration the importance of the hydrostatic pressure on the initiation, growth and coalescence of voids, the triaxiality (hydrostatic stress divided by an equivalent stress) is often present in the aforementioned function of the stress state.

\subsection{Objective of this thesis}

The main objective of the research presented in this thesis is the modelling and validation of ductile fracture initiation, in order to predict the shape of the cut edge of a blanked product. Additionally, to achieve quantitative predictions, an accurate material description is needed for large strains, which in itself is not trivial. Furthermore, 
sophisticated experimental techniques are required to verify the numerical results for the deformation history prior to fracture. The description of ductile fracture as proposed in this thesis, might be general, and not only useful for blanking processes. However, the main focus will be on the application of ductile fracture in the blanking process.

\subsection{Scope of the study}

The research to be presented in this thesis is part of a more extensive research project explored in the Materials Technology (MaTe) group aiming at the construction of a validated model of the blanking process. While this thesis concentrates on the modelling of ductile fracture initiation and its validation, the development of a numerical model for the blanking process has been elaborated, in a parallel study, by Brokken (1999). Consequently, the attention in this research is focused on the modelling and validation of a ductile fracture initiation model (including the material characterisation and the experimental techniques), while the numerical model is only briefly described.

Ductile fracture propagation is not considered in this thesis. Ductile fracture initiation is assumed to fully determine the blanked edge. However, using the numerical procedures proposed by Brokken (1999), it is possible to model fracture propagation employing the same class of fracture criteria.

Only two-dimensional blanking geometries are regarded. The numerical procedures, needed to cope with the large and localised deformations in three-dimensional configurations, are not available yet. The computational costs for a realistic threedimensional blanking simulation with its highly non-linear character would become excessive. However, the fracture criteria employed are expected to be valid also for three-dimensional applications.

Only classical blanking geometries are considered in this thesis. Nevertheless, the fracture criteria proposed and evaluated, as well as the numerical procedures, are believed to be well-suited for an adequate analysis of blanking processes with different geometries. This implies that optimisation is feasible even for complex shaped products.

\subsection{Outline of the thesis}

In chapter 2 all methods employed are elucidated: an elasto-plastic and a rate dependent constitutive model, experimental setups and techniques, and the numerical model. The numerical model is verified in chapter 3, since a correct description of the deformation and loading history, prior to fracture, is essential for the accurate 
prediction of ductile fracture initiation. In chapter 4 various existing ductile fracture criteria are evaluated, some are adapted and a new criterion is proposed, all for one particular metal. Before evaluating a number of criteria for different metals, the influence of the blanking speed is investigated in chapter 5. Subsequently, in chapter 6 the adapted and newly proposed criteria are applied to four other metals. In chapter 7 a pilot investigation is performed into the effect of grain sizes on the blanking process, in order to explore the limitations of the continuum models for blanking applications with very thin sheets. The main conclusions of the integral study are recapitulated in chapter 8 and some recommendations for future research are provided. 
10 Chapter 1 


\section{Chapter 2}

\section{Methods}

In this chapter, the key methods used throughout this thesis are discussed. In the first section principles from continuum mechanics, that form the basis for the finite element method (FEM) simulations used in this thesis, will be summarised. Furthermore, emphasis is placed on two constitutive models: an elasto-plastic model using the Von Mises flow rule and an elasto-viscoplastic model with a Bodner-Partom viscosity. In section 2.2 the material parameters for a $13 \%$ chrome stainless steel will be determined in the context of these constitutive models. In section 2.3 the experimental setup of both a planar and an axisymmetric blanking configuration will be discussed as well as some measuring techniques. Finally, in section 2.4 the FEM-simulation of the blanking process will be elucidated.

\subsection{Continuum mechanics}

In order to describe the mechanical behaviour of a metal sheet in the blanking process, the material is assumed to behave as a continuum. The continuum description of this process is based on the local version of the balance laws, combined with the relation between deformations and stresses for a specific material: the constitutive model. Thermal effects are left out of consideration. The finite element method is used to solve the resulting set of equations, based on a discretisation of the displacement field in the continuum.

Firstly, some kinematic quantities are introduced that are needed for both constitutive models to be presented in this section. To define the local finite deformation in a continuum the deformation gradient tensor $\boldsymbol{F}$ is used:

$$
\boldsymbol{F}=\left(\vec{\nabla}_{0} \vec{x}\right)^{c}
$$


in which $\vec{\nabla}_{0}$ is the gradient operator with respect to the reference configuration and $\vec{x}$ is the current position of a material point in the deformed configuration. The velocity gradient tensor $\boldsymbol{L}$ is defined according to equation (2.2):

$$
L=(\vec{\nabla} \dot{\vec{x}})^{c}=\dot{\boldsymbol{F}} \cdot F^{-1}
$$

in which $\vec{\nabla}$ is the gradient operator with respect to the current configuration and a superposed dot denotes the material time derivative. This velocity gradient tensor can be written as the sum of the symmetric deformation rate tensor $\boldsymbol{D}$ and the skewsymmetric spin tensor $\boldsymbol{\Omega}$ :

$$
\begin{aligned}
& \boldsymbol{L}=\boldsymbol{D}+\boldsymbol{\Omega} \\
& \boldsymbol{D}=\frac{1}{2}\left(\boldsymbol{L}+\boldsymbol{L}^{c}\right) \\
& \boldsymbol{\Omega}=\frac{1}{2}\left(\boldsymbol{L}-\boldsymbol{L}^{c}\right)
\end{aligned}
$$

Next, the local versions of the balance laws (conservation of momentum and moment of momentum), disregarding inertia effects and body forces, read:

$$
\begin{aligned}
& \vec{\nabla} \cdot \boldsymbol{\sigma}=\overrightarrow{0} \\
& \boldsymbol{\sigma}=\boldsymbol{\sigma}^{c}
\end{aligned}
$$

in which $\sigma$ denotes the Cauchy stress tensor, which determines the stress vector on every plane through a material point.

Equations (2.4) provide a set of equilibrium equations. Constitutive relations between the deformations and stresses, as well as boundary and initial conditions are needed to complete the set of equations. Two constitutive models, used throughout this thesis, will be outlined. In section 2.1.1 an elasto-plastic constitutive law incorporating Von Mises plasticity will be described. To be able to model strain rate effects an elasto-viscoplastic constitutive model is presented in section 2.1.2.

\subsubsection{Constitutive model using the Von Mises flow rule}

In the well-known Von Mises elasto-plastic model, the deformation rate tensor $\boldsymbol{D}$ is written as the sum of an elastic part $\boldsymbol{D}_{e}$ and a plastic part $\boldsymbol{D}_{p}$ :

$$
D=D_{e}+D_{p}
$$

In a hypo-elastic formulation the objective Jaumann derivative (denoted with a superposed ${ }^{\circ}$ ) of the Cauchy stress is coupled to the elastic part of the deformation rate tensor $\boldsymbol{D}_{e}$ :

$$
\stackrel{\circ}{\boldsymbol{\sigma}}={ }^{4} \boldsymbol{C}: \boldsymbol{D}_{e}={ }^{4} \boldsymbol{C}:\left(\boldsymbol{D}-\boldsymbol{D}_{p}\right)
$$


In this formulation, the fourth order isotropic elastic stiffness tensor ${ }^{4} \mathrm{C}$ reads:

$$
{ }^{4} \boldsymbol{C}=\frac{v E}{(1+v)(1-2 v)} \boldsymbol{I I}+\frac{E}{1+v}{ }^{4} \boldsymbol{I}
$$

with $v$ Poisson's ratio and $E$ Young's modulus.

Deformation increments can be either elastic $\left(\boldsymbol{D}_{p}=\mathbf{0}\right)$ or elasto-plastic. During elasto-plastic deformation the Von Mises yield condition should be satisfied, which incorporates isotropic hardening:

$$
f=\bar{\sigma}^{2}-\sigma_{y}^{2}=0
$$

with the equivalent Von Mises stress $\bar{\sigma}$ defined in the usual way:

$$
\bar{\sigma}=\sqrt{\frac{3}{2} \boldsymbol{\sigma}^{d}: \boldsymbol{\sigma}^{d}}
$$

The actual yield stress $\sigma_{y}$ is governed by the equivalent logarithmic plastic strain $\left(\bar{\varepsilon}_{p}\right)$ as a history parameter:

$$
\begin{aligned}
& \sigma_{y}=\sigma_{y}\left(\bar{\varepsilon}_{p}\right) \\
& \dot{\bar{\varepsilon}}_{p}=\sqrt{\frac{2}{3} \boldsymbol{D}_{p}^{d}: \boldsymbol{D}_{p}^{d}}
\end{aligned}
$$

The specification of equation (2.10a) will be elaborated in section 2.2.1. The associated flow rule of equation (2.11) is used to define the direction of plastic deformation:

$$
\boldsymbol{D}_{p}=\frac{3 \dot{\bar{\varepsilon}} p}{2 \sigma_{y}} \boldsymbol{\sigma}^{d}
$$

Equation (2.11) shows that plastic deformation will exhibit volume invariance in this constitutive model ( $\left.\boldsymbol{\sigma}^{d}: I \equiv 0 \Rightarrow D_{p}: I=0\right)$.

The formulation of the model is then completed with the standard Kuhn-Tucker loading-unloading conditions (equation 2.12a) and the consistency condition in equation (2.12b):

$$
\begin{aligned}
& f \leq 0, \quad \dot{\bar{\varepsilon}}_{p} \cdot f=0 \\
& \dot{\bar{\varepsilon}}_{p} \cdot \dot{f}=0
\end{aligned}
$$

Application of this constitutive model is a standard option in the commercial finite element package MARC (1997). This package will be used throughout this thesis. 


\subsubsection{Constitutive model with Bodner-Partom viscosity}

The second constitutive model that will be used in this thesis assumes an elastoviscoplastic behaviour. The important difference compared to the elasto-plastic model of the previous section is that this model includes viscous effects: larger strain rates induce larger stresses such that, at isothermal conditions, higher blanking velocities generate higher blanking forces.

To incorporate viscous effects into the constitutive description the enhanced compressible Leonov model (Leonov, 1976; Baaijens, 1991; Tervoort et al., 1998) is used with a viscosity function that is similar to the one defined by Bodner \& Partom (1975). This compressible Leonov model is based on a multiplicative decomposition of the deformation gradient tensor $\boldsymbol{F}$ :

$$
\boldsymbol{F}=J^{\frac{1}{3}} \tilde{\boldsymbol{F}}_{e} \cdot \boldsymbol{F}_{p}
$$

with $J^{\frac{1}{3}}$ the volumetric elastic part $(J=\operatorname{det}(\boldsymbol{F})), \tilde{\boldsymbol{F}}_{e}$ is the isochoric elastic part and $\boldsymbol{F}_{p}$ is the isochoric plastic part (plastic deformation is assumed to be incompressible). The isochoric elastic left Cauchy-Green strain tensor $\tilde{\boldsymbol{B}}_{e}$ is used to characterise the elastic deformation, and is defined to be:

$$
\tilde{\boldsymbol{B}}_{e}=\tilde{\boldsymbol{F}}_{e} \cdot\left(\tilde{\boldsymbol{F}}_{e}\right)^{c}
$$

From purely kinematical considerations and the assumption for the plastic spin tensor: $\boldsymbol{\Omega}_{p}=\mathbf{0}$ (which also ensures that the tensor $\tilde{\boldsymbol{B}}_{e}$ is objective), a differential equation can be derived that defines the evolution of $\tilde{\boldsymbol{B}}_{e}$ :

$$
{\stackrel{\circ}{\tilde{\boldsymbol{B}}_{e}}}_{e}\left(\boldsymbol{D}^{d}-\boldsymbol{D}_{p}\right) \cdot \tilde{\boldsymbol{B}}_{e}+\tilde{\boldsymbol{B}}_{e} \cdot\left(\boldsymbol{D}^{d}-\boldsymbol{D}_{p}\right)^{c}
$$

where a small superposed circle ${ }^{\circ}$ denotes the objective Jaumann derivative.

For the relation between elastic deformations and stresses, the deviatoric part of the Cauchy stress is coupled to the deviatoric part of the isochoric elastic left CauchyGreen strain tensor, while the hydrostatic part is coupled to the volume change:

$$
\boldsymbol{\sigma}=G \tilde{\boldsymbol{B}}_{e}^{d}+K(J-1) \boldsymbol{I}
$$

In this equation $G$ is the elastic shear modulus and $K$ is the elastic bulk modulus, which can also be written in terms of $E$ and $v$ by:

$$
\begin{aligned}
& G=\frac{E}{2(1+v)} \\
& K=\frac{E}{3(1-2 v)}
\end{aligned}
$$


To incorporate the influence of strain rates on stresses, a generalised Newtonian flow rule is used in the plastic region. In this flow rule the plastic deformation rate tensor is again defined to be codirectional with the deviatoric part of the Cauchy stress:

$$
\boldsymbol{D}_{p}=\frac{\boldsymbol{\sigma}^{d}}{2 \eta}
$$

The chosen viscosity function is an adaptation of the definition in the original BodnerPartom model (Bodner \& Partom, 1975), suggested by Rubin (1987):

$$
\eta=\frac{\bar{\sigma}}{\sqrt{12 \Gamma_{0}}} \exp \left(\frac{1}{2}\left[\frac{Z\left(\bar{\varepsilon}_{p}\right)}{\bar{\sigma}}\right]^{2 n}\right)
$$

In this formulation $\bar{\sigma}$ is the equivalent stress (according to the Von Mises definition in equation 2.9) and $\bar{\varepsilon}_{p}$ is the equivalent strain (eq. 2.10b). The material parameters $\Gamma_{0}$ and $n$ are related to the strain rate sensitivity. The function $Z\left(\bar{\varepsilon}_{p}\right)$ is the resistance to plastic flow and influences the yield stress. In section 2.2.2 the function $Z\left(\bar{\varepsilon}_{p}\right)$, employed by Brokken (1995) and van der Aa (1999), will be used in the characterisation process as well as a modification thereof to achieve better results.

The enhanced compressible Leonov model, including the Bodner-Partom viscosity definition, was implemented in the updated Lagrange environment of the commercial finite element package MARC (1997) by Smit et al. (1999). This implementation is based on an implicit time integration procedure proposed by Rubin (1989).

\subsection{Material characterisation}

In chapters 3,4 and 5 only one material will be considered: a ferritic $13 \%$ chrome stainless steel (X30Cr13, DIN 17006). This material is common in industrial applications and is mostly used for cutting applications (e.g. in shavers). In this section this material will be characterised and material parameters will be determined for the elasto-plastic constitutive model using Von Mises plasticity (section 2.2.1) and for the elasto-viscoplastic constitutive model with the Bodner-Partom viscosity (section 2.2.2).

\subsubsection{Von Mises plasticity for large strains}

Characterising the X30Cr13 steel within the context of the elasto-plastic model using Von Mises plasticity of section 2.1.1 actually means the determination of the yield stress as a function of the (equivalent logarithmic plastic) strain (eq. 2.10a). Usually, this is done by performing a tensile test to establish the yield stress - strain relationship. To arrive at this relationship, the tensile force and the strain in tensile direction 
are measured. Using the assumption of volume invariance during homogeneous plastic deformation the yield stress can be calculated from the tensile force and the tensile strain. This procedure is widely used to specify equation (2.10a).

Generally, the characterisation using a tensile test will provide only information up to a strain of approximately 0.2 , because in the neighbourhood of that value the tensile specimen will neck, and local stresses can no longer be determined from global data. For many forming processes strains become much larger. In FEM-simulations of the blanking process (in this thesis as well as in the research by Brokken, 1999) strains occur larger than 3. Thus, the range of strains occurring in a blanking simulation is over 15 times larger than the range that can be covered by a tensile test. Extrapolation is often used but can introduce considerable errors because of the large domain of the extrapolation. Therefore, another approach is pursued.

Swinden \& Bolsover (1927) already presented a method to measure yield stresses for large strains. The method involves the execution of tensile tests with specimens that have experienced rolling as a pre-deformation. Assuming a homogeneous deformation which is negligible in the lateral direction of the rolls, the equivalent logarithmic plastic strain of the material after the rolling process can be derived:

$$
\bar{\varepsilon}_{p}=\frac{2}{\sqrt{3}} \ln \left(\frac{t_{0}}{t_{r}}\right)
$$

with $t_{0}$ the initial sheet thickness and $t_{r}$ the thickness after rolling. As the constitutive model assumes isotropic hardening, the equivalent logarithmic plastic strain of the rolled pre-deformation can be added to the tensile strain of a specific specimen to
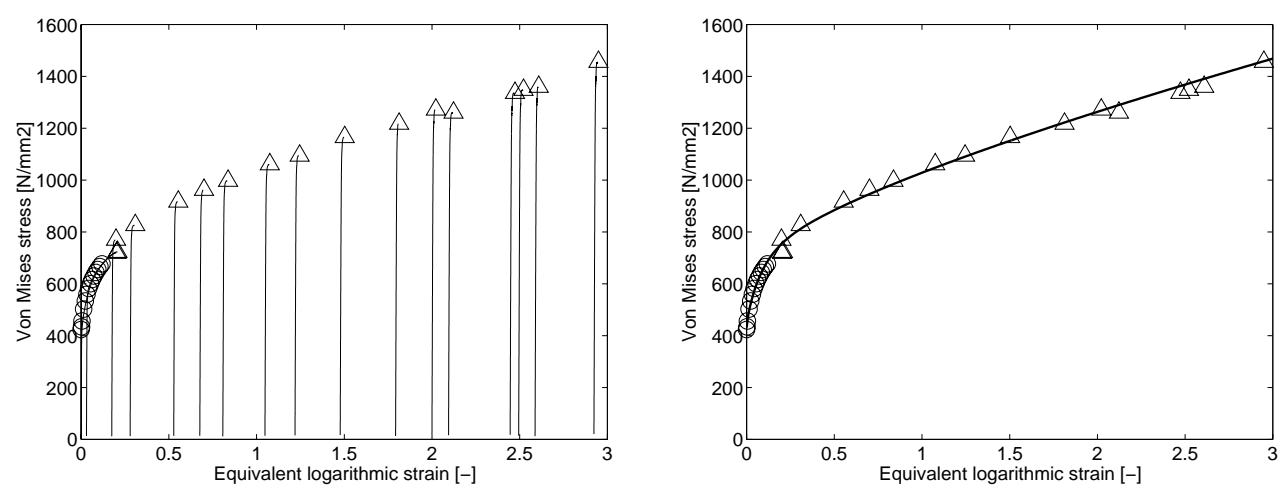

Figure 2.1: Presentation of the fitting procedure for the strain hardening curve of X30Cr13. Left, the separate tensile curves are presented and their maxima (triangles), together with a number of points (circles) on the tensile curve of the as-received material. Right, the mastercurve is fitted through all measurements. 
Table 2.1: Material parameters of X30Cr13 for elasto-plastic model using Von Mises plasticity.

\begin{tabular}{|c|c|c|c|c|c|c|}
\hline$E[\mathrm{MPa}]$ & $v[-]$ & $\sigma_{y 0}[\mathrm{MPa}]$ & $M_{1}[\mathrm{MPa}]$ & $M_{2}[-]$ & $M_{3}[\mathrm{MPa}]$ & $M_{4}[\mathrm{MPa}]$ \\
\hline $1.87 \cdot 10^{5}$ & 0.28 & 420 & 133 & 0.0567 & 406 & 70.7 \\
\hline
\end{tabular}

obtain the equivalent logarithmic plastic strain that describes the total deformation history for that specimen. A number of tensile tests is performed on specimens that have experienced different thickness reductions in the rolling process. The measured $\bar{\sigma}$ versus $\bar{\varepsilon}_{p}$ hardening curves are all plotted in the left diagram of figure 2.1. All the maxima of the separate tensile curves, as well as some extra points in the tensile curve of the as-received material, are used to fit a mastercurve that describes the yield stress as a function of the (equivalent logarithmic plastic) strain according to equation (2.10a). In order to describe this function accurately the following expression is chosen:

$$
\sigma_{y}=\sigma_{y 0}+M_{1}\left(1-\exp \left(-\bar{\varepsilon}_{p} / M_{2}\right)\right)+M_{3} \sqrt{\bar{\varepsilon}_{p}}+M_{4} \bar{\varepsilon}_{p}
$$

with $\sigma_{y 0}$ being the initial yield stress. The fitted parameters $\sigma_{y 0}, M_{1}, M_{2}, M_{3}$ and $M_{4}$ are presented in table 2.1 together with the elastic material parameters. The resulting mastercurve is plotted at the right-hand side of figure 2.1, together with the points that are used in the fitting procedure. Young's modulus $E$ is the average of measurements on 20 tensile specimens, $v$ is taken from the material specifications.

\subsubsection{Constitutive model with adapted Bodner-Partom viscosity}

The constitutive model with the Bodner-Partom viscosity is able to incorporate strain rate effects. Therefore, to quantify the material characteristics for X30Cr13 using this constitutive model, tensile tests are performed at three different strain rates. $E$ and $v$ have already been presented in section 2.2.1. As it is common for metals, $\Gamma_{0}$ is assumed to be $10^{8}\left[\mathrm{~s}^{-2}\right.$ ] (Bodner \& Partom, 1975; Kolkailah \& McPhate, 1990; van der Aa, 1999). What is left to be determined is parameter $n$ and function $Z\left(\bar{\varepsilon}_{p}\right)$ in the viscosity formulation (eq. 2.19).

To arrive at an equation that is able to fit the remaining parameters, relation (2.19) is substituted into equation (2.18) and the result is elaborated for a bar in tension. Neglecting elastic effects and knowing that in a tensile test the axial component of $\boldsymbol{D}_{p}$ equals $\dot{\bar{\varepsilon}}_{p}$ and the axial component of $\boldsymbol{\sigma}^{d}$ equals $\frac{2}{3} \bar{\sigma}$, the following relation between $n$, $\bar{\sigma}, \bar{\varepsilon}_{p}$ and $\dot{\bar{\varepsilon}}_{p}$ can be derived:

$$
2 n \ln (\bar{\sigma})-2 n \ln \left(Z\left(\bar{\varepsilon}_{p}\right)\right)+\ln \left(-2 \ln \left(\frac{1}{2} \sqrt{\frac{3}{\Gamma_{0}}} \dot{\bar{\varepsilon}}_{p}\right)\right)=0
$$


Table 2.2: Material parameters of X30Cr13 for the elasto-viscoplastic model with $Z\left(\bar{\varepsilon}_{p}\right)$ according to equation (2.23).

\begin{tabular}{|c|c|c|c|c|c|c|}
\hline$E[\mathrm{MPa}]$ & $v[-]$ & $\Gamma_{0}\left[\mathrm{~s}^{-2}\right]$ & $n[-]$ & $Z_{0}[\mathrm{MPa}]$ & $Z_{1}[\mathrm{MPa}]$ & $Z_{2}[-]$ \\
\hline $1.87 \cdot 10^{5}$ & 0.28 & $10^{8}$ & 3.92 & 689 & 1155 & 12.6 \\
\hline
\end{tabular}

Having the stress versus strain relations for three tensile tests at different strain rates (assuming the strain rates are constant in each single tensile test), it is possible, using equation (2.22), to fit all parameters in a least square estimation procedure, adopting a particular expression for $Z\left(\bar{\varepsilon}_{p}\right)$.

To a first attempt a function $Z\left(\bar{\varepsilon}_{p}\right)$ was adopted which has successfully been used by Brokken (1995) and van der Aa (1999):

$$
Z=Z_{1}+\left(Z_{0}-Z_{1}\right) \exp \left(-Z_{2} \bar{\varepsilon}_{p}\right)
$$

The fitted parameters are presented in table 2.2. The results of the fitting procedure are presented in figure 2.2 together with the results of the three tensile tests and the fitted mastercurve of the previous section. The different strain rates are given in the legends. The strain rate for the mastercurve is taken to be the estimate of the average strain rate for all tensile tests performed in section 2.2.1. As it can be observed, the resulting material behaviour describes the three tensile tests very well for small strains,
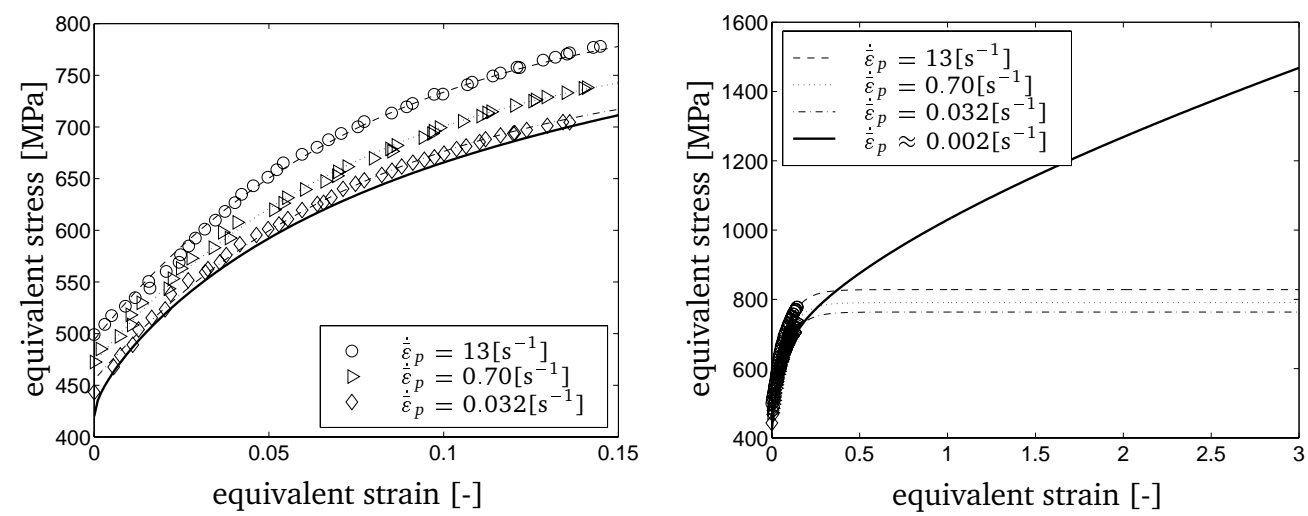

Figure 2.2: Performance of the constitutive model with the Bodner-Partom viscosity function using $Z\left(\bar{\varepsilon}_{p}\right)$ according to equation (2.23) for small (left) and large (right) plastic strains. The markers represent the experimentally reconstructed stress - strain relations from the tensile tests for different strain rates. The bold solid line represents the 'Von Mises' mastercurve characterised in section 2.2.1 with an approximated strain rate of: $\dot{\bar{\varepsilon}}_{p} \approx 0.002\left[\mathrm{~s}^{-1}\right]$ and is drawn for reference purposes. 
Table 2.3: Material parameters of X30Cr13 for the elasto-viscoplastic model with $Z\left(\bar{\varepsilon}_{p}\right)$ according to equation (2.24).

\begin{tabular}{|c|c|c|c|c|c|c|c|c|}
\hline$E[\mathrm{MPa}]$ & $v[-]$ & $\Gamma_{0}\left[\mathrm{~s}^{-2}\right]$ & $n[-]$ & $Z_{0}[\mathrm{MPa}]$ & $Z_{1}[\mathrm{MPa}]$ & $Z_{2}[-]$ & $Z_{3}[\mathrm{MPa}]$ & $Z_{4}[\mathrm{MPa}]$ \\
\hline $1.87 \cdot 10^{5}$ & 0.28 & $10^{8}$ & 3.95 & 654 & 863 & 15.0 & 600 & 115 \\
\hline
\end{tabular}

thus in the range of the tensile tests. However, for large strains the fitted model performs badly compared to the strain hardening of the mastercurve determined in section 2.2.1. Obviously, the strain hardening is not adequately represented by the function $Z\left(\bar{\varepsilon}_{p}\right)$ specified by expression (2.23). Therefore, an adaptation is proposed inspired by the formulation of equation (2.21):

$$
Z=Z_{1}+\left(Z_{0}-Z_{1}\right) \exp \left(-Z_{2} \bar{\varepsilon}_{p}\right)+Z_{3} \sqrt{\bar{\varepsilon}_{p}}+Z_{4} \bar{\varepsilon}_{p}
$$

Again, the least square estimator is used in combination with equation (2.22) to fit all parameters involved and the results are presented in table 2.3 and figure 2.3. It can be observed that, using the modification for $Z\left(\bar{\varepsilon}_{p}\right)$ according to equation (2.24), the model describes the mechanical behaviour of X30Cr13 very well for different strain rates as well as for both small and large strains. When the constitutive elastoviscoplastic model is applied in chapter 5, equation (2.24) will be used for $Z\left(\bar{\varepsilon}_{p}\right)$ with the material parameters given in table 2.3 .
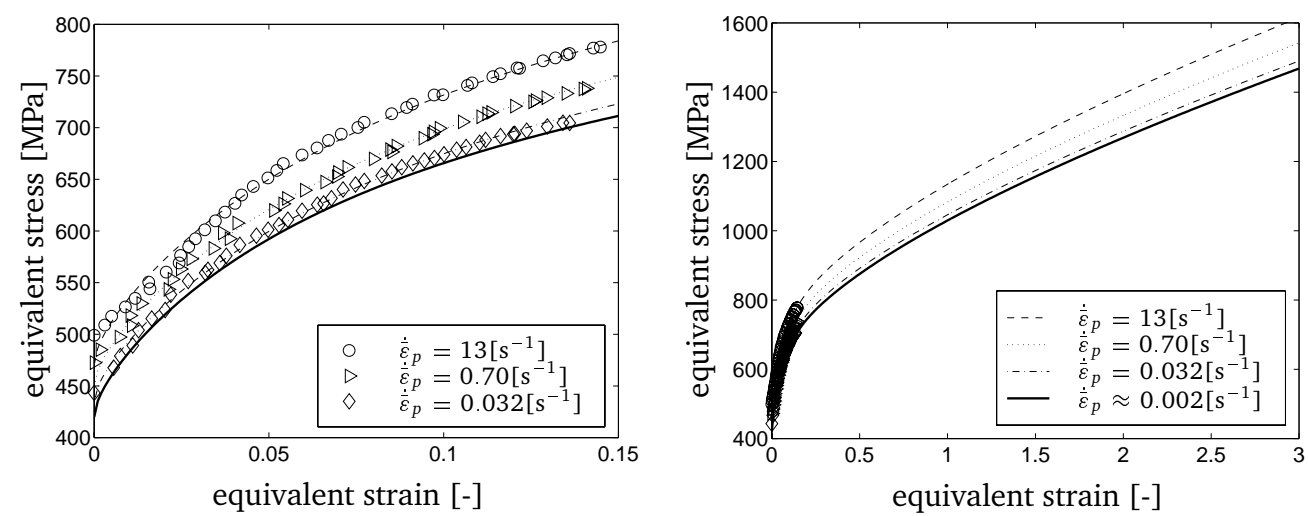

Figure 2.3: Performance of constitutive model with the Bodner-Partom viscosity function using $Z\left(\bar{\varepsilon}_{p}\right)$ according to equation (2.24) for small and large plastic strains. The markers represent the experimentally found stress - strain relations out of the tensile tests for different strain rates. The bold solid line represents the mastercurve characterised in section 2.2.1. 


\subsection{Experimental}

In this section, two different blanking setups are presented as well as two measuring techniques, related to these experimental setups. A planar blanking setup (section 2.3.1) is used because it enables the verification of blanking simulations not only with respect to process force but also to the deformation field. The deformation field can be measured by a digital image correlation (DIC) technique (section 2.3.2). In section 2.3.3 an axisymmetric blanking setup is presented. This setup is needed to measure ductile fracture initiation after the blanking process. This was not possible with the planar setup because in that case fracture was found to initiate at the side of the specimen, because of the plane stress situation. Finally, the measurement of the characteristics of the blanked edge, which is largely determined by ductile fracture initiation, is explained in section 2.3.4.

\subsubsection{Planar blanking setup}

The planar blanking experiments were performed using the apparatus shown in figure 2.4, which was built into a universal testing machine. The upper body (A) is connected to the moving part of the testing machine, while the lower body (B) is fixed. During an experiment, the testing machine pushes the upper body down, causing the springs (F) to exert a force on the centre body (D) when this body touches the specimen. The blankholder (G), attached to this centre body, in turn exerts a pressure of about $5[\mathrm{MPa}]$ on the specimen $(\mathrm{H})$. The specimen geometry is shown in figure 2.5. The internal edges of the die $(\mathrm{J})$ are $10.0[\mathrm{~mm}]$ apart. The pressure plate restricts

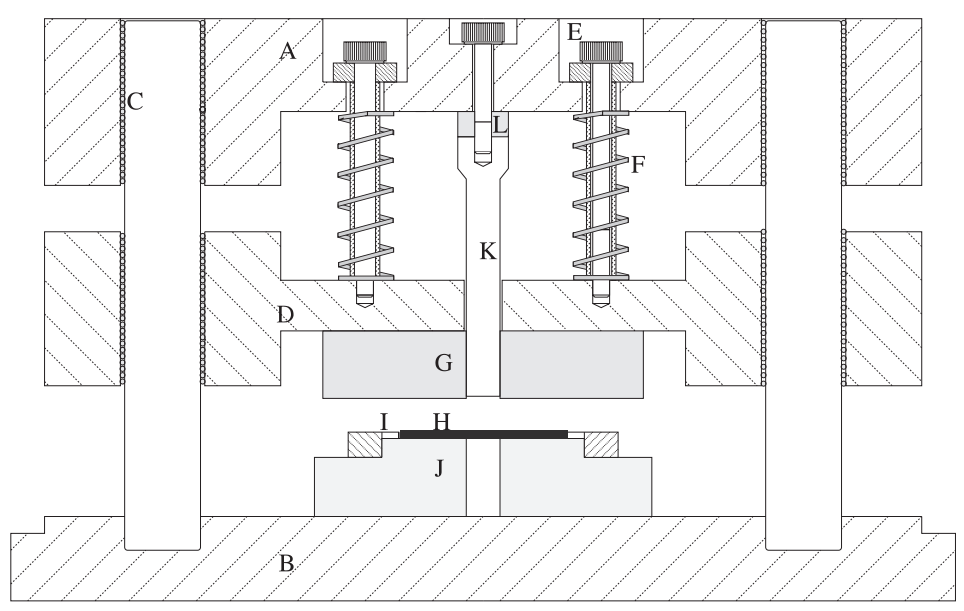
A upper body
B lower body
C roll bearings
D centre body
E bolts
$F$ springs
G blankholder
$\mathrm{H}$ specimen
I mount
$\mathrm{J}$ die
$\mathrm{K}$ punch
L piezo force transducer

Figure 2.4: Planar blanking apparatus. 


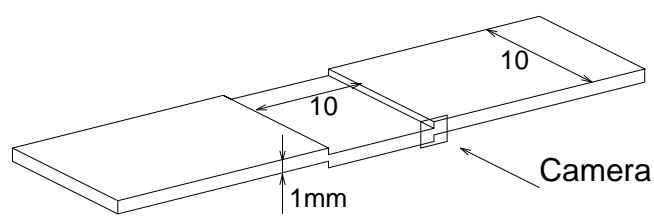

Figure 2.5: Dimensions of a deformed sample ([mm]).

the horizontal motion of the punch, while the testing machine controls the vertical movement. A piezo force transducer (L) can measure the punch load directly. At low speeds, the strain gauge Wheatstone bridge force transducer of the testing machine gives better results. Therefore, this force transducer is used, which is corrected for the spring forces. An extra advantage is that the friction between punch and pressure plate is compensated with this correction.

A set of four punches and two dies was available to accomplish two different clearances for both small and large radii. Although in industrial practice only small radii are utilised, also a setup is used with large radii because this eases the corresponding FEM-simulations a great deal. For small radii very fine FEM-meshes are needed and thus very large computing times.

Two different clearances are used because the blanking process is known to behave diversely for different clearances. One of the demands for a useful FEM-model of the blanking process is that it can predict the different behaviour for varying clearances. In order to have the possibility to verify this aspect two different clearances are incorporated in the experimental setup. The tools with the characteristic dimensions to realise setups with different tool radii and different clearances are presented in table 2.4

The advantage of a planar blanking setup is that between punch and die radius the deformations of the specimen can be measured. In figure 2.5 it is indicated that a

Table 2.4: Tool dimensions to accomplish different setups.

\begin{tabular}{|r||c|r|c|}
\hline & tool & \multicolumn{1}{|c|}{ radius } & clearance \\
\hline \hline small & die & $11[\mu \mathrm{m}]$ & \\
radii & punch 1 & $7[\mu \mathrm{m}]$ & $0.02[\mathrm{~mm}]$ \\
& punch 2 & $7[\mu \mathrm{m}]$ & $0.10[\mathrm{~mm}]$ \\
\hline large & die & $0.10[\mathrm{~mm}]$ & \\
radii & punch 1 & $0.05[\mathrm{~mm}]$ & $0.02[\mathrm{~mm}]$ \\
& punch 2 & $0.05[\mathrm{~mm}]$ & $0.10[\mathrm{~mm}]$ \\
\hline
\end{tabular}


camera can record the deformation process in-situ. With the help of a digital image correlation technique (section 2.3.2) the deformation of the material can be monitored.

\subsubsection{Digital Image Correlation (DIC)}

During the blanking process, a digital camera together with a computer controlled framegrabber can record a set of consecutive images of the sample surface shown in figure 2.5. A zoom lens is mounted on the CCD-camera to focus on the small deformation zone of approximately $1\left[\mathrm{~mm}^{2}\right]$.

To quantify the displacements of material points at this surface, a digital image correlation technique (Gonzalez \& Wintz, 1983; Sutton et al., 1986; Bruck et al., 1989) is used. This contrast correlation technique does not require markers on the specimen surface. This feature is essential, because the high deformations, in combination with the small area observed, make the use of markers impossible. Instead of locating markers in consecutive images, the contrast correlation technique uses the contrast information (i.e. the grey level of each camera pixel) in the images to reconstruct the displacement field. For this purpose, the contrast produced by the milling process may be sufficient (see figures 2.6 and 2.7). Sometimes it is necessary to sand-blast the surface to obtain enough contrast in the images (chapter 7). Because of the large deformations, the contrast information changes rapidly during the process and only small deformation steps can be handled by the correlation technique. Therefore, 20 to 50 subsequent images are required to cover the process and the measured incremental displacements are added to arrive at the total displacements.

The method is briefly explained with the help of figure 2.6, in which the displacements of a set of points from image A (reference) to image B (deformed) are measured:

- A set of points is chosen in image A of which the displacements have to be measured.
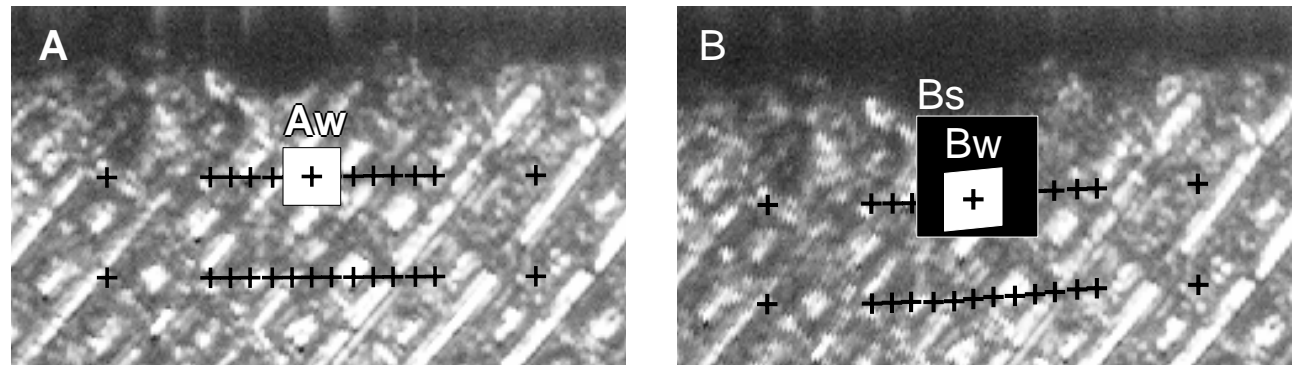

Figure 2.6: Explanation of Digital Image Correlation. 
- A window Aw is defined for each point of the set with a size in the order of $30 \times 30$ pixels.

- A search area Bs is defined in image B, in which the window Aw has to be traced. The size of Bs is determined by the size of the window Aw and the maximum expected displacement of the points.

- The window position, with optimal correlation in the search area, is calculated. This is done in two phases. Firstly, a relatively fast FFT-calculation is used to determine all the correlation functions for all possible window positions - on pixel-resolution - in the search area. The maximum is determined, which yields a maximum correlation position in pixel-resolution. In this calculation the window is assumed to remain a square (Hwang \& Chang, 1990). Secondly, this maximum correlation position on pixel-level is used as an initial estimate in an algorithm to maximise the correlation function on sub-pixel-level. In this calculation two aspects are important: the window is allowed to deform linearly and the gray levels are interpolated with bicubic splines to obtain sub-pixel information (which is necessary according to Sutton et al., 1986). A more extensive elaboration of these two phases is given by Meuwissen (1998) and van der Aa (1999).

The accuracy of the measured total displacement (initial stage up to fracture) is observed to be about 0.3 pixel, corresponding to approximately one micrometer (magnification results in $\pm 3[\mu \mathrm{m}]$ per pixel). A typical example of results for the measured displacements in the blanking process is presented in figure 2.7.

To be able to visualise the comparison between experimental and numerical deformations, the displacement grid is transformed to a grid with different levels of strain. To accomplish this, the local two-dimensional deformation gradient tensor $\boldsymbol{F}$ is determined incrementally on the grid. Considering the rather coarse grid and
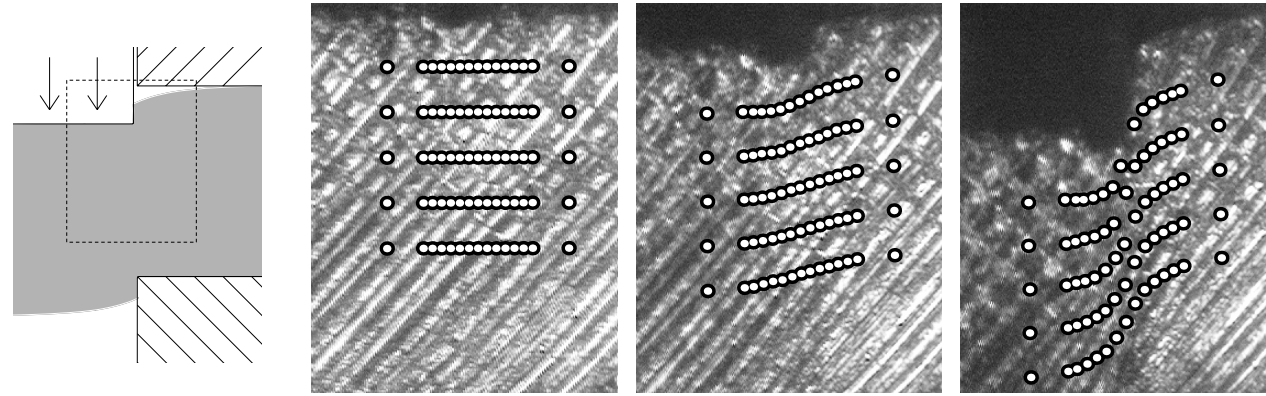

Figure 2.7: Examples of DIC on recorded images (images 1, 18 and 35 of a successive set) during the blanking process. 

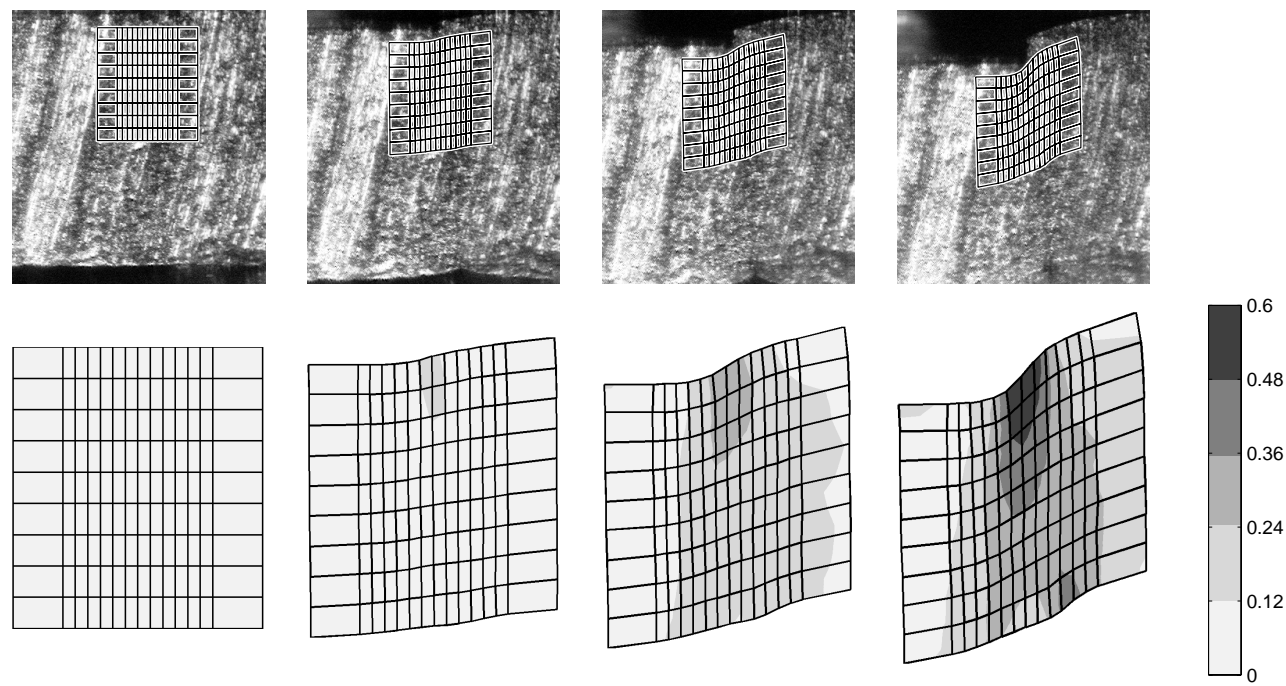

Figure 2.8: Example of the transformation of a grid and corresponding equivalent logarithmic strain field in four stages of deformation.

the existence of large strain gradients, a second order approach, developed by Geers et al. (1996), is used in calculating this tensor $\boldsymbol{F}$. Once the right polar decomposition of the deformation gradient tensor $(\boldsymbol{F}=\boldsymbol{R} \cdot \boldsymbol{U}$, with $\boldsymbol{R}$ the rotation tensor and $\boldsymbol{U}$ the right stretch tensor) is determined, the incremental equivalent logarithmic strain, defined in equation $2.10 \mathrm{~b}$, can be derived if a conveniently smooth evolution of the deformation during the increment is assumed:

$$
\Delta \bar{\varepsilon}=\sqrt{\frac{2}{3} \ln (U): \ln (\boldsymbol{U})}
$$

The total equivalent logarithmic strain can be obtained easily by adding the contributions of all the increments. This procedure can also be performed on exactly the same displacement grid in the numerical simulation in order to get a fair method of comparing experimental to numerical strains. An example of a calculated equivalent logarithmic strain field based on a deformed grid is presented in figure 2.8 for four different stages in the deformation process.

\subsubsection{Axisymmetric blanking setup}

For two reasons an axisymmetric setup is developed that can be built into a hydraulic tensile testing machine. Firstly, with this experimental setup it is possible to measure the moment of fracture initiation in the blanking process, by measuring the product 


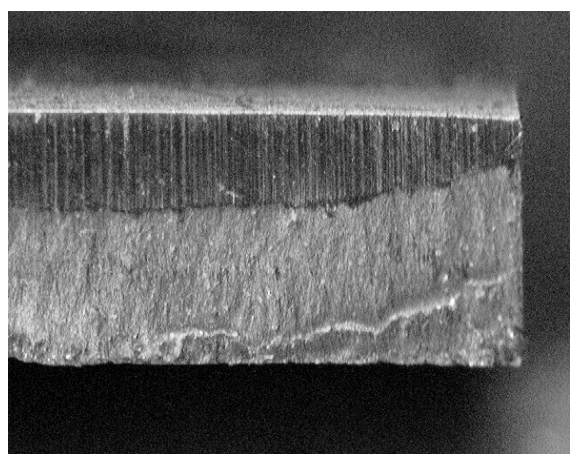

Figure 2.9: Fractured sample from the planar blanking setup of section 2.3. It is shown that fracture initiates earlier at the side of the specimen due to the stress state. This early fracture initiation is a side effect and not representative for the blanking process in general.

shapes afterwards. This does not yield satisfactory results in the planar setup because in that case fracture initiates at the side of the specimen as is shown in figure 2.9. This is due to the plane stress situation at the side of the specimen, which is not a representative state of stress for blanking in general. Secondly, with this setup in the mentioned tensile testing machine it is possible to perform experiments at high blanking speeds, in the order of $1[\mathrm{~m} / \mathrm{s}]$.

The setup developed is schematically presented in figure 2.10. The lower body A is connected to the moving part of the hydraulic tensile machine. The upper body B
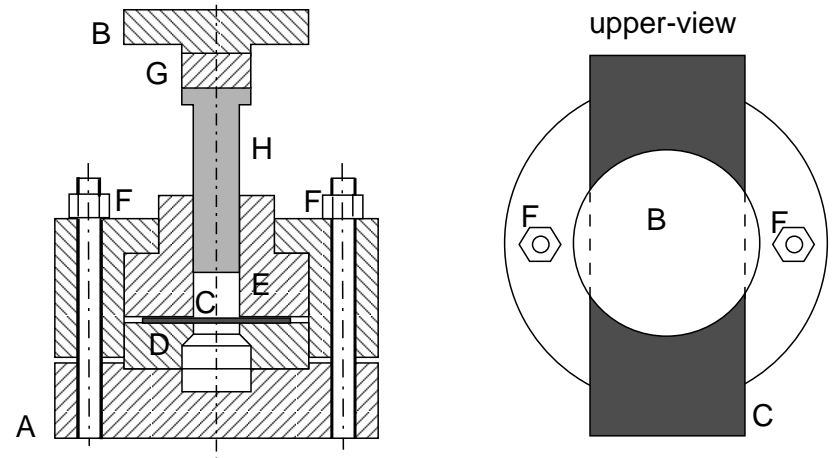
A lower body
B upper body
C specimen
D die
E blankholder
$\mathrm{F}$ female screw
$G$ piezo force transducer
$\mathrm{H}$ punch

Figure 2.10: Schematic representation of the axisymmetric blanking apparatus. 
Table 2.5: Tool dimensions to accomplish different setups.

\begin{tabular}{|c||c|r|c|c|}
\hline & tool & diameter & cutting radius & clearance \\
\hline \hline \multirow{2}{*}{ small } & die & $10.00[\mathrm{~mm}]$ & $0.01[\mathrm{~mm}]$ & \\
\cline { 2 - 5 } radii & punch 1 & $9.98[\mathrm{~mm}]$ & $0.01[\mathrm{~mm}]$ & $0.01[\mathrm{~mm}]$ \\
& punch 2 & $9.70[\mathrm{~mm}]$ & $0.01[\mathrm{~mm}]$ & $0.15[\mathrm{~mm}]$ \\
\hline \hline large & die & $10.00[\mathrm{~mm}]$ & $0.136[\mathrm{~mm}]$ & \\
\cline { 2 - 5 } radii & punch 1 & $9.98[\mathrm{~mm}]$ & $0.082[\mathrm{~mm}]$ & $0.01[\mathrm{~mm}]$ \\
& punch 2 & $9.94[\mathrm{~mm}]$ & $0.088[\mathrm{~mm}]$ & $0.03[\mathrm{~mm}]$ \\
& punch 3 & $9.88[\mathrm{~mm}]$ & $0.086[\mathrm{~mm}]$ & $0.06[\mathrm{~mm}]$ \\
& punch 4 & $9.80[\mathrm{~mm}]$ & $0.098[\mathrm{~mm}]$ & $0.10[\mathrm{~mm}]$ \\
& punch 5 & $9.70[\mathrm{~mm}]$ & $0.088[\mathrm{~mm}]$ & $0.15[\mathrm{~mm}]$ \\
\hline
\end{tabular}

is fixed with an aligning-device that can ensure the needed positioning accuracy of $0.01[\mathrm{~mm}]$ for the punch relative to the die. The blankholder E clamps the specimen C (approximately $1[\mathrm{~mm}]$ thick) onto the die with a pressure of approximately $5[\mathrm{MPa}]$ that is forced by two female screws $\mathrm{F}$ on two bolts tightened to the lower body. To achieve results for varying clearances and different tool radii, a complete set of tools is used which is presented in table 2.5.

\subsubsection{Measurements at the blanked edge}

To obtain experimental results, that mark ductile fracture initiation, measurement of the shear zone in the blanked hole and measurement of the burr at the blank are needed. Together with the numerical prediction of the roll-over zone (without springback), these dimensions determine the punch displacement at fracture initiation (see e.g. section 4.2).

The shear zone in the blanked hole has to be measured optically (figure 2.11). The light source is used in combination with the beam splitter to obtain a perpendicularly projected illumination on the blanked edge which causes the smooth shear zone to reflect light into the camera. The prism, that is used as a mirror, is mounted on a device that can be rotated along the axis of the camera view. This way, the camera can observe the shear zone of the blanked hole circumferentially around $360^{\circ}$. A typical image, viewed by the camera is presented at the right-hand side of figure 2.11 . The shear zone can be measured after calibration of the camera view.

The burr height is measured using a mechanical clock gauge (accuracy: $1[\mu \mathrm{m}]$ ). The blank is clamped and a reference measurement is performed right next to the burr. Then, the clamped blank is moved perpendicular to the measuring direction and a measurement is taken by putting the dial gauge plunger on top of the burr. Subtraction of the two measurements yields the burr height. 


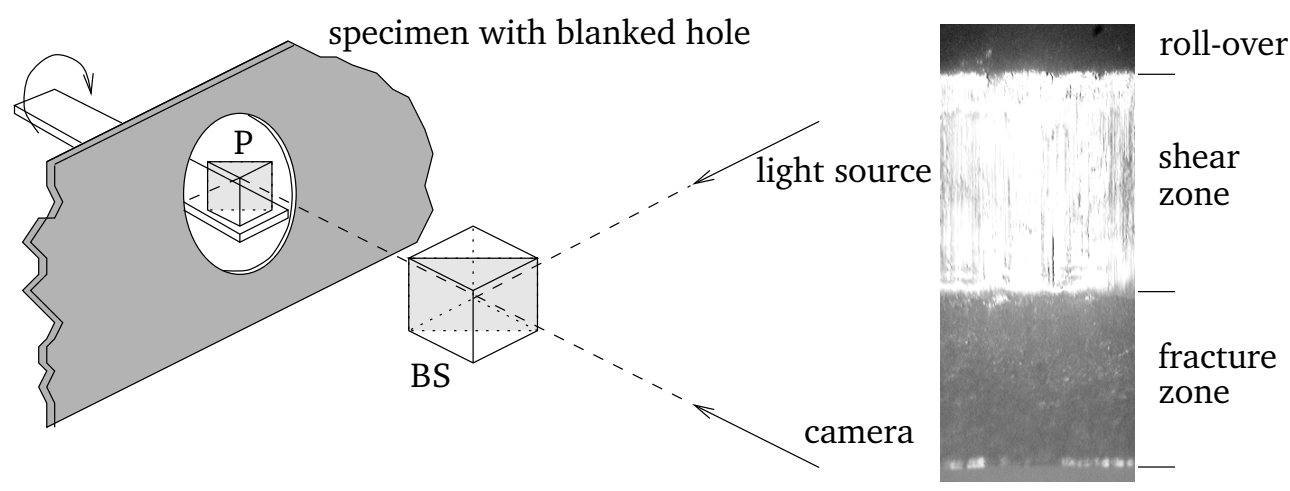

Figure 2.11: Optical measurement of the shear zone in the blanked hole. Left, the setup using a camera, a light source, a beam splitter BS and a prism $P$, which can be rotated to give a view over $360^{\circ}$. Right, a typical image, viewed by the camera, where the illuminated zone indicates the smooth shear zone.

\subsection{Finite element model of the blanking process}

When the Finite Element Method (FEM) is used to describe the blanking process, some numerical difficulties may arise, associated with the occurrence of the large and local deformations and the initiation and propagation of ductile fracture. These difficulties were solved by Brokken (1999). The large and local deformations were handled using an Operator Split Arbitrary Lagrange Euler (OS-ALE) description in combination with an automatic adaptive remeshing algorithm. Furthermore, a discrete crack model was developed that is able to mesh independently describe ductile fracture propagation.

In this thesis, the OS-ALE description in combination with the automatic adaptive remeshing procedure will be adopted as proposed by Brokken (1999). Because it is assumed that ductile fracture initiation determines the quality of the blanked edge, the discrete cracking procedure will not be used in this thesis. The methods to handle the large and local deformations will briefly be described in this section. For a more detailed elaboration reference is made to the thesis of Brokken (1999).

The two-dimensional plane strain and axisymmetric FEM-models of the blanking process are presented schematically in figure 2.12 . Because of the symmetry existing in the experimental setups, only half of the process needs to be modelled (the axis of symmetry is located at the left). The blankholder presses the sheet (thickness $T$ ) on the die with a pressure $P$ and then the punch starts to move down deforming the sheet. The blankholder, punch and die are assumed to be rigid; the latter two have tool radii of $R p$ and $R d$, respectively. The clearance $S$ is determined by the size of the die hole $(L d)$ and the size of the punch $(L p): S=L d-L p$. 


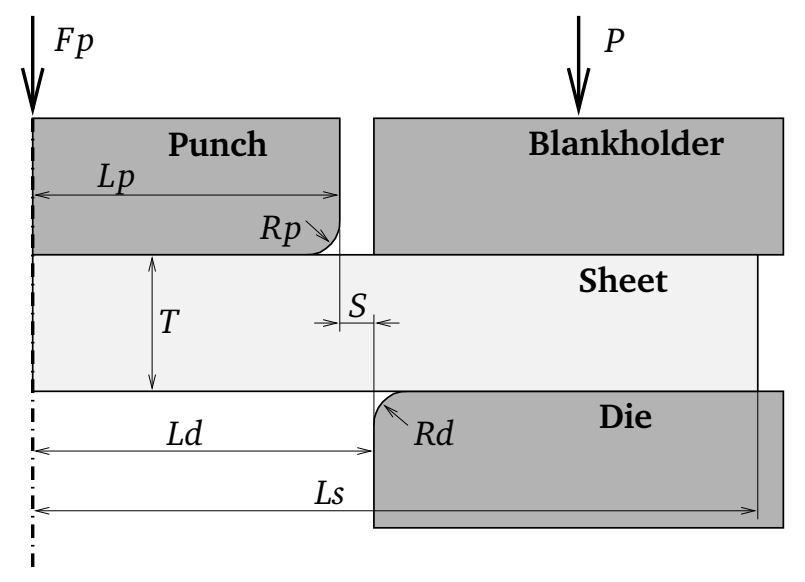

Figure 2.12: Schematic representation of the FEM-model with geometry and boundary conditions.

In order to model the deformation process accurately, approximately 10 finite elements are needed over the tool radii. For industrial applications (read: small radii) this results in very small elements in the region where the deformations are large and localised. Moreover, these elements will soon be deformed so severely that the FEMsimulation will become inaccurate and unstable due to the distorted mesh. To overcome this problem the numerical scheme proposed by Brokken (1999), controlled by a MATLAB (1996) frame, is adopted which will now be explained with the help of figure 2.13.

A FEM-model according to figure 2.12 is considered and its characteristic dimensions are initialised. Then an initial FEM-mesh is generated that consists of quadrilateral four-noded elements, to accommodate the restrictions in the FEM-package MARC (1997). Nevertheless, a triangular mesh generator is used and the resulting mesh is converted into a quadrilateral mesh as suggested by Rank et al. (1993). The incremental punch displacement is the punch displacement that will be simulated in a single MARC calculation, and is chosen such that the elements will not deform too much and remain of good quality. Together with the desired total punch displacement, this incremental punch displacement and the initial mesh constitute the input for the numerical loop (figure 2.13).

The incremental punch displacement and the FEM-model of figure 2.12 determine the boundary conditions and prescribe, together with the mesh, the input for a calculation with the implicit FEM-package MARC (1997). This package uses an updated Lagrangian formulation to calculate the displacements and state variables corresponding to the incremental punch displacement. Furthermore, it is capable to 


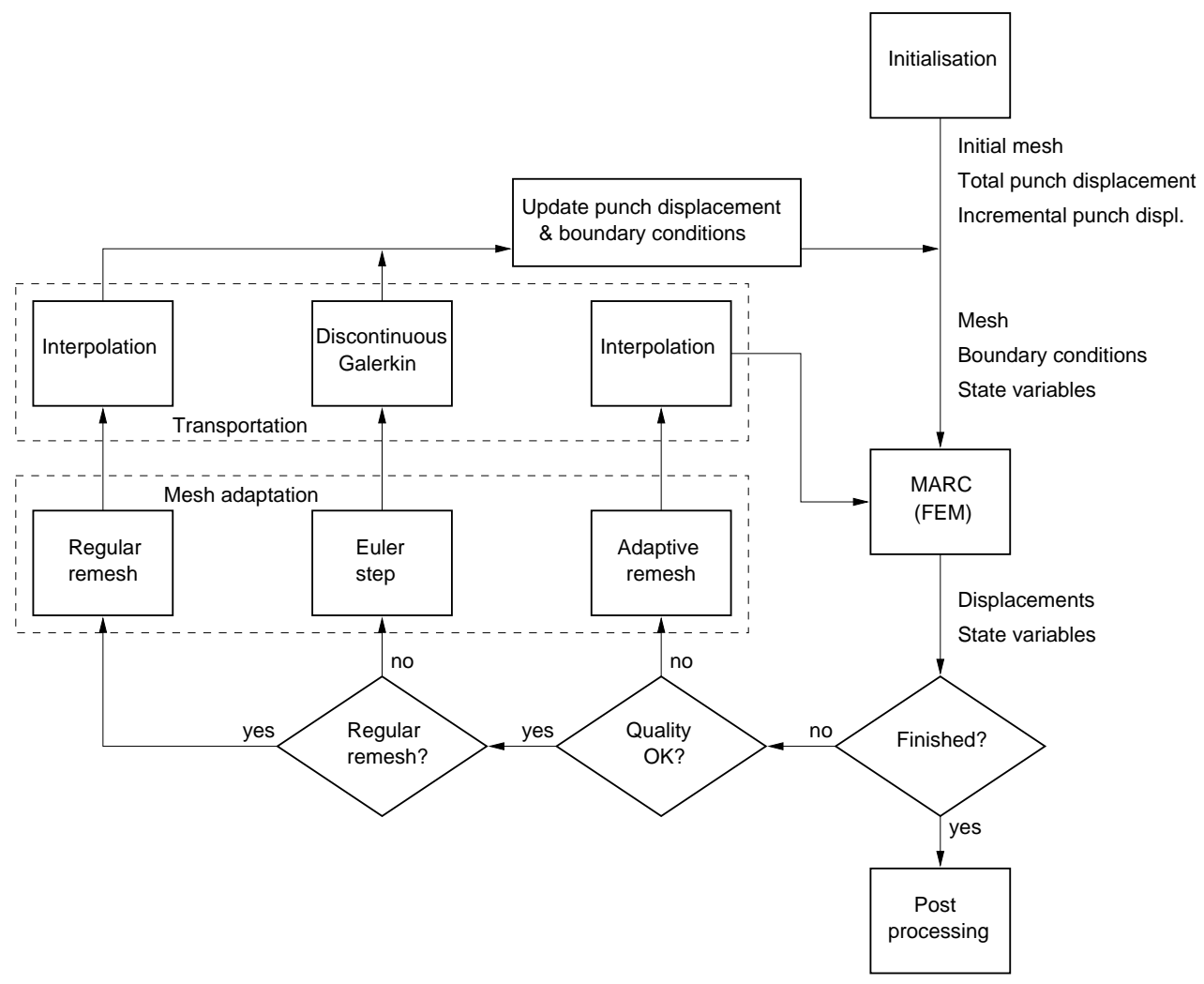

Figure 2.13: Flow scheme of the numerical procedure to handle large and localised deformations.

deal with complex non-linear material behaviour and it can perform advanced contact analyses. As long as the total punch displacement is not reached, the mesh will be adapted and the state variables need transportation from the old mesh to the new mesh. The mesh adaptation and the data transportation can be realised in three ways:

1. When an error estimator (Zienkiewicz \& Zhu, 1992, 1995; Brokken, 1999) indicates that the element sizes are not appropriately distributed, an adaptive remeshing step will be executed. Using the same mesh generator, the mesh that was used as input for the FEM-calculation will be refined where necessary, and coarsened where allowed. The interpolation procedure used to transport the state variables to the new mesh is thoroughly described by Brokken (1999). This transportation algorithm incorporates diffusivity and can introduce inaccu- 
racies in case the mesh is too coarse. With the new mesh, the MARC calculation will be repeated without updating the punch displacement and corresponding boundary conditions.

2. When the quality of the results is estimated to be sufficient (figure 2.13), the mesh will be adapted using an Euler step or a regular (not adaptive) remeshing step. During initialisation this choice is determined by assuming that after every $n$ Eulerian steps a regular remeshing step is needed, because an Eulerian step can improve the mesh quality only if the mesh is not distorted too much by the changing boundary conditions. In such an Eulerian step the mesh connectivity is preserved as well as the positions of the nodes on the material boundary, while the internal nodes are moved to acquire higher quality of the mesh. During such an Eulerian step the grid points of the mesh are fully uncoupled from the material points. In combination with the Lagrangian MARC calculation this procedure is referred to as ALE (see e.g. Schreurs et al., 1986; Huétink et al., 1990; Baaijens, 1993). This method is called Operator Split because the Eulerian step and the Lagrangian step are separated. After this mesh adaptation, a more accurate transportation algorithm can be used due to the preservation of the connectivity: Discontinuous Galerkin. For a more detailed elaboration reference is made to Brokken (1999).

3. The use of regular remeshing steps is minimised because of the less accurate transportation algorithm. However, remeshing steps are still needed because a continuous Eulerian adaptation of the mesh will not suffice in preserving mesh quality because of the changing boundary conditions. A remeshing step is performed with the aforementioned mesh generator using the current mesh coarseness. The same interpolation scheme is used as after adaptive remeshing to transport the state variables from the old to the new mesh.

If the state variables are transported after either an Eulerian step or a regular remeshing step, the punch displacement and the boundary conditions are updated and a new MARC calculation is performed. When an adaptive remeshing step is performed the MARC calculation is repeated with the same boundary conditions but with an improved mesh. The numerical incremental procedure (figure 2.13) will be continued until the total punch displacement is reached. Finally, results can be visualised. 


\section{Chapter 3}

\section{Experimental validation prior to fracture}

\subsection{Introduction}

As it has been mentioned in chapter 1, the deformation and loading history largely determine ductile fracture initiation in forming processes. Because a numerical model is desired that can predict ductile fracture initiation, it is important that the numerical model correctly describes the deformation history in the blanking process up to fracture. Therefore, in this chapter the performance of the numerical model, elucidated in section 2.4, is verified for two different clearances prior to fracture.

\subsection{Verification}

For the verification of the numerical model, the planar blanking setup of section 2.3.1 is considered. In this chapter, the blanking tools with small radii of table 2.4 are used. For the numerical predictions the plane strain finite element model of section 2.4 is applied using the parameters of figure 2.12, presented in table 3.1. Since approximately 10 elements are needed over the tool radii to obtain smooth and accurate solutions (Brokken, 1999), these parameters result in the mesh of figure 3.1 with

The content of this chapter was presented earlier in:

- Goijaerts, A.M., Stegeman, Y.W., Govaert, L.E., Brokken, D., Brekelmans, W.A.M. and Baaijens F.PT., 1998, A validated FEM model to improve metal blanking, Simulation of Materials Processing: Theory, Methods and Applications, J. Huétink and F.P.T. Baaijens, eds., A.A. Balkema, Rotterdam, pp. 979-984.

- Stegeman, Y.W., Goijaerts, A.M., Brokken, D., Brekelmans, W.A.M., Govaert, L.E., Baaijens, F.P.T., 1999, An experimental and numerical study of a planar blanking process, Journal of Materials Processing Technology, vol. 87, pp. 266-276. 
Table 3.1: Parameters of the numerical model in figure 2.12 for different clearances.

\begin{tabular}{|c|c|c|c|c|c|c|c|}
\hline \multicolumn{7}{|c|}{ Clearance: $2 \%$ of thickness } \\
\hline$L p[\mathrm{~mm}]$ & $R p[\mu \mathrm{m}]$ & $L d[\mathrm{~mm}]$ & $R d[\mu \mathrm{m}]$ & $T[\mathrm{~mm}]$ & $S[\mathrm{~mm}]$ & $L s[\mathrm{~mm}]$ & $P[\mathrm{MPa}]$ \\
\hline 4.98 & 7 & 5.00 & 11 & 1.00 & 0.02 & 25 & 5.5 \\
\hline \hline \multicolumn{8}{|c|}{ Clearance: $10 \%$ of thickness } \\
\hline$L p[\mathrm{~mm}]$ & $R p[\mu \mathrm{m}]$ & $L d[\mathrm{~mm}]$ & $R d[\mu \mathrm{m}]$ & $T[\mathrm{~mm}]$ & $S[\mathrm{~mm}]$ & $L s[\mathrm{~mm}]$ & $P[\mathrm{MPa}]$ \\
\hline 4.90 & 7 & 5.00 & 11 & 1.00 & 0.10 & 25 & 5.5 \\
\hline
\end{tabular}

up to 7500 elements. The material $\mathrm{X} 30 \mathrm{Cr} 13$ is employed, which is characterised in section 2.2.1 using the elasto-plastic model. Blanking speeds are applied generating strain rates that are comparable to the strain rates in the tensile tests, employed for the material characterisation in section 2.2.1.

Three aspects of the performance of the numerical model are tested. First of all, the process force is verified by comparing the experimental and numerical punch load - displacement curves for different clearances in section 3.2.1. A good agreement might suggest that the local stresses are well described by the numerical model. However, comparable global forces definitely do not allow the conclusion that the local deformations are described correctly. Therefore, the local deformation fields are evaluated in section 3.2.2, which makes the use of a planar setup necessary. To explain the deviations found between experiments and numerical predictions, a qual-

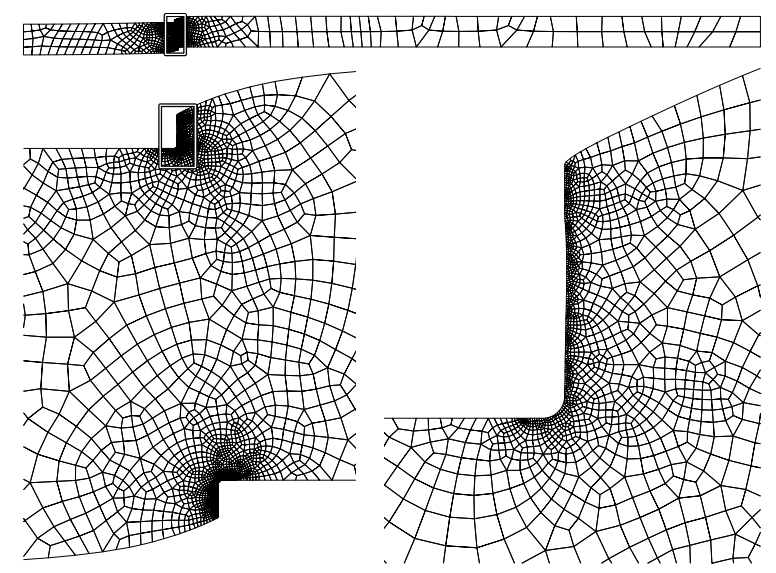

Figure 3.1: Finite element mesh for the planar blanking process with small radii at a punch displacement of $0.20[\mathrm{~mm}]$ for the clearance of $10 \%$ with two zoomed plots. 
itative three-dimensional FEM-simulation is performed in section 3.2.3. Finally, the numerical description of the roll-over zone is verified in section 3.2.4. Good agreement in roll-over confirms high quality of the numerical model and can provide a tool for the prediction of the punch displacement at fracture initiation in chapters 4 and 6 .

\subsubsection{Process force}

Results for the experimental and numerical punch load - displacement curves for clearances of $2 \%$ and $10 \%$ are presented in figure 3.2. The numerical simulation overestimates the punch loads slightly with approximately $5 \%$. This may be caused by the side-effects; at the front and the back of the punch the pressures under the punch will be smaller during experiments due to the fact that the material can move in the direction perpendicular to the plane of the analysis.

The influence of a change in clearance is predicted very well. In the numerical as well as in the experimental results, an increase in the clearance causes a decrease in the punch load. Because strains are larger when applying a smaller clearance, the stresses are higher (see figure 2.1) which results in higher punch loads.

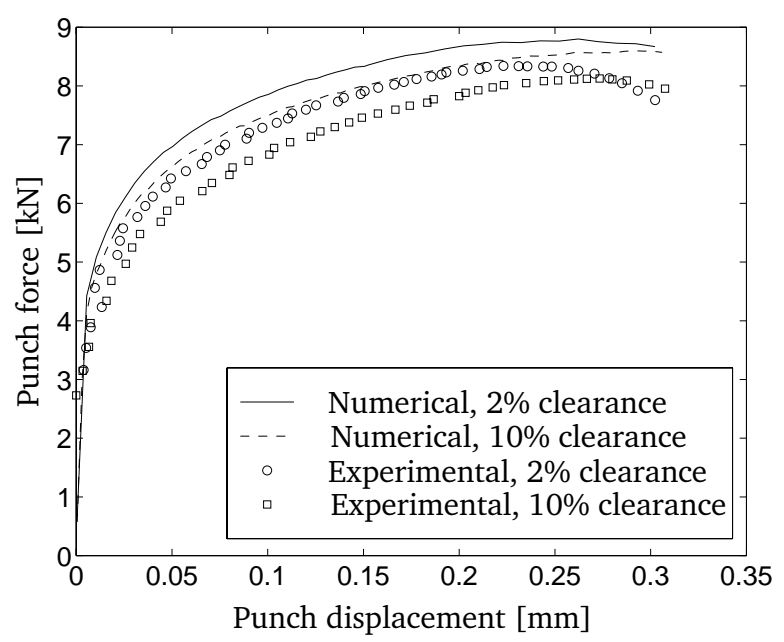

Figure 3.2: Comparison of experimental and numerical punch load - displacement curves for two different clearances.

\subsubsection{Deformation field}

In section 2.3.2 it was explained that digital images of the specimen surface during the blanking process are recorded. Images of $400 \times 400$ pixels with 256 gray-levels are used, with windows and search areas of $21 \times 21$ and $43 \times 43$ pixels, respectively. 

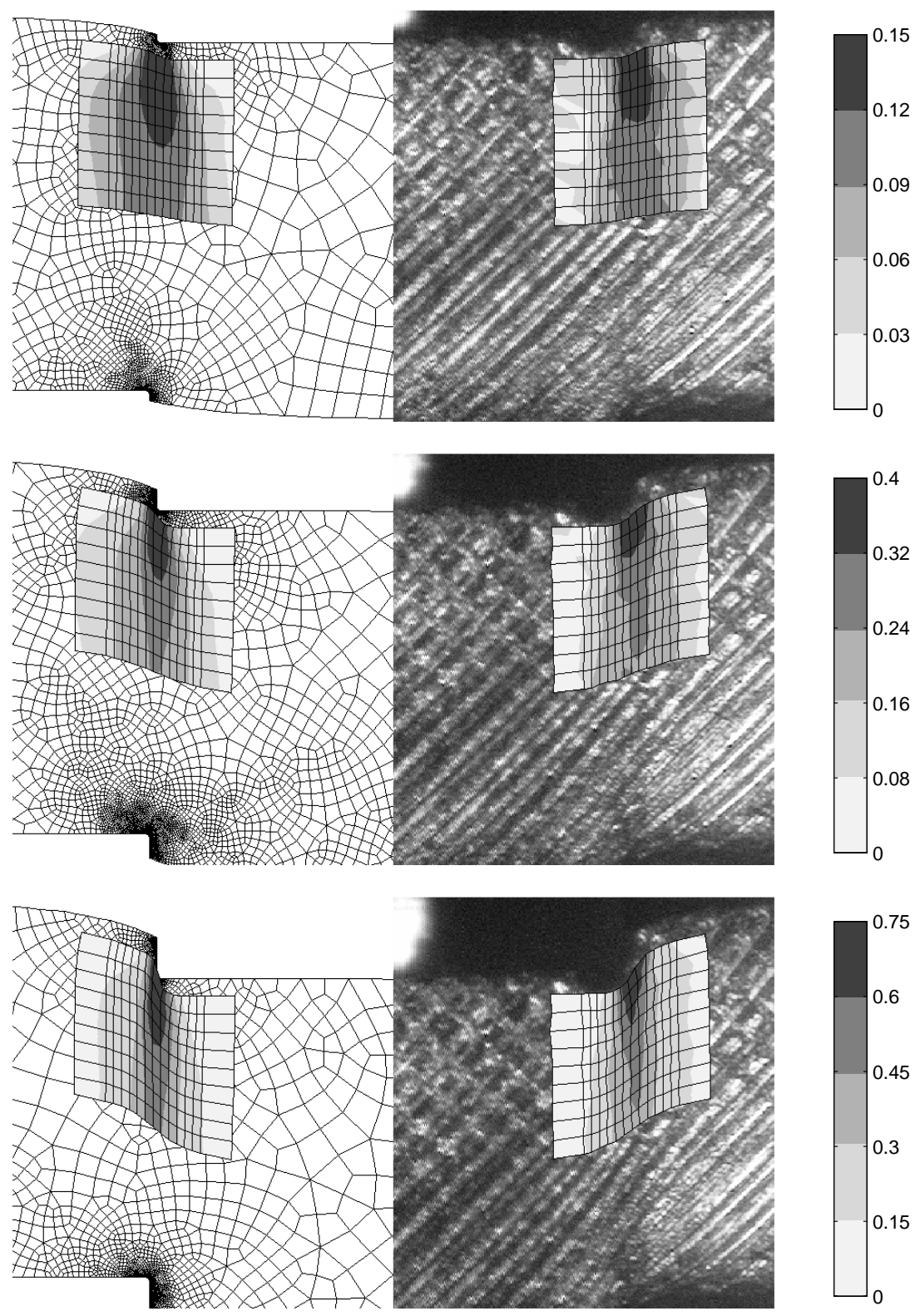

Figure 3.3: Comparison of the numerical and experimental strain field for a clearance of $2 \%$ for three process stages: punch displacements of $0.07,0.14$ and $0.20[\mathrm{~mm}]$. The five gray-levels represent the strains that are calculated on the initially rectangular grid. 

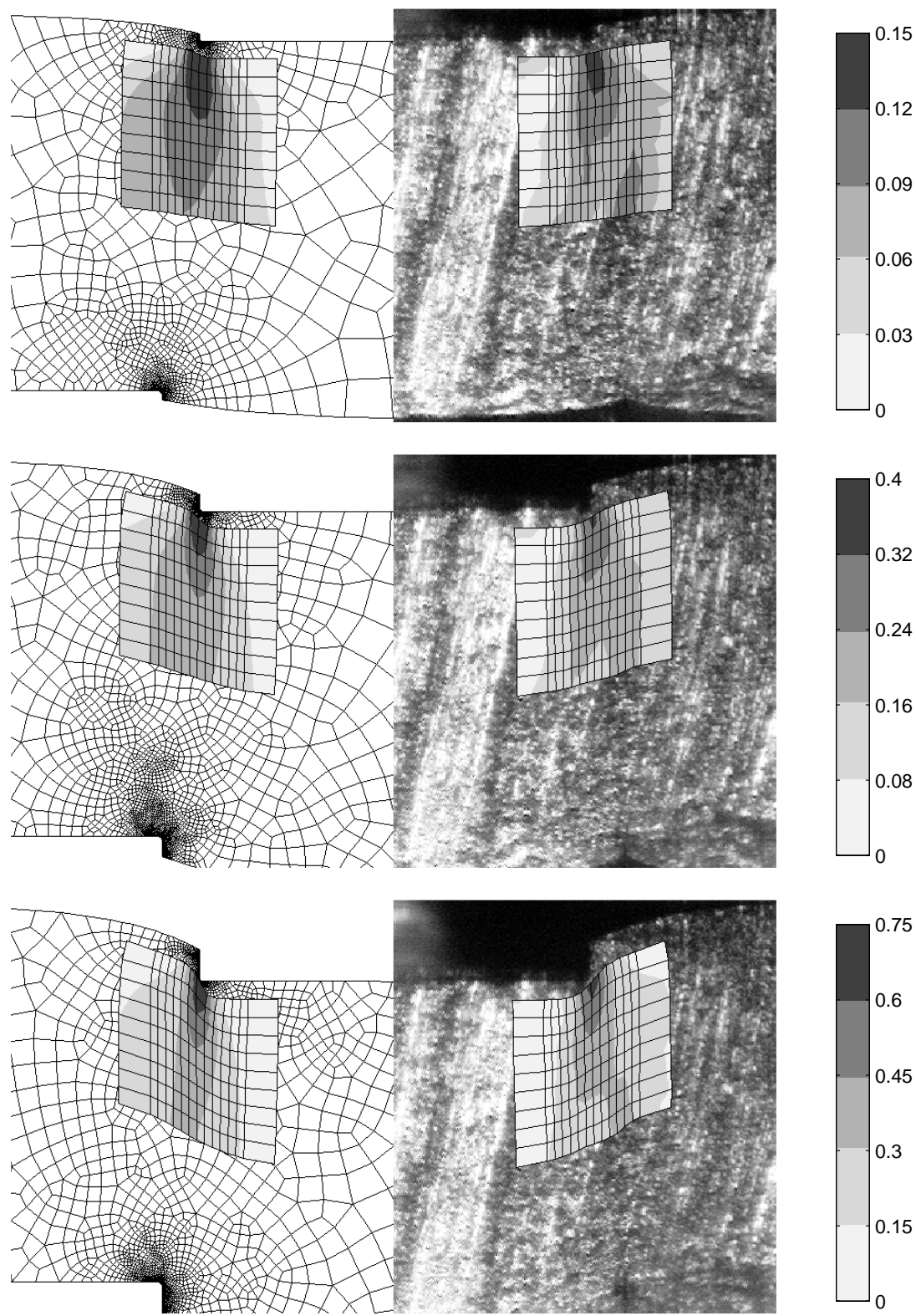

Figure 3.4: Comparison of the numerical and experimental strain field for a clearance of $10 \%$ for three process stages: punch displacements of $0.07,0.14$ and $0.20[\mathrm{~mm}]$. The five gray-levels represent the strains that are calculated on the initially rectangular grid. 
To improve the performance of the correlation technique, all images are smoothed prior to the use of DIC by the filter of equation (3.1):

$$
G^{\prime}(x, y)=\frac{1}{10}\left[G(x, y)+\sum_{i, j} G(x+i, y+j)\right] \quad i, j \in\{-1,0,1\}
$$

where $G(x, y)$ and $G^{\prime}(x, y)$ represent the old and the new gray-level values, respectively, at a point identified by the array integers $(x, y)$.

The logarithmic equivalent strain fields, computed according to the method of section 2.3.2, are measured using a rectangular grid of material points. The grid is defined by 10 rows of material points between 0.05 and $0.5[\mathrm{~mm}]$ from the upper side of the specimen. Each row consists of fifteen points, of which the central thirteen points have a mutual distance of $20[\mu \mathrm{m}]$. Initially, the central point of each row is situated exactly below the punch edge. Up to a punch displacement of $0.20[\mathrm{~mm}]$, approximately 30 images are used to calculate the total displacements and strains.

Using the displacements of the material points of exactly the same rectangular grid as mentioned in the previous paragraph, the logarithmic equivalent strain fields are also determined for the numerical predictions. Numerical and (reproducible) experimental results for the strain fields are presented in figures 3.3 and 3.4 for a clearance of $2 \%$ and $10 \%$, respectively. The results are only up to a punch displacement of $0.20[\mathrm{~mm}]$ to avoid ductile fracture initiation to influence the deformation results. Ductile fracture is expected to initiate at a punch displacement of approximately $0.25[\mathrm{~mm}]$ for the $2 \%$ clearance experiment (see the sudden force drop of the $2 \%$ clearance experiment in figure 3.2 ).

In figures 3.3 and 3.4, strain levels are compared at three different stages of the blanking process: at punch displacements of $0.07,0.14$ and $0.20[\mathrm{~mm}]$. As it could be expected, the strain levels are larger for the $2 \%$ experiment than for the $10 \% \mathrm{ex}$ periment because the deformation zone is more localised for the smaller clearance. The differences in strain levels that occur in the experiments between the two clearances are very well predicted by the numerical calculations, although the numerical predictions slightly overestimate all the experiments. This may be caused by the fact that at the surface, where the strains are experimentally determined, the plane strain assumption of the numerical model is not valid; material at the surface is free to move in the direction perpendicular to the surface. Considering the comparisons at three stages for both clearances, the numerical predictions overestimate the maximum occurring strain by approximately $10 \%$. In section 3.2 .3 a qualitative three-dimensional FEM-simulation of the planar blanking process is performed in order to confirm the differences in strain level at the surface (where the strains were measured experimentally) and at the centre of the specimen (where the plane strain assumption is acceptable). 

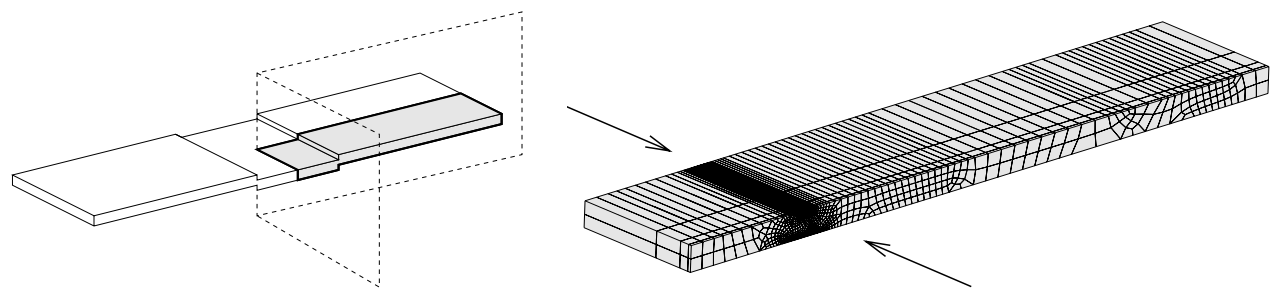

Figure 3.5: Three-dimensional model of a quarter of a specimen (left plot). The arrows in the right plot depict two different views. The right bottom arrow reflects the experimental camera view. The other arrow views the inner surface at the centre of the specimen, where the numerical plane strain condition applies.

\subsubsection{Qualitative three-dimensional FEM-model}

Figures 3.3 and 3.4 show differences between the experimentally and numerically determined strain fields. To investigate these differences, a qualitative three-dimensional simulation of the blanking process is performed. For that purpose, a simple threedimensional quasi-static elasto-plastic FEM-model of a quarter of a specimen (figure 3.5) is constructed, using 3764 linear 8-noded brick elements (MARC, 1997). This simulation allows the investigation of the differences in strain distribution between the surface viewed by the camera and the internal symmetry surface (the two arrows in figure 3.5). In a three-dimensional simulation, the OS-ALE algorithm and
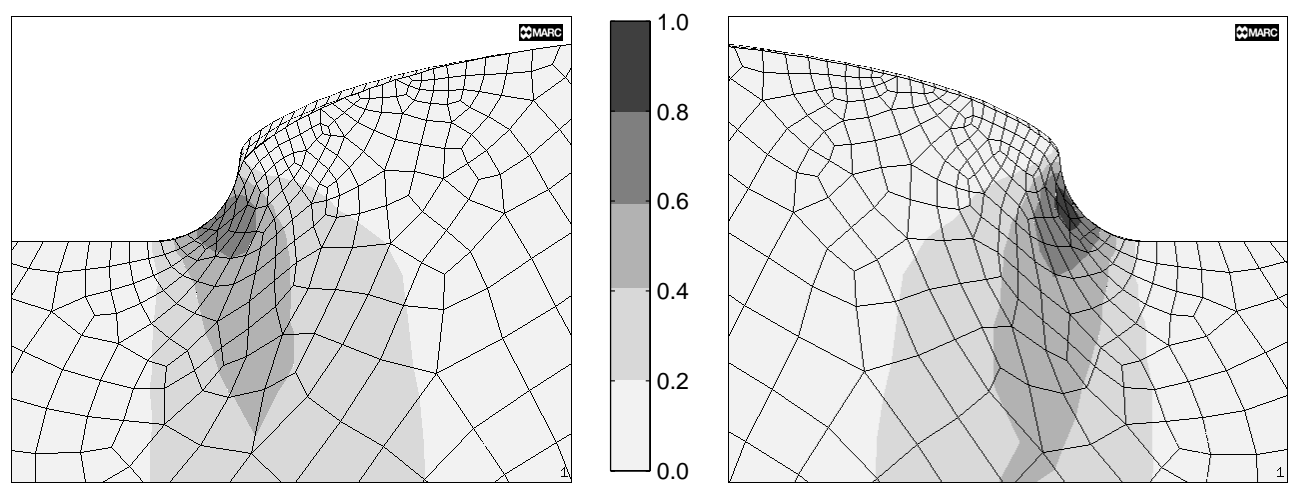

Figure 3.6: At the left the surface is shown as it is viewed by the camera, where the material can flow towards the camera (in conformity with the experimental observation). At the right, a view is presented on the inner surface of the middle of the specimen, where the plane strain condition applies (numerical prediction). 
the remeshing algorithm are not operational. Therefore, the simulation is restricted to a blanking process with a large punch radius $(0.1[\mathrm{~mm}])$ and a large die radius $(0.2[\mathrm{~mm}])$ while relatively large elements (not the required 10 elements over the tool radii) are used. Because of this, the simulation will not give quantitatively reliable results. However, results will still supply a qualitative indication.

The results are shown in figure 3.6, where the two views (associated with the arrows in figure 3.5) on the different surfaces are presented. It can be observed that the equivalent strains at the symmetry surface are larger than at the outer surface which is viewed by the camera. A closer investigation of the levels of the maximum strain reveals that the maxima at both surfaces differ a little more than $10 \%$. This result explains the differences between experimental and numerical results of figures 3.3 and 3.4.

\subsubsection{Roll-over}

The roll-over is verified using different clearances for two reasons. First of all, a good prediction confirms the quality of the numerical description of the deformation history. Secondly, the correct prediction of the roll-over zone, as a part of the product shape (the blanked edge), is one of the main goals of this thesis. Moreover, a correct prediction of the roll-over provides a tool for the prediction of punch displacement at fracture initiation in chapters 4 and 6 . In these chapters the correct description of the roll-over zones will not be verified further.

The roll-over zones are verified for two clearances at three different stages of the blanking process in figure 3.7. For the $2 \%$ clearance the verification is hampered by the poor quality of the images, where the edges are not depicted very sharply, at the bottom side of the specimen. At the top side of the specimen the roll-over is well predicted. For the $10 \%$ clearance the roll-over is very well predicted at both sides of the specimen. Also, it is shown that for a larger clearance the roll-over zone becomes larger. This is explained by the fact that the deformation zone is wider and this effect is well described by the numerical simulations. Considering figure 3.7, predictions for the roll-over are estimated to have deviations of less than $5 \%$.

\subsection{Discussion}

In order to predict ductile fracture initiation in chapters 4 and 6 , a FEM-model of the blanking process is desired that is validated to correctly describe the deformation history. In section 3.2.1 the process forces are verified and good agreement between experiments and numerical predictions is shown within 5\%. In section 3.2.2 the deformations during the blanking process up to fracture are verified. Results of a qualitative three-dimensional FEM-simulation in section 3.2.3 show that the deformation 

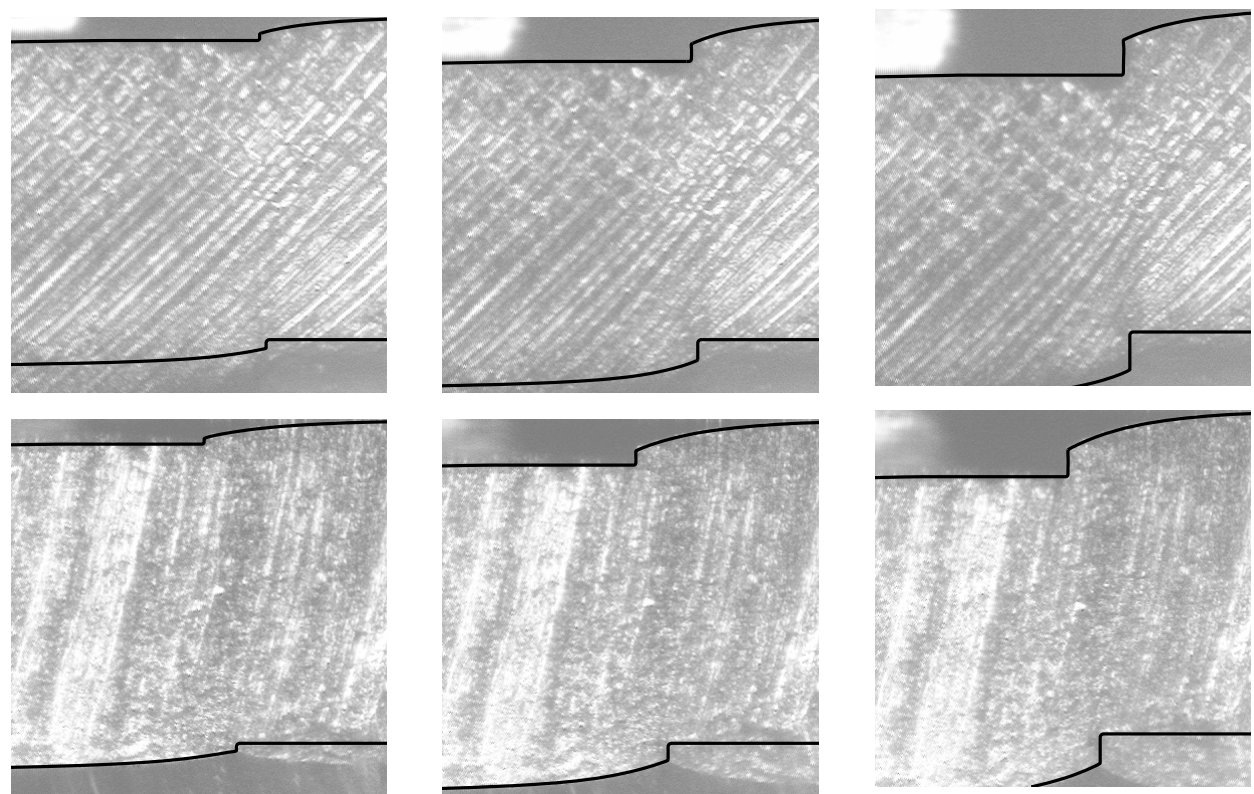

Figure 3.7: Verification of the roll-over zones for the $2 \%$ clearance (at the top) and the 10\% clearance (at the bottom). The black curves represent the numerical predictions. The three images for every clearance depict three different stages in the blanking process (punch displacements of $0.07,0.14$ and $0.20[\mathrm{~mm}]$ ).

is very well predicted by the two-dimensional numerical model. After a correction for the side effect, the error is estimated to be below 5\%. In section 3.2.4 the verification of the prediction of the roll-over zones has been presented. Experimental and numerical results for the roll-over zones agree within $5 \%$ as is shown in figure 3.7.

Considering all results of this chapter it is concluded that the numerical model of section 2.4 describes the deformation history in the blanking process very well. The material characterisation of $\mathrm{X} 30 \mathrm{Cr} 13$, described in section 2.2.1, may be an essential issue for the correct simulation of forming processes where extremely large strains occur. Now that the numerical model is found to describe the deformation history correctly during the blanking process, the essential tool for the prediction of ductile fracture initiation is present. 
$40 \quad$ Chapter 3 


\section{Chapter 4}

\section{Prediction of ductile fracture in blanking for a stainless steel}

\subsection{Introduction}

In this chapter, some procedures are elaborated that are capable of predicting ductile fracture initiation in the blanking process for a ferritic 13\% chrome stainless steel (X30Cr13, DIN 17006). In chapter 1 the choice has been made to consider only local ductile fracture initiation criteria with the following general format:

$$
\int_{\bar{\varepsilon}_{p}} f(\boldsymbol{\sigma}) d \bar{\varepsilon}_{p}=C
$$

In this formulation, ductile fracture is assumed to initiate if the integral over the equivalent plastic strain of a scalar function of the stress reaches a critical (material) parameter $C$.

The quantification of the right-hand side of equation (4.1) is referred to as the characterisation of the fracture model. An experiment needs to be chosen that allows the identification of ductile fracture initiation. Accordingly, a numerical simulation of that experiment is executed up to the moment of ductile fracture initiation. During the numerical simulation the left-hand side of equation (4.1) is computed as a field variable. As the simulation reaches the experimentally determined point of ductile fracture initiation, the parameter $C$ is quantified to be the occurring limit value of the integral. A check should confirm that the location of the maximum agrees with the experimental position of ductile fracture initiation.

The content of this chapter is partly reproduced from:

Goijaerts, A.M., Govaert, L.E., and Baaijens F.PT., 1999, Prediction of ductile fracture in metal blanking. Accepted for publication in Journal of Manufacturing Science and Engineering, Transactions of the ASME. 
When the ductile fracture initiation model is characterised it can be applied to predict ductile fracture initiation in a blanking simulation with an arbitrary geometry. For this purpose the validated blanking model of chapter 3 is employed, which is shown to accurately describe the deformation history. Again, the left-hand side of equation (4.1) is updated and stored as a field variable during the simulation of the blanking process. When the integral reaches the critical $C$ in the simulation, ductile fracture is predicted to initiate and the surface information required at the blanked edge is established.

Two different approaches are elaborated in this chapter, involving two different experiments for the characterisation of the fracture model. The most promising procedure, considering the literature, involves the determination of $C$ in an experiment with similar loading conditions as in the application, and is therefore based on the use of a rather complicated blanking experiment. The second approach that will be outlined, employs an ordinary tensile test for the characterisation of the fracture model and is therefore more favourable for industrial applications. For different specifications of equation (4.1), both approaches will be verified over a range of blanking processes with varying geometries.

In section 4.2 the blanking experiments are discussed that are needed for the first approach and for the verification. In section 4.3 the parameter $C$ is determined in a blanking experiment and verification results are presented. Experimental results and numerical simulations of the tensile test are outlined in section 4.4, followed by the elaboration of the approach, where the ductile fracture initiation criterion is characterised in a tensile test, section 4.5. Finally, results are discussed in section 4.6.

\subsection{Blanking experiments}

Blanking experiments are performed using the axisymmetric setup of section 2.3.3. To avoid exorbitant simulation times in the characterisation and verification, the tools with the relatively large cutting radii are used. The cutting radii of the punch are somewhat smaller than the cutting radius of the die, to ensure that fracture will initiate at the punch and will grow towards the die.

The punch displacement at fracture captures the moment of ductile fracture initiation in the blanking process and needs experimental quantification. This punch displacement at fracture is shown to consist of the roll-over, the shear zone and the burr $(a+b+c$, figure 4.1).

In the blanking setup, six experiments are performed for every clearance. The shear zone (b) and the burr (c) are measured afterwards (section 2.3.4) at eight positions over the circumference of the blanked products, and averaged to account for possible misalignment of the punch. Then, the values are averaged over the six experiments and the standard-deviation is calculated (figure 4.1). 

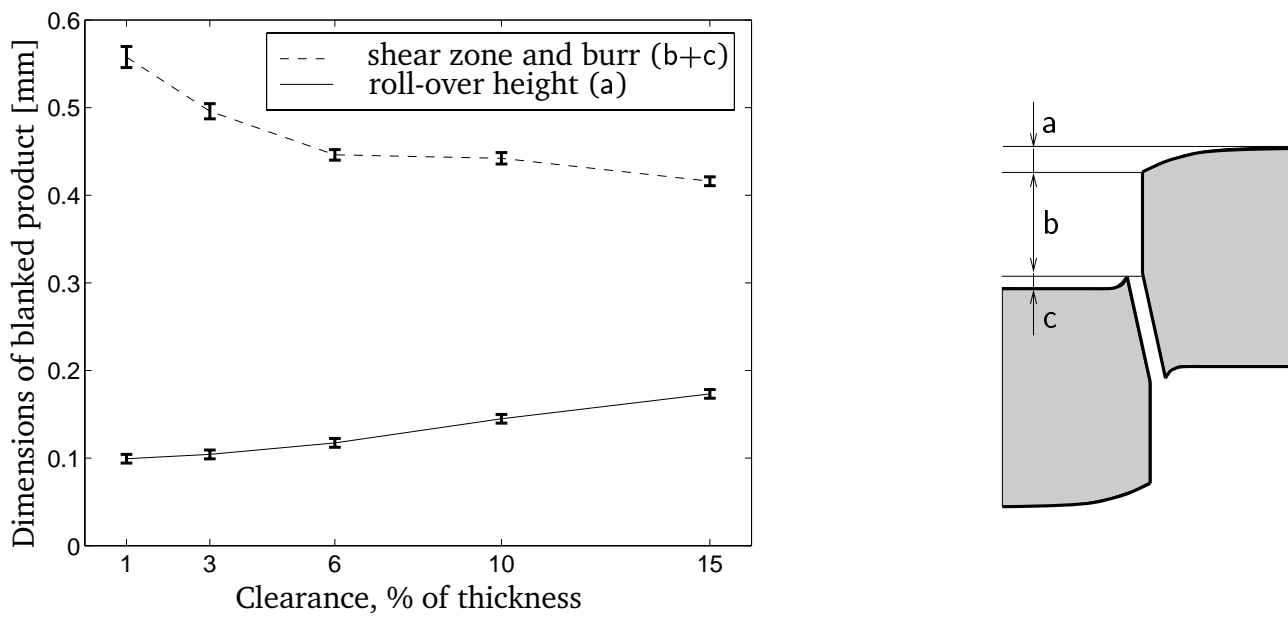

Figure 4.1: Experimental results for the identification of the punch displacement at fracture $(\mathrm{a}+\mathrm{b}+\mathrm{c})$ for large cutting radii of the tools for varying clearances. The error bars represent the standard-deviations.

It is shown in chapter 3 that the roll-over (a) could be accurately predicted for this material, with the validated model. Because it is difficult to experimentally account for the spring-back of the specimen, the roll-over is taken from the numerical simulations. The element size near the transition of roll-over and shear zone is adopted as the experimental standard-deviation. (This standard-deviation is in the same order of magnitude as the expected error, shown in chapter 3.) The results are depicted in figure 4.1.

The roll-over is very small for small clearances and increases for larger clearances because the wider deformation zone allows more bending. The shear zone becomes smaller for larger clearances which is caused by the hydrostatic stress state; for small clearances the hydrostatic pressure is larger and this postpones ductile fracture initiation, despite of the fact that the deformation is more localised and that the strains are larger. The burr height is very small (in the order of $5[\mu \mathrm{m}]$ ) and is largely determined by the cutting radius of the punch.

The average punch displacements at fracture $(a+b+c)$ are firstly plotted in figure 4.2, along with twice the standard-deviations (95\% interval). The combination of the trend for roll-over height and shear height (plus burr) explains the minimum in the experimental trend. There is a small experimental deviation for the clearance of $10 \%$. This is probably a result of the larger cutting radius for the specific $10 \%$ clearance punch (table 2.5). A larger cutting radius of the punch postpones ductile fracture initiation because the deformation becomes less localised. 
In the final stage of validation (sections 4.3.2 and 4.5.3) also the tools with small cutting radii of table 2.5 are employed. Experimentally, exactly the same procedures are utilised as for the large cutting radii of the tools. Thus, experimental results are available to verify the ductile fracture initiation models both for varying clearances and cutting radii of the tools.

\subsection{Characterising ductile fracture in blanking}

In section 4.3.1 the strategy to characterise a ductile fracture model in the blanking process and to, subsequently, predict ductile fracture initiation over a wide range of clearances is explained. Next, the most relevant ductile fracture criteria, proposed in literature, are evaluated and some adaptations are proposed to make two models valid for the blanking process.

\subsubsection{Strategy}

The characterisation of ductile fracture is performed by the experimental determination of the punch displacement at fracture initiation for one clearance and simulating this blanking process up to the point of fracture initiation. During this simulation not only the usual state variables are stored, but also the left-hand side of equation (4.1). When the experimental punch displacement at fracture is reached in the simulation, $C$ is determined to be the maximum value of $\int f(\boldsymbol{\sigma}) d \bar{\varepsilon}_{p}$ considered over all material points of the entire FEM-mesh, and at this point the criterion is declared to be characterised.

If a ductile fracture initiation model is characterised, the validity for the blanking process over the entire range of clearances and for different cutting radii of the tools can be evaluated. This evaluation is performed using FEM-simulations of the blanking processes for the different geometries. During the simulations $\int f(\boldsymbol{\sigma}) d \bar{\varepsilon}_{p}$ is stored as a field variable and as soon as it reaches the critical value $C$, the associated punch displacement at fracture is predicted. If the predictions for all blanking processes with different geometries are within satisfying margins of the experiments, a proper ductile fracture initiation model for the blanking process has been achieved (for this material).

\subsubsection{Application of ductile fracture models}

A number of ductile fracture initiation criteria, taken from literature, are evaluated pursuing the strategy explained in section 4.3.1. A selection of appropriate and promising formulations is discussed here and displayed in table 4.1. The plastic work criterion is based on the assumption that the material can only absorb a cer- 
Table 4.1: Four ductile fracture initiation criteria, selected from literature.

\begin{tabular}{lr}
\hline Plastic Work (Freudenthal, 1950) & $\int_{\bar{\varepsilon}_{p}} \bar{\sigma} d \bar{\varepsilon}_{p}=C$ \\
Cockroft \& Latham (1968) & $\int_{\bar{\varepsilon}_{p}}\left\lfloor\sigma_{1}\right\rfloor d \bar{\varepsilon}_{p}=C$ \\
Rice \& Tracey (1969), $A_{R T}=3 / 2$ & $\int_{\bar{\varepsilon}_{p}} \exp \left(A_{R T} \cdot \sigma_{h} / \bar{\sigma}\right) d \bar{\varepsilon}_{p}=C$ \\
Oyane et al. (1980) & $\int_{\bar{\varepsilon}_{p}}\left\lfloor 1+A_{O} \cdot \sigma_{h} / \bar{\sigma}\right\rfloor d \bar{\varepsilon}_{p}=C$ \\
\hline
\end{tabular}

tain amount of energy. This energy criterion was firstly proposed in this form by Freudenthal (1950). The Cockroft \& Latham criterion considers the effect of the maximum principal stress $\left(\sigma_{1}\right)$ over the plastic strain path. Maximum principal stresses are often used in linear elastic fracture mechanics to describe brittle fracture. The $\lfloor.$.$\rfloor notation according to equation (4.2) is used here to make sure that the fracture$ integral cannot decrease for a growing equivalent plastic strain.

$$
\lfloor x\rfloor= \begin{cases}x, & x>0 \\ 0, & x \leq 0\end{cases}
$$

This assumption reflects the concept in damage mechanics that damage cannot decrease. The Cockroft \& Latham criterion has already been used for the blanking process by several authors (Jeong et al., 1996; Klocke \& Sweeney, 1998; Faura et al., 1998). Unfortunately, they either did not confront their simulations with experiments or did not show good agreement over a range of different geometries. The Rice \& Tracey criterion is based on a theoretical study of the growth of a void in an infinite perfectly plastic matrix and in this study they found that the constant $A_{R T}$ should be equal to $3 / 2$. In their formulation, the triaxiality $\left(\sigma_{h} / \bar{\sigma}\right)$ is defined as the ratio of hydrostatic stress and the equivalent Von Mises stress. The Oyane criterion is derived from a plasticity approach for porous materials, assuming that the volumetric strain has a critical level. In this criterion a parameter $A_{O}$ was inserted, which supplies more freedom to arrive at a valid ductile fracture model (this parameter is proposed as a material constant by Oyane et al., 1980).

For the evaluation of the criteria mentioned above, the $15 \%$ clearance experiment was taken as the characterisation experiment in which the parameter $C$ is determined. For the other clearances the displacement at fracture initiation is predicted and results are shown in figure 4.2 for the criteria with only one parameter. The plastic work or energy criterion predicts fracture initiation completely wrong. For the smallest clearance a punch displacement of only $0.39[\mathrm{~mm}]$ is predicted. The Cockroft \& Latham criterion, that was already used for the blanking process, does not predict the trend correctly; the punch displacement at fracture should be larger for a small 


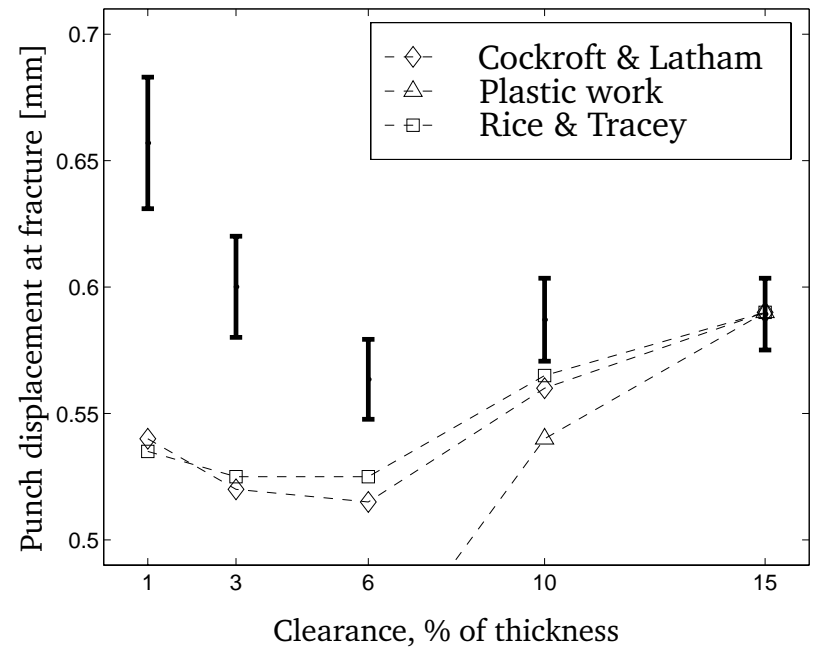

Figure 4.2: The evaluation of three criteria from literature with a single parameter. The critical values $C$ are determined in the 15\%-experiment; Cockroft \& Latham: $C=1.40 \cdot 10^{3}[\mathrm{MPa}]$; Plastic work: $C=3.49 \cdot 10^{3}[\mathrm{MPa}]$; Rice \& Tracey: $C=2.32[-]$.

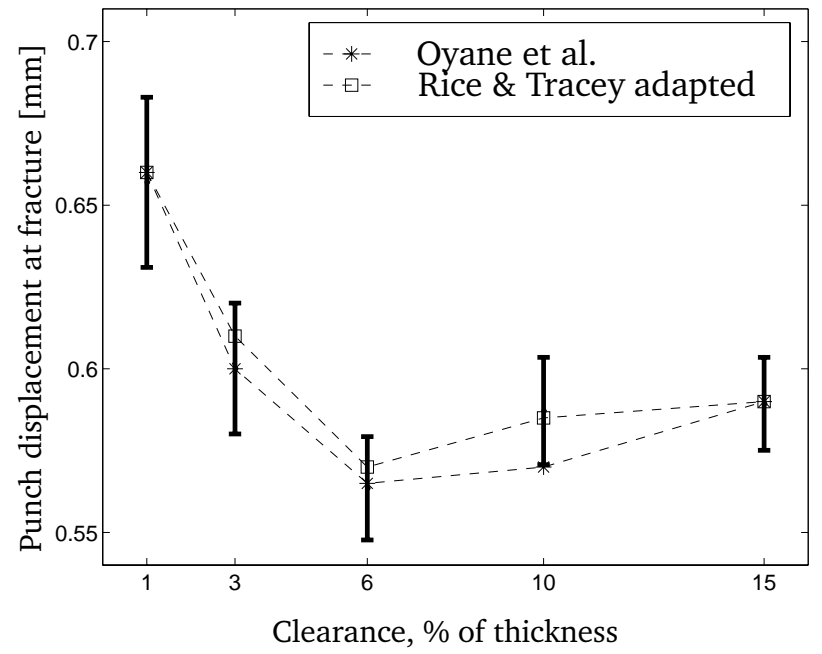

Figure 4.3: Results for the adapted Rice \& Tracey and Oyane criteria (table 4.2), for the blanking process with relatively large cutting radii of the tools. 
Table 4.2: Two ductile fracture initiation criteria, valid for the blanking process.

\begin{tabular}{lc}
\hline Rice \& Tracey, adapted: $A_{R T}=2.9$ & $\int_{\bar{\varepsilon}_{p}} \exp \left(A_{R T} \cdot \sigma_{h} / \bar{\sigma}\right) d \bar{\varepsilon}_{p}=C_{R T}$ \\
Oyane et al. (1980), $A_{O}=3.9$ & $\int_{\bar{\varepsilon}_{p}}\left\lfloor 1+A_{O} \cdot \sigma_{h} / \bar{\sigma}\right\rfloor d \bar{\varepsilon}_{p}=C_{O}$ \\
\hline
\end{tabular}

clearance than for a wide clearance. Moreover, this criterion deviates more than $20 \%$ for the smallest clearance, which is considered to be unacceptable. The Rice \& Tracey criterion gives comparable mismatches.

To achieve better results the quantitative influence of triaxiality (which is more negative for smaller clearances) on ductile fracture initiation should be changed for the blanking process. For the Rice \& Tracey criterion this is realised by varying the constant $A_{R T}$, originally equal to $3 / 2$. If $A_{R T}$ is considered as an adjustable parameter, the criterion starts to resemble the Oyane criterion. The adapted Rice \& Tracey criterion $\left(A_{R T}=3 / 2\right.$ is modified into $\left.A_{R T}=2.9\right)$ and the Oyane criterion $\left(A_{O}=3.9\right)$ yield good results for the large cutting radii of the tools (table 4.2, figure 4.3). The dimensionless constants $C$ are determined in the $15 \%$ experiment resulting in $C_{R T}=2.76$ and $C_{O}=2.38$, for the Rice \& Tracey and the Oyane criterion, respectively. Finally, these criteria are verified for a change in cutting radii of the tools for the two extreme clearances, applying the predetermined constants $C$, and again good results are obtained (figure 4.4).
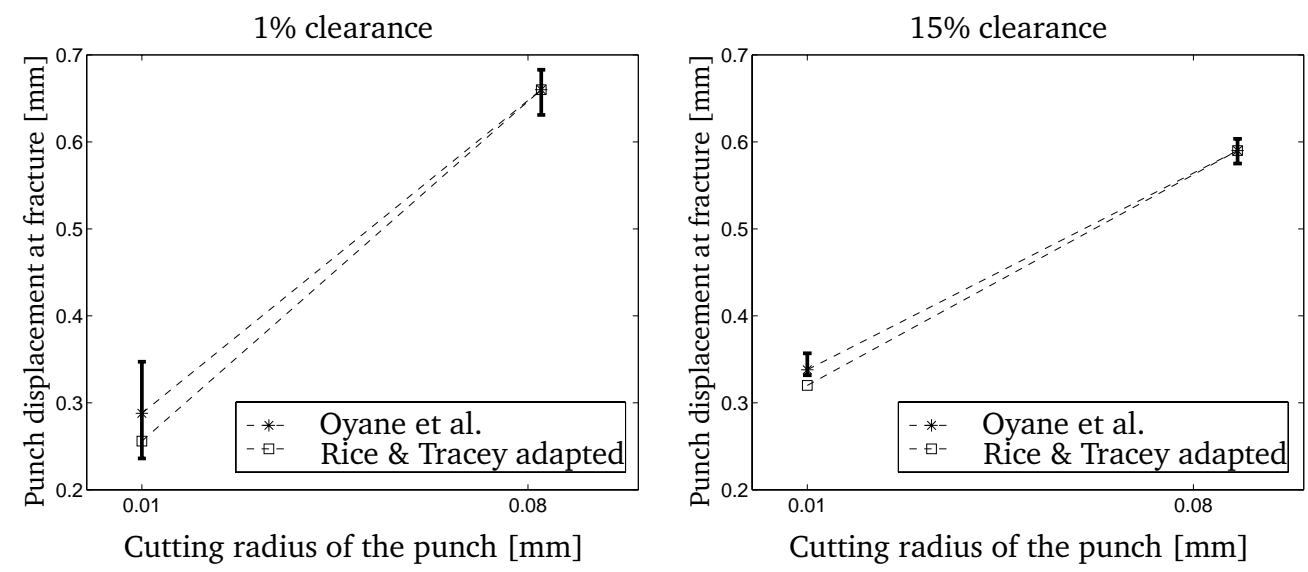

Figure 4.4: Verification of the adapted Rice \& Tracey and Oyane model on the effect of the cutting radius of the tools for two extreme clearances. The parameters $C$ are determined in the $15 \%$ experiment with large cutting radii of the tools. 


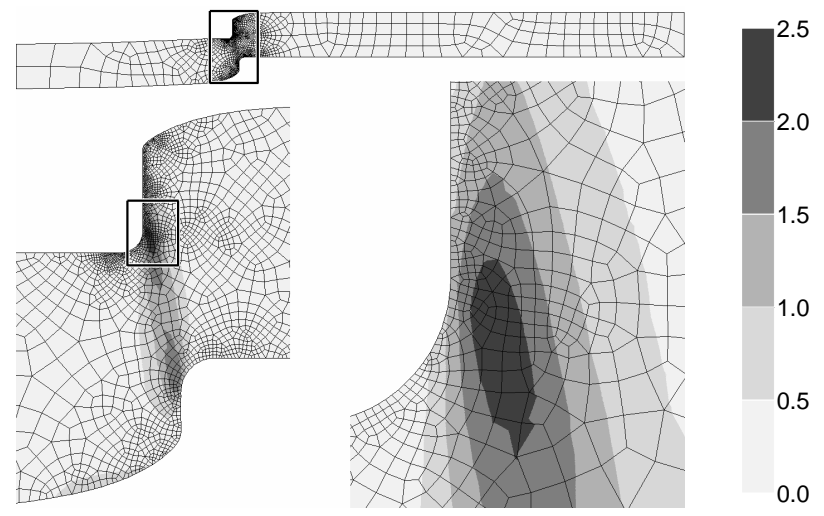

Figure 4.5: Field variable plot of the Oyane integral for an axisymmetric blanking model, at the punch displacement where fracture initiated (15\% clearance), with two zoomed plots. Maximum value is 2.38. The location of the maximum is in agreement with experimental results.

In figure 4.5 the value of the Oyane integral expression is drawn as a field variable in the 15\%-experiment at the punch displacement where experimentally fracture initiation was detected. The maximum value is located close to the cutting radius of the punch and this is in good agreement with the position that was experimentally found. If the parameter $C$ is determined in another blanking experiment (with another clearance) results are obtained with similar quality. The two criteria that can predict ductile fracture initiation in the blanking process over a wide range of clearances, by performing only one blanking experiment, have been summarised in table 4.2.

\subsection{Tensile tests under different hydrostatic pressures}

In section 4.5 it will be tried to predict ductile fracture in the blanking process by characterising the fracture model in a tensile test. This implies that a fracture model must be found that can accurately predict ductile fracture initiation both in blanking and in tensile testing after necking.

As it was already mentioned in chapter 1 , the triaxiality is very important in predicting the loading condition when ductile fracture occurs. To verify the correct influence of the triaxiality on fracture in tensile testing some tensile experiments are performed under different hydrostatic pressures. Experimental results are presented in section 4.4.1 and the FEM-simulations in section 4.4.2. 


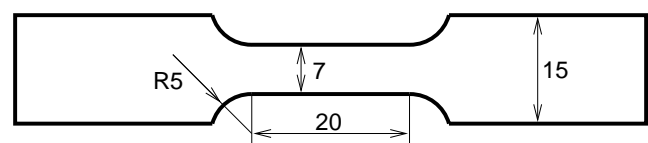

Figure 4.6: Dimensions of the tensile specimens in [mm], thickness is $1[\mathrm{~mm}]$.

\subsubsection{Experimental results}

At the Interdisciplinary Research Centre (IRC) for Polymer Science and Technology in Leeds, an experimental setup is operational which enables tensile testing under superposed hydrostatic pressures. The tensile test can be performed in an oil chamber and the oil-pressure is maintained constant during the entire tensile test. Measurements are performed at three different levels of superposed hydrostatic pressure: 0 , 250 and $500[\mathrm{MPa}$. Strain rates are realised in the same order of magnitude as in section 2.2.1. Clamp force and displacement are measured. The dimensions of the tensile specimens are chosen addressing the requirements of the pressurised tensile apparatus and are shown in figure 4.6.

The measured force displacement curves (see also figure 4.11) were identical for all different hydrostatic pressures within the experimental error. This demonstrates that the hydrostatic pressure has no influence on the plastic yielding and hardening

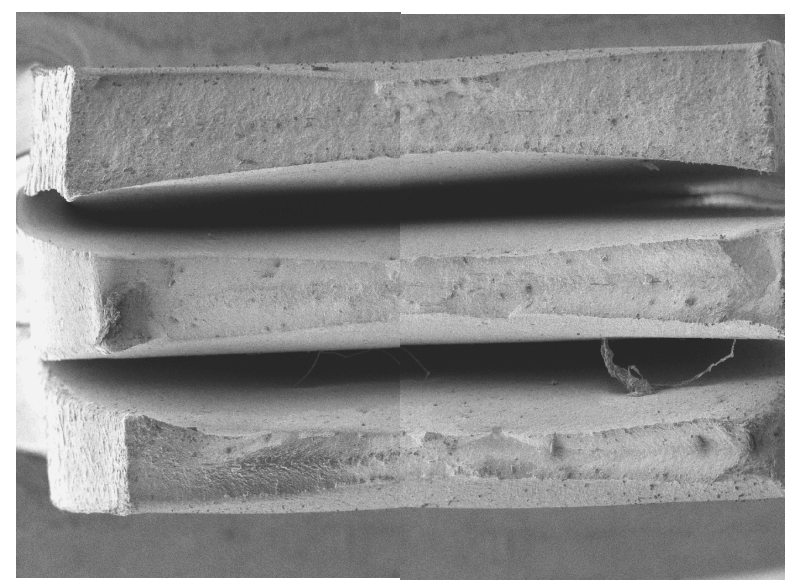

Figure 4.7: Composed ESEM picture taken in the tensile direction perpendicular to the fractured neck of tensile specimens tested under different hydrostatic pressures (from top to bottom: 0, 250 and $500[\mathrm{MPa}]$ ). 


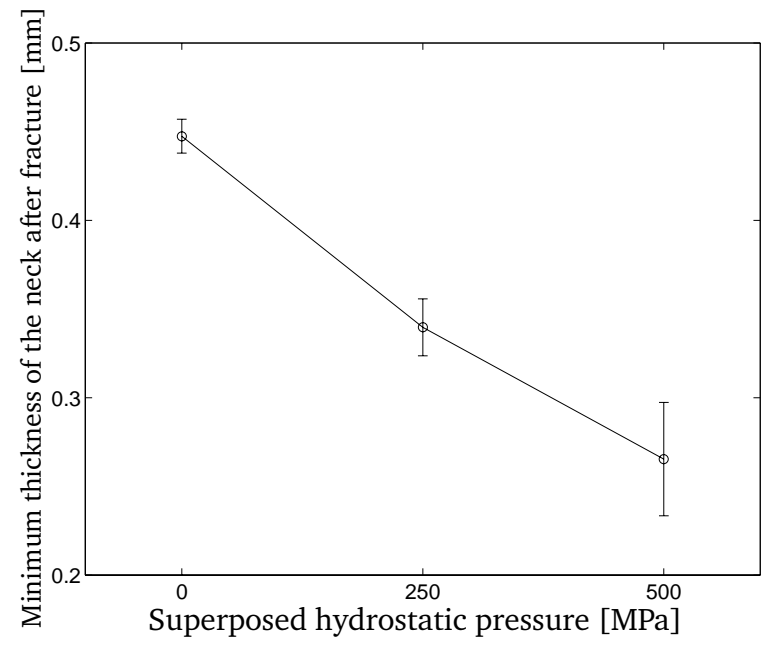

Figure 4.8: Minimum thickness of the neck after fracture as a function of the hydrostatic pressure with twice the standard-deviations (95\% interval).

behaviour, which is an experimental approval for the use of a yield condition without pressure influence. A closer investigation of the broken tensile specimens showed a significant difference: the thickness of the material at the neck after fracture was reproducibly smaller for larger hydrostatic pressures (figure 4.7). This means that the process of necking was interrupted by ductile fracture in an earlier stage under a smaller hydrostatic pressure. Results of the minimum thicknesses of the neck after fracture are shown in figure 4.8 along with twice the standard-deviations (95\% interval) for three measurements at every hydrostatic pressure. These experimental findings can be explained by considering the influence of the triaxiality $\left(\sigma_{h} / \bar{\sigma}\right)$ on the physical mechanism of ductile fracture initiation, being the initiation, growth and coalescence of voids. The triaxiality is greatly influenced by the hydrostatic pressures because these are in the same order of magnitude as the equivalent Von Mises stresses. A larger hydrostatic pressure, or, equivalently, a more negative hydrostatic stress, makes the triaxiality more negative and postpones ductile fracture initiation. One can imagine that voids inside the material will not initiate or grow that fast when there is a large hydrostatic pressure. Thus, there will be more plastic deformation in the neck, and thus larger local strains, for larger hydrostatic pressures.

\subsubsection{FEM-simulation}

A tensile test is simulated with a FEM-computation, using the material model of section 2.1.1 and the material data presented in section 2.2.1. The Von Mises yield 
condition is used, in which the hydrostatic stress component has no influence on the yielding behaviour. Thus, the calculated force displacement curve for the tensile test is independent of the hydrostatic pressures. This was already experimentally observed in section 4.4.1. Because of all this, only one FEM-simulation is required to obtain the stress and strain history for tensile tests under different hydrostatic pressures. This is,
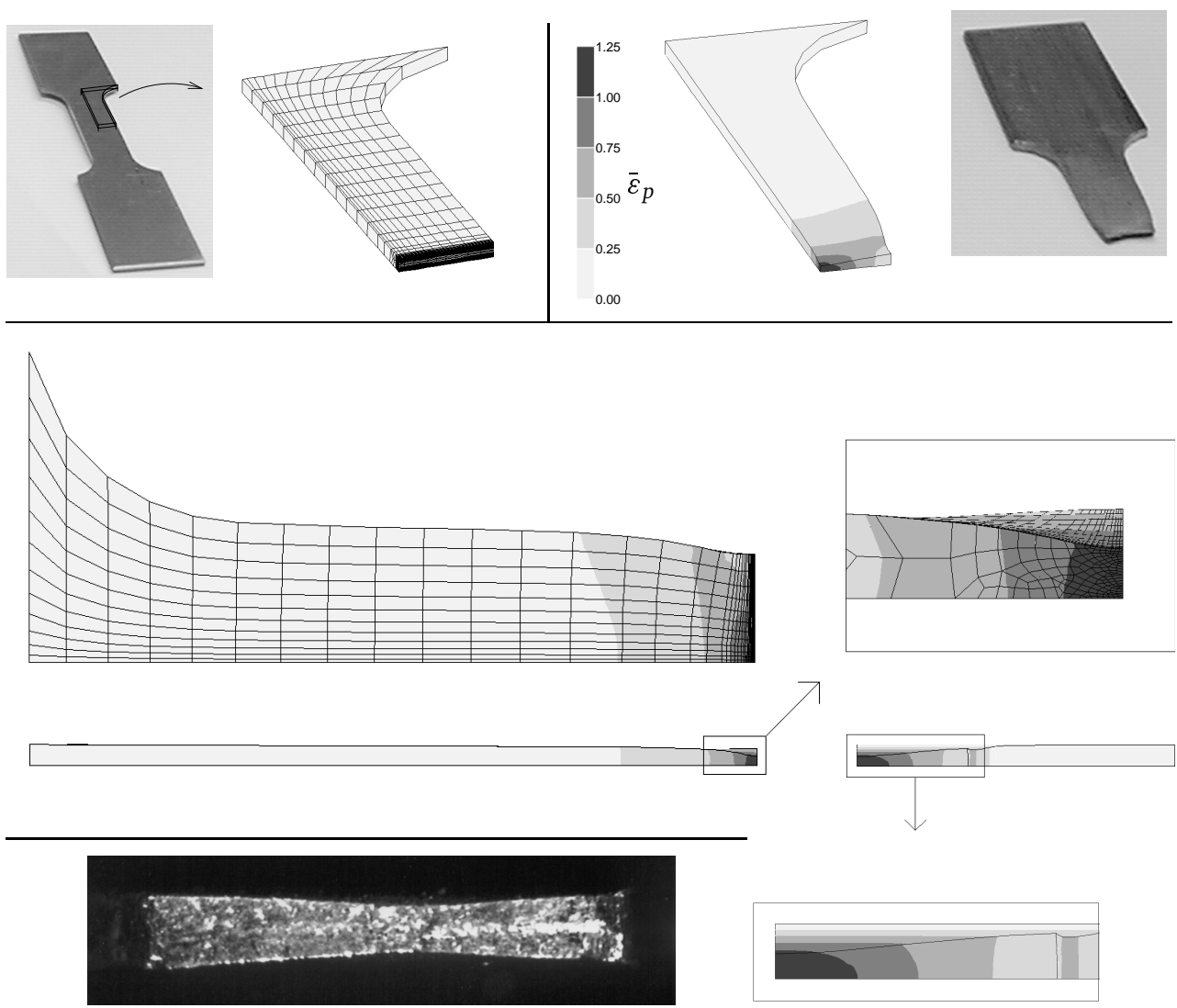

Figure 4.9: Simulation of a tensile test and experimental verification on deformations. In the upper left corner the undeformed tensile specimen is shown with the modelled part (1/8). Upper right, the calculated deformations at fracture initiation are shown with five levels of the equivalent plastic strain together with the fractured specimen. In the centre, the three orthogonal views of the deformed specimen are shown with a zoomed plot of the refined mesh in the neck. At the bottom, the experimental fracture surface is compared with the calculated cross-sectional area in the neck at fracture initiation (notice the wedge-like shape). 


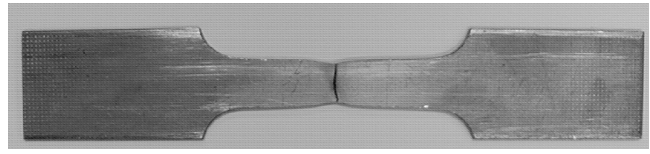

Figure 4.10: Two fractured halves of a tensile specimen put back together. Notice the gap in the centre.

because the stress state can be compensated afterwards for the hydrostatic pressure. A three-dimensional model is needed to simulate the necking process correctly.

The modelled tensile specimen, the initial mesh, the deformed mesh and the fractured specimen are all displayed in figure 4.9. The results show that the FEM-model predicts the deformation of the tensile specimen well, including the wedge-like shape of the specimen at fracture. The photograph of the fractured surface as well as the FEM-simulation show that the highest plastic deformation is located at the overall centre of the specimen. That this centre point is also the point of fracture initiation can be demonstrated by a fitting attempt of the two fractured halves of the tensile specimen (figure 4.10). They do not fit perfectly because a gap exists in the middle; after fracture initiation in the centre, there was still some plastic deformation at the edges.
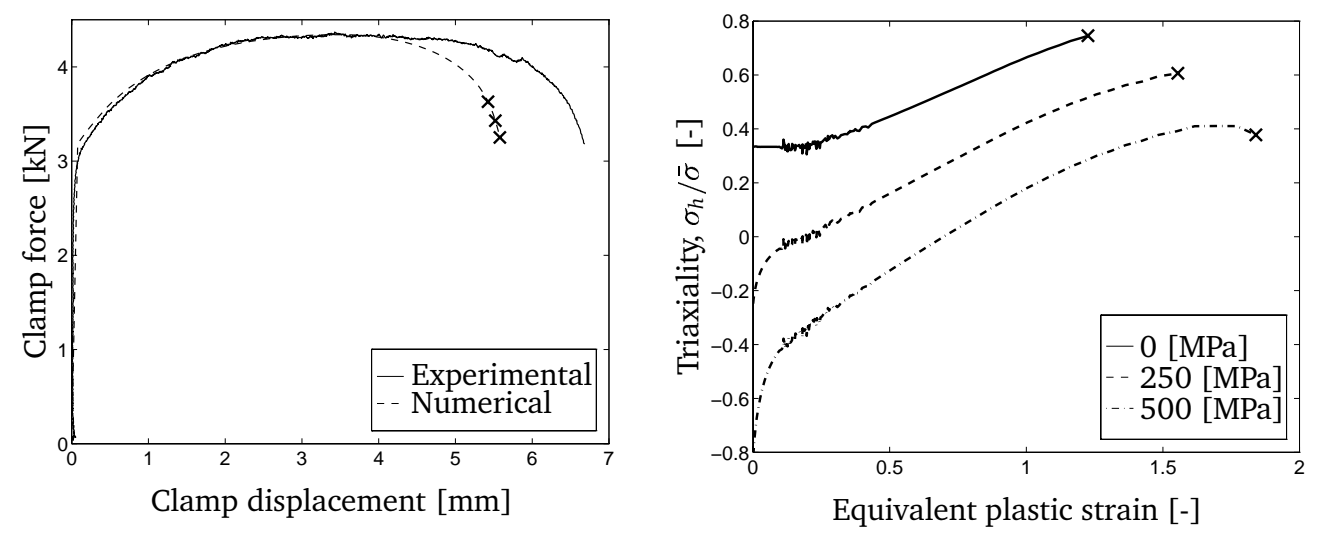

Figure 4.11: The numerical and experimental force displacement curves (left plot). The crosses are the points where the experimental thickness of the neck is numerically reached for the three different hydrostatic pressures. In the right plot, the calculated deformation history at the overall centre of the tensile specimen is presented up to the point of fracture initiation (crosses) for different hydrostatic pressures. 
Besides this check on deformation behaviour, the FEM-simulation is also verified on the force displacement curve. The experimental and numerical force displacement curves are depicted in the left-hand side of figure 4.11. The only difference between experiment and FEM-simulation is the point of necking. The error in the description of the deformation history, due to this difference in the point of necking, is small. This statement is supported by the right-hand side of figure 4.11. In the plot of the triaxiality versus equivalent plastic strain for the three different hydrostatic pressures, the homogeneous deformation should have lasted just a bit longer; the straight part for the $0[\mathrm{MPa}]$ curve at a triaxiality of $1 / 3$, is from an experimental point of view only negligibly more extended. The triaxiality plots for the hydrostatic pressures of 250 and $500[\mathrm{MPa}]$ are deduced from the simulated one for a superposed pressure equal to $0[\mathrm{MPa}]$. The wrinkles on the plots are caused by numerical difficulties to initiate the neck, because no imperfection was used to activate the necking process. (No imperfection is needed to activate the necking process due to the chosen geometry.)

Now, the information is present required to characterise ductile fracture criteria in a tensile test and to, subsequently, apply these criteria on the blanking process. Moreover, the validity of criteria for tensile tests over a range of superimposed hydrostatic pressures can be checked.

\subsection{Characterising ductile fracture in tensile testing}

For industrial applications it would be of great advantage if a fracture criterion could be characterised by performing an easy test, instead of a complicated and difficult blanking experiment as in section 4.3. In this section, the potential of the tensile test to characterise ductile fracture criteria is elaborated.

Firstly, the strategy to predict ductile fracture in blanking, using a tensile test, is explained. Then, some criteria are evaluated in section 4.5.2 and a new criterion is proposed in section 4.5.3, since the existing criteria prove to be not valid for both blanking and tensile testing under different hydrostatic pressures.

\subsubsection{Strategy}

The strategy to predict ductile fracture in blanking is outlined. Firstly, a tensile test is performed at atmospheric pressure, and the minimum thickness of the neck after fracture is measured. Accordingly, the tensile test is simulated up to the point where this thickness of the neck is reached (this is the point of fracture initiation). This simulation provides the deformation history during the tensile test (figure 4.11), with which the integral $\int f(\boldsymbol{\sigma}) d \bar{\varepsilon}_{p}$ is calculated. At the moment of ductile fracture initiation, the parameter $C$ of the ductile fracture criterion is quantified as the occurring maximum of the integral. The location of the maximum should agree with the experimentally 
found position of fracture initiation.

The characterised ductile fracture criterion can be applied to the blanking process for a specified geometry; during the simulation of this blanking process $\int f(\boldsymbol{\sigma}) d \bar{\varepsilon}_{p}$ is stored as a field variable and as soon as this field variable reaches the critical value $C$, the punch displacement at fracture is predicted. This approach will be verified over the range of clearances for the large cutting radii as well as for small cutting radii of the tools for two extreme clearances.

During the search for a valid ductile fracture initiation criterion, an extra intermediate verification is performed; the critical parameter $C$ should also be applicable for tensile tests at different hydrostatic pressures. If a criterion does not satisfy this requirement it is rejected, because the influence of hydrostatic pressure on ductile fracture should be accounted for adequately.

\subsubsection{Application of ductile fracture models, using a tensile test}

The objective is to characterise a ductile fracture initiation model in a tensile test and to use this characterised model to predict the punch displacement at fracture initiation in blanking. An appropriate ductile fracture initiation model should be valid for both blanking and tensile testing. Of all criteria examined, two were found to be applicable

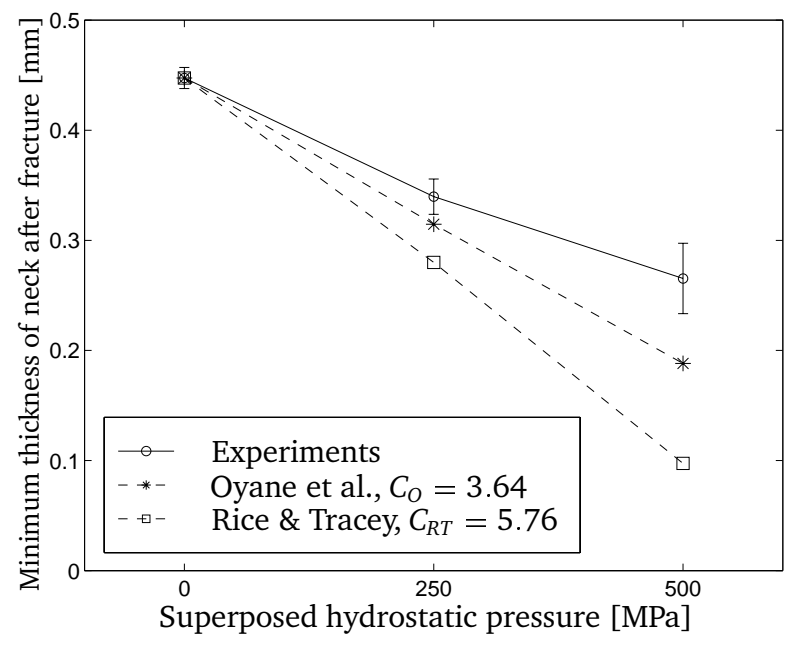

Figure 4.12: Validity check with the pressurised tensile tests for the criteria that performed well in section 4.3 (characterisation in blanking). The Rice \& Tracey and Oyane criteria deviate respectively $60 \%$ and $30 \%$ in case of the 500 [MPa] experiment, when the parameter $C$ is determined in the experiment at atmospheric pressure. 
for the blanking process in section 4.3. These criteria, specified in table 4.2, are now tested according this procedure.

The first step is to determine the parameters $C$ in the tensile test at atmospheric pressure (' 0 ' $[\mathrm{MPa}]$ ). While the parameters $C$ were determined to be $C_{R T}=2.76$ and $C_{O}=2.38$ for the adapted Rice \& Tracey and Oyane criterion, respectively, in the blanking process, now, in the tensile tests, the parameters are found to be $C_{R T}=5.76$ and $C_{O}=3.64$. Using the adapted Rice \& Tracey criterion, this resulted in an overestimation of the punch displacement at fracture of more than $30 \%$, and for the Oyane criterion the deviations were about $25 \%$. These deviations are not acceptable. Moreover, both criteria were not able to predict ductile fracture initiation for the tensile tests under different hydrostatic pressures within satisfying margins as is shown in figure 4.12. Consequently, for these criteria, $C$ is not just a material constant; it varies for different processes. From the results it can be concluded that the criteria of table 4.2, which assume that $C$ is a material constant, cannot describe ductile fracture initiation for both blanking and tensile tests under different hydrostatic pressures, for this specific material. Therefore, they are rejected.

\subsubsection{A new ductile fracture model for both blanking and tensile testing}

Because no criterion has been found yet that can correctly predict ductile fracture initiation in both blanking and tensile testing a new model is proposed:

$$
\int_{\bar{\varepsilon}_{p}}\left\lfloor 1+A_{G} \cdot \sigma_{h} / \bar{\sigma}\right\rfloor \bar{\varepsilon}_{p}^{B_{G}} d \bar{\varepsilon}_{p}=C_{G}
$$

with $A_{G}$ and $B_{G}$ being constants. This criterion incorporates the triaxiality influence of the Oyane criterion (table 4.2) but also the equivalent plastic strain is inserted in the integral expression. Therefore, the formulation $f(\boldsymbol{\sigma})$ of equation (4.1) is now changed into $f\left(\boldsymbol{\sigma}, \boldsymbol{\varepsilon}_{p}\right)$, with $\boldsymbol{\varepsilon}_{p}$ being the logarithmic plastic strain tensor. Mathematically, this means that the integral will grow faster for larger strains (if $B_{G}>0$ ). Physically, this seems reasonable because at larger strains the dislocation density will be larger. Therefore, the void initiation is expected to be higher for larger plastic strains. The parameter $A_{G}$ is chosen equal to $A_{O}\left(=3.9\right.$, section 4.3) and $B_{G}$ is estimated to be 0.63 to yield a valid criterion that describes ductile fracture initiation for both blanking and tensile testing under different hydrostatic pressures. The parameter $C_{G}$ is determined to be 3.53 in the tensile test at atmospheric pressure. The results for the other tensile tests are plotted in the left-hand side of figure 4.13. For the 250[MPa] experiment the deviation is below $10 \%$ and the prediction falls within the experimental error for the $500[\mathrm{MPa}]$ experiment. The parameter $C_{G}$, determined in the $0[\mathrm{MPa}]$ tensile test, is used to predict fracture initiation in blanking with large cutting radii of the tools and results are depicted at the right-hand side of figure 4.13. Not all results are within 

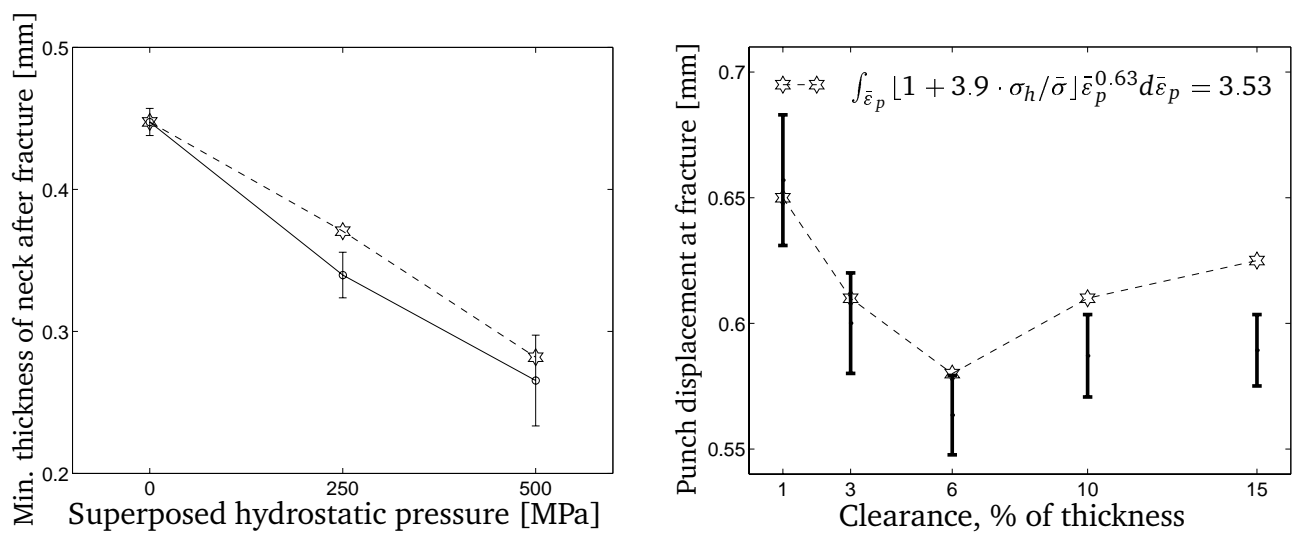

Figure 4.13: Validity check of the newly proposed criterion for the pressurised tensile tests (left plot) and for the blanking process for large cutting radii of the tools (right plot). All error bars represent twice the standard-deviations (95\% interval).

the experimental range of twice the standard-deviation, but the largest deviation of the predicted punch displacement at fracture is $6 \%$.

The newly proposed criterion is also verified for small cutting radii of the tools for two extreme clearances. Results are presented in figure 4.14. The maximum deviation that is beyond the experimental range is smaller than $7 \%$.
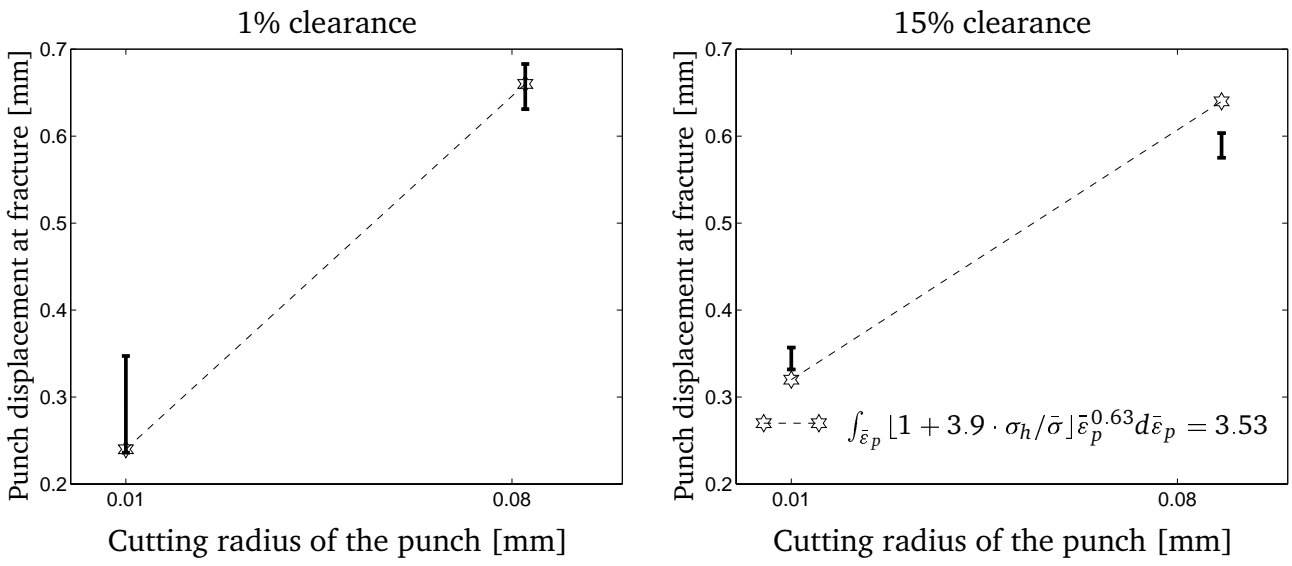

Figure 4.14: Verification of the newly proposed criterion on the effect of cutting radius of the tools for two extreme clearances. Again, the parameter $C$ is determined in the tensile test at atmospheric pressure. All error bars represent twice the standarddeviations (95\% interval). 


\subsection{Discussion}

A FEM-model of the blanking process, validated in chapter 3, was available, but the problem of ductile fracture initiation had not been solved yet. The category of local ductile fracture criteria has been selected to solve this problem. For the characterisation of such a model two approaches have been proposed in this chapter.

The approach that was expected to give the best results is the characterisation of a fracture model in the blanking process. The two criteria of table 4.2 produce very good results if the influence of triaxiality on ductile fracture initiation $\left(A_{R T}\right.$ or $\left.A_{O}\right)$ has been determined. This means that in an industrial environment the product shape can be predicted for different blanking geometries by performing only one blanking experiment to determine the parameter $C$.

The second approach is the characterisation of the fracture model in an easier tensile test. Because existing criteria do not provide satisfying results, a reformulation has been proposed in equation (4.3). This new criterion is not derived from a physical background but it incorporates parameters that are known to be important for ductile fracture initiation. The newly proposed criterion can predict ductile fracture initiation in tensile tests for different hydrostatic pressures. This is important, because it shows that the criterion can predict fracture for a wide variety of triaxialities, which is known to be an important effect for ductile fracture initiation. In figures 4.13 and 4.14, it has been shown that this criterion can predict ductile fracture initiation over a wide range of blanking geometries using the critical $C$ as determined in a tensile test. This approach yields satisfactory results and is the preferably selected, since the parameter $C$ in the proposed criterion is a material parameter and independent of the process.

The question remains, whether these approaches can also be pursued for other materials. If the formulation of the integral does not depend on the material (if $A_{R T}$ and $A_{O}$ in table 4.2 and $A_{G}$ and $B_{G}$ in equation (4.3) cannot be identified as material parameters), both approaches will be applicable for other materials as well. The only material parameter will then be the critical $C$. This will be checked in chapter 6 for various materials. 
58 Chapter 4 


\section{Chapter 5}

\section{Influence of the blanking velocity}

\subsection{Introduction}

In chapters 3 and 4, the constitutive model using Von Mises plasticity (characterised in section 2.2.1) has been used in the numerical simulations for the validation procedure and the prediction of ductile fracture initiation. This implies that no strain rate effects were incorporated in the modelling. In this chapter, the effect of strain rate on the blanking process is investigated using the elasto-viscoplastic constitutive model with the Bodner-Partom viscosity (section 2.1.2). The material parameters for X30Cr13, characterised in section 2.2.2 (table 2.3), will be applied throughout this chapter. The axisymmetric blanking setup of figure 2.10 is placed into a universal tensile testing machine for low velocities and into a hydraulic tensile testing machine for high speeds (up to $1[\mathrm{~m} / \mathrm{s}]$ ). To the authors' knowledge, the maximum blanking speeds employed in industrial applications are in the range of $50[\mathrm{~mm} / \mathrm{s}]$.

In section 5.2 the effect of strain rate on the blanking force is investigated both experimentally and numerically by varying the punch velocity. The same is done for the punch displacement at ductile fracture initiation in section 5.3. The results will be discussed in section 5.4 .

The content of this chapter corresponds to:

Goijaerts, A.M., Govaert, L.E., and Baaijens F.P.T., 1999, Experimental and numerical investigation on the influence of process speed on the blanking process. In preparation for publication. 


\subsection{Effect of punch speed on process force}

In this section, the effect of the punch velocity on the process force is considered. In section 5.2.1 the maximum process forces from experimental research and numerical simulations are compared. Deviations are explained in sections 5.2.2 and 5.2.3.

\subsubsection{Comparison of experimental and numerical forces}

For the experimental determination of the maximum blanking force the axisymmetric setup of figure 2.3 .3 is used with the $10 \%$ clearance. The tool dimensions for this specific clearance can be found in table 2.5. Two tensile testing machines are utilised to obtain information over a large range of punch velocities; with a universal tensile testing machine, slow punch speeds are accomplished up to $10[\mathrm{~mm} / \mathrm{s}]$; punch speeds up to $1[\mathrm{~m} / \mathrm{s}]$ are realised using a hydraulic tensile testing machine. The results for the maximum punch forces, averaged over five experiments for every punch velocity, are presented in figure 5.1. The error bars represent twice the standard-deviation (95\% interval).

Numerical predictions of the maximum blanking forces are also presented in figure 5.1. The compressible Leonov model with the Bodner-Partom viscosity is applied adopting the material parameters determined in section 2.2.2 (table 2.3). These material parameters were quantified by performing different tensile tests with strain

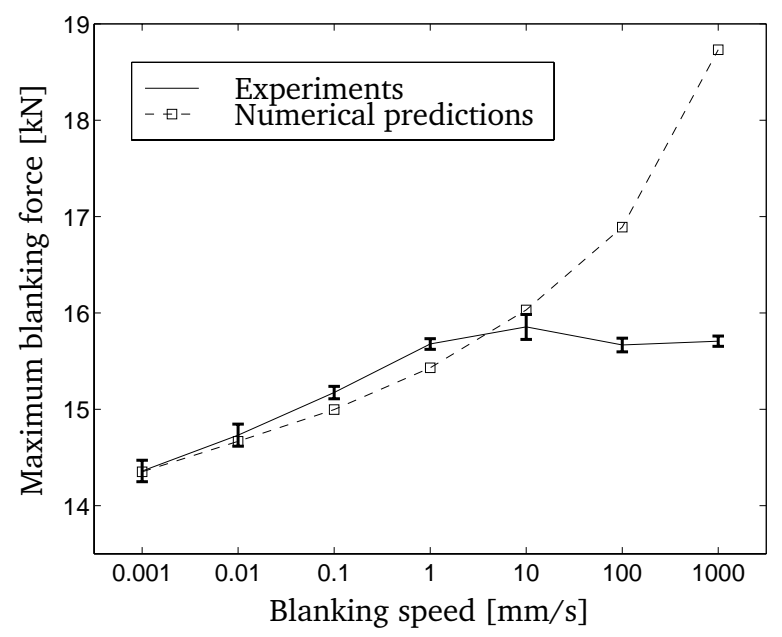

Figure 5.1: Comparison of experimental maximum blanking forces with numerical predictions using the compressible Leonov model with Bodner-Partom viscosity over a large range of punching velocities. 
rates varying from $0.032\left[\mathrm{~s}^{-1}\right]$ to $13\left[\mathrm{~s}^{-1}\right]$. These values compare well with the maximum strain rates observed in the numerical simulations with punch velocities from $0.001[\mathrm{~mm} / \mathrm{s}]$ to $1[\mathrm{~mm} / \mathrm{s}]$, respectively. Figure 5.1 shows that for the range of strain rates, used for the material parameter identification, the numerical predictions agree well with the experiments. However, for the larger blanking velocities the numerical predictions start to deviate from the experiments. Possible sources of the deviations are thermal softening and inadequate constitutive modelling. Deviations due to thermal softening are explained in section 5.2.2 and the problems to be expected when extrapolating to larger strain rates using the compressible Leonov model with the Bodner-Partom viscosity are reported in section 5.2.3.

\subsubsection{Deviations due to thermal softening}

For metals in general, an increase in temperature will cause a decrease of the actual yield stress. During deformation, plastic work will generate heat. At low deformation velocities, the local increase of temperature will not be excessive due to thermal conduction, resulting in a non-significant local temperature change. However, when large speeds are applied, the temperature rise is not negligible anymore and a local drop in the yield stress will result. For X30Cr13, the material parameters describing plastic yielding, fitted on the Nadai formulation, were determined for four different temperatures by van Alphen (1996). The resulting stress - strain curves for different temperatures are presented in figure 5.2. A temperature rise of $300\left[{ }^{\circ} \mathrm{C}\right]$ causes a

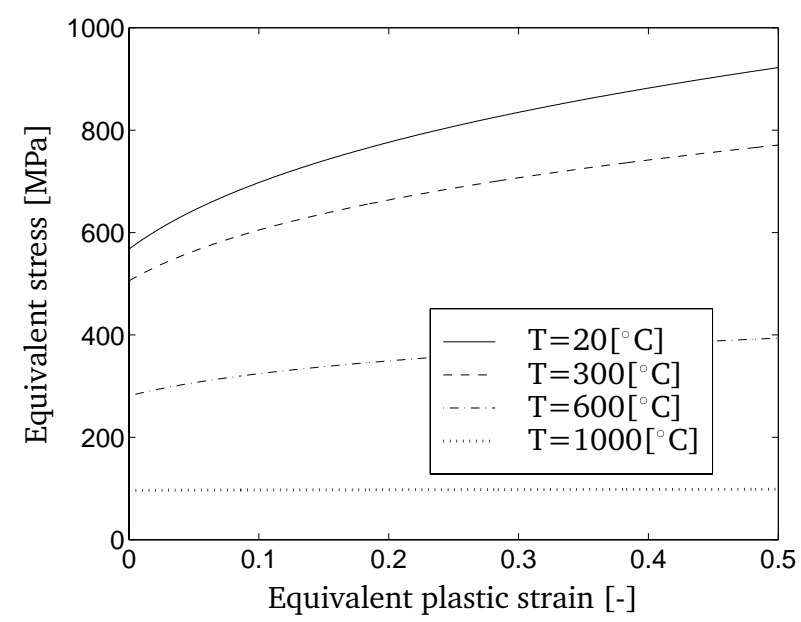

Figure 5.2: Yield curves for X30Cr13 according to Nadai fits for different temperatures (van Alphen, 1996). 
stress decrease of approximately 20\%. Apparently, this thermal effect becomes significant for the blanking process at punch speeds larger than $1[\mathrm{~mm} / \mathrm{s}]$ for X30Cr13 (figure 5.1).

As thermal softening is not included in the actual numerical formulation, the decrease of the maximum blanking force observed for larger punch velocities cannot be predicted by the isothermal numerical model employed.

\subsubsection{Extrapolation to larger strain rates}

In figure 5.1 the numerical predictions for the maximum blanking force show an increasing growth with increasing punch speeds. The high speeds result in strain rates that exceed the domain of strain rates for which the material parameters have been determined. The unproportional force increase can be illustrated by considering the mathematical description of the compressible Leonov model with the Bodner-Partom viscosity.

From equations (2.9), (2.10b), (2.18) and (2.19), one can derive a relation between equivalent stress and equivalent plastic strain rate:

$$
\bar{\sigma}=Z\left(\bar{\varepsilon}_{p}\right) \cdot\left(-2 \ln \left[\frac{3 \dot{\bar{\varepsilon}}_{p}}{\sqrt{12 \Gamma_{0}}}\right]\right)^{-\frac{1}{2 n}}
$$

with $Z\left(\bar{\varepsilon}_{p}\right)$ according to equation (2.24). The equivalent stress - equivalent plastic strain rate relationship of equation (5.1) is presented in figure 5.3, for three levels

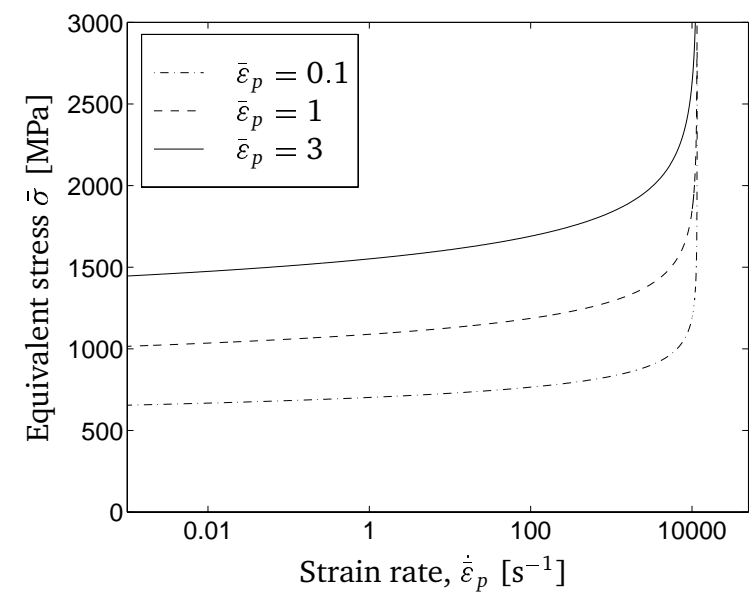

Figure 5.3: Equivalent stress as a function of equivalent plastic strain rate according to equation (5.1) for three different levels of equivalent plastic strain using the material parameters of table 2.3 . 
of equivalent plastic strains. The equivalent plastic strain rate range, for which the constitutive description is applicable, is apparently limited. This can be rationalised considering equation (5.1): because both $\bar{\sigma}$ and $Z\left(\bar{\varepsilon}_{p}\right)$ are always positive, the expression in brackets must also be positive; thus, the natural logarithm is forced to be negative, resulting in a constraint for the argument of the natural logarithm:

$$
\frac{3 \dot{\bar{\varepsilon}}_{p}}{\sqrt{12 \Gamma_{0}}}<1 \quad \Rightarrow \quad \dot{\bar{\varepsilon}}_{p}<\sqrt{\frac{4}{3} \Gamma_{0}}
$$

This limited equivalent plastic strain rate depends on the assumption for $\Gamma_{0}$ in the fitting procedure (section 2.2.2).

Observing figure 5.3, one may expect unrealistic behaviour of the constitutive model when a deformation is prescribed with strain rates close to the asymptotic limit expressed in equation (5.2). To show this expected strange behaviour, a blanking process is simulated with a punch speed of $10[\mathrm{~m} / \mathrm{s}]$. Results for the process force and strain rate field are compared to blanking simulations with a smaller punch velocity in figure 5.4. The process forces for punch speeds of $10^{-3}[\mathrm{~m} / \mathrm{s}]$ and for $1[\mathrm{~m} / \mathrm{s}]$ show the usual behaviour. However, the simulation of the blanking process with a punch speed of $10[\mathrm{~m} / \mathrm{s}]$ shows a very different behaviour. The process force keeps growing with further punch displacement. This can be explained with the help of the right-hand side of figure 5.4. As the punch starts to move into the material at a speed of $10[\mathrm{~m} / \mathrm{s}]$, immediately strain rates are reached close to the limit. Because a small deformation zone, with corresponding large and local strains, cannot handle the high
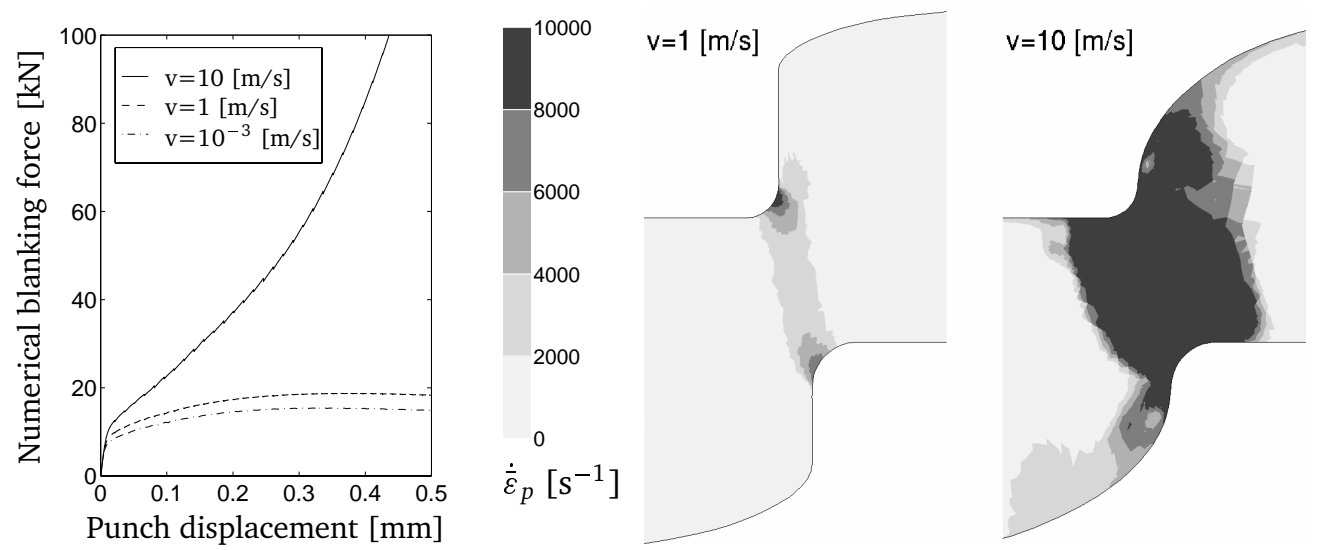

Figure 5.4: Extreme deviations for extrapolation to very large punch speeds. At the left-hand side the process forces are presented for three different punch velocities $(\mathrm{V})$. At the right the deformations for two punch speeds are displayed. The five gray levels represent the strain rate. 
punch speed within the strain rate limit, the deformation zone has to become broader in order to 'delocalise' the strain field. The total deformation behaviour is changed completely into an unrealistically large domain, as is shown at the right-hand side of figure 5.4.

The deformation behaviour, as calculated for extremely large punch speeds, is unrealistic. Again it is emphasised that the constitutive model is fitted for a domain of strain rates from $0.032\left[\mathrm{~s}^{-1}\right]$ to $13\left[\mathrm{~s}^{-1}\right]$. The compressible Leonov model with the Bodner-Partom viscosity can be applied in the range of strain rates for which the material parameters are determined. However, extrapolation to larger strain rates requires special attention and care.

\subsection{Effect of punch speed on ductile fracture initiation}

In this section, the effect of strain rate on ductile fracture initiation for $\mathrm{X} 30 \mathrm{Cr} 13$ is discussed. Experimental results are reported in section 5.3.1 and numerical predictions are presented in section 5.3.2.

\subsubsection{Experimental results}

The shear zone is measured in five experiments for every punch velocity, using the setup of figure 2.11 with the $10 \%$ clearance. The average values with twice the standard-deviations (95\% interval) are presented in figure 5.5. It is shown that

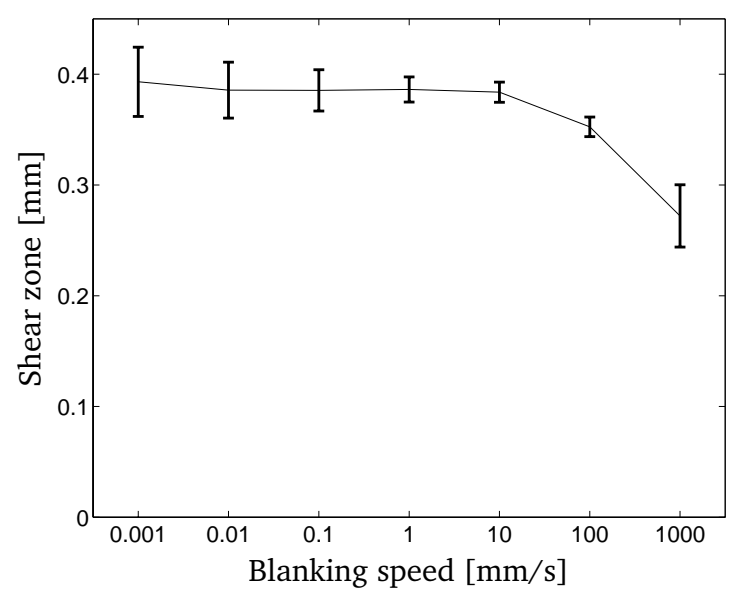

Figure 5.5: Experimental results for the shear zone as a function of blanking velocities. 
strain rate has no influence on ductile fracture initiation up to punch velocities of $10[\mathrm{~mm} / \mathrm{s}]$. For larger punch speeds the shear zone becomes smaller, which implies that ductile fracture has initiated in an earlier stage of the blanking process. This can again be explained by thermal effects. As it has been shown in section 5.2.2, thermal effects become significant at a punch speed of approximately $10[\mathrm{~mm} / \mathrm{s}]$. When the temperature rises in the deformation zone, local stresses will decrease (figure 5.2). Thus, thermal softening will occur in the deformation zone and the deformation will become more localised, generating extra heat, introducing extra softening, and so on. This progressing localisation results in early ductile fracture initiation in the blanking process and thus in a small shear zone.

\subsubsection{Numerical predictions}

Because thermal effects are not included in the current numerical model, only punch velocities up to and including $10[\mathrm{~mm} / \mathrm{s}]$ are considered. Moreover, for higher punch speeds, the numerical model can introduce errors due to extrapolation of the constitutive behaviour to larger strain rates, as was shown in section 5.2.3.

To evaluate the predictive abilities of the numerical model on ductile fracture initiation for different strain rates, both strategies to predict ductile fracture initiation (chapter 4) are applied for different punch velocities. For the approach where ductile

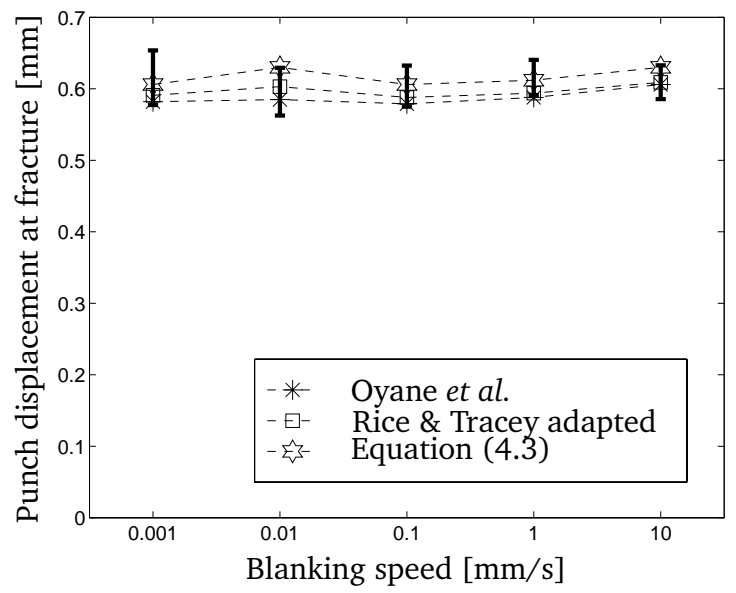

Figure 5.6: Comparison for experimental punch displacements at fracture and numerical predictions using the criteria of table 4.2, characterised in blanking, and using the criterion of equation (4.3), characterised in a tensile test, as a function of blanking velocities. The error bars represent twice the standard-deviations for the experiments (95\% interval). 
fracture criteria are characterised in the blanking process, the Oyane and the adapted Rice \& Tracey criterion (table 4.2) are evaluated for different punch velocities $\left(C_{O}\right.$ and $C_{R T}$ are determined in the experiment with the $15 \%$ clearance, chapter 4 ). For the approach in which the characterisation is performed in a tensile test, the criterion of equation (4.3) is employed. Results are presented in figure 5.6 along with the experimentally determined punch displacements at ductile fracture initiation (the error bars correspond with twice the standard-deviation: 95\% interval).

Both procedures for the prediction of ductile fracture initiation perform within the experimental error.

\subsection{Discussion}

It is clear that the compressible Leonov model with the Bodner-Partom viscosity is able to describe the effect of punch speed on the blanking process for punch velocities up to approximately $10[\mathrm{~mm} / \mathrm{s}]$. This domain of punch speeds agrees with the range of strain rates for which the material parameters have been determined. However, for larger punch speeds, thermal softening starts to become significant and causes a drop in the maximum blanking force. Furthermore, the numerical model overestimates blanking forces for punch speeds that correspond to strain rates close to the strain rate limit, which is an intrinsic property of the elasto-viscoplastic constitutive model with the Bodner-Partom viscosity, with which special care is required.

In order to accurately model the blanking process for punch speeds larger than $10[\mathrm{~mm} / \mathrm{s}]$, it is needed to cope with the thermal softening and to make the constitutive model valid for larger strain rates. The thermal softening could be accounted for by a thermo-mechanical coupling in the numerical formulation, as was done by Brokken (1999). In that case it is important to know the thermal material parameters correctly, as well as the mechanical material parameters as a function of temperature. In order to expand the validity of the constitutive model it seems possible to increase $\Gamma_{0}$ (equation 5.2) before fitting all material parameters. Still, to perform this expansion successfully, it will be necessary to fit these material parameters using experimental data for larger strain rates.

Up to blanking velocities of $10[\mathrm{~mm} / \mathrm{s}]$ (which is within the range of nearly every industrial application) the blanking speed has no influence on the punch displacement at ductile fracture initiation for X30Cr13 (figure 5.6). This is an important conclusion, because it shows that blanking processes with punch velocities smaller than $10[\mathrm{~mm} / \mathrm{s}]$ can be described by the elasto-plastic constitutive model using Von Mises plasticity, when ductile fracture initiation is considered. When process forces are considered, the effect of the strain rate is small but noticeable. Therefore, if the correct prediction of the blanking force as a function of the strain rate is not an issue, the constitutive model using Von Mises plasticity will suffice. 


\section{Chapter 6}

\section{Evaluation of fracture models for different metals in blanking}

\subsection{Introduction}

In chapter 4, two approaches have been proposed to predict fracture initiation in the blanking process for a ferritic stainless steel (X30Cr13):

1. In the first approach (section 4.3) a ductile fracture initiation model is characterised by using the blanking process. The adapted Rice \& Tracey (1969) criterion of table 4.2 performs well over a wide range of geometries (five clearances, two different cutting radii of the punch). Also satisfactory results are achieved when $A_{O}$ is determined for the Oyane et al. (1980) criterion.

2. The second strategy (section 4.5) involves characterisation of a fracture model in a tensile test, which represents a procedure that is more favourable for industrial applications. Existing criteria are unable to predict ductile fracture in both blanking and tensile testing and, therefore, a new criterion has been proposed in equation (4.3) that shows good results within 7\% of the experimental blanking data. This new model can also predict ductile fracture initiation for tensile tests under different superposed hydrostatic pressures (resulting in different triaxialities). This is important, because it shows that the criterion is applicable for different loading conditions.

Both approaches show good results for X30Cr13. The remaining question is (see section 4.6) whether the utilised criteria contain more material dependent parameters

The content of this chapter is partly reproduced from:

Goijaerts, A.M., Govaert, L.E., and Baaijens F.PT., 1999, Evaluation of ductile fracture models for different metals in blanking. Submitted to Journal of Materials Processing Technology. 
than only the critical $C$. Therefore, in this chapter, both strategies are evaluated for five different metals (including X30Cr13) using the procedures of sections 4.3 and 4.5. For the first approach only the adapted Rice \& Tracey and Oyane criteria could predict ductile fracture in blanking and they performed equally well. In this chapter the Oyane criterion will be disregarded and only the adapted Rice \& Tracey criterion will be employed for the first procedure. For the second strategy the newly proposed criterion of equation (4.3) will be applied. Both criteria are reproduced in equations (6.1):

$$
\begin{aligned}
& \int_{\bar{\varepsilon}_{p}} \exp \left(2.9 \cdot \sigma_{h} / \bar{\sigma}\right) d \bar{\varepsilon}_{p}=C_{R T} \\
& \int_{\bar{\varepsilon}_{p}}\left\lfloor 1+3.9 \cdot \sigma_{h} / \bar{\sigma}\right\rfloor \bar{\varepsilon}_{p}^{0.63} d \bar{\varepsilon}_{p}=C_{G}
\end{aligned}
$$

In the adapted Rice \& Tracey criterion, equation (6.1a), and the newly proposed criterion, equation (6.1b), the parameters $A_{R T}$ of table 4.1 and $A_{G}$ and $B_{G}$ of equation 4.3 are assumed to be constants, independent of the material. Thus, it is assumed that for both criteria the only material parameter will be the critical parameter $C\left(C_{R T}\right.$ and $\left.C_{G}\right)$.

The constitutive model using Von Mises plasticity of section 2.1.1 will be applied throughout this chapter because the results of chapter 5 have shown that strain rate effects are not significant when blanking velocities are not too high. For the identification of the plastic material parameters for all metals, the method of section 2.2.1 (with tensile tests on pre-rolled tensile specimens) will be utilised.

In section 6.2 the metals investigated are defined. In section 6.3 results are presented for all five metals concerning material characterisation, tensile testing and prediction of both maximum force and fracture in blanking. To obtain these results the experimental and numerical methods from section 2.2.1 and chapter 4, respectively, are utilised. Finally, the results will be discussed in section 6.4 .

\subsection{Investigated metals}

In chapter 4, the two procedures to characterise ductile fracture initiation for X30Cr13 were elaborated. To verify the general applicability of these strategies, the same procedures are applied to four other metals which are presented, along with X30Cr13, in table 6.1. X30Cr13 is a ferritic stainless steel and 316Ti is an austenitic stainless steel. Ms64 is a brass that is often used in cutting and forming processes. DC04 is a high quality steel with a large formability that is commonly applied in deepdrawing processes. Aluminium A151ST is employed often in cutting operations and is relatively brittle. 
Table 6.1: Five different metals that are employed in the total verification procedure. The names that are used are presented along with the material codes and their corresponding norm-tables.

\begin{tabular}{|l|l|l|}
\hline indication & material code & norm-table \\
\hline X30Cr13 & X30Cr13 & DIN 17006 \\
316Ti & X10CrNiMoTi 18 10 & DIN 17440 \\
Ms64 & CuZn36 & DIN 17660 \\
DC04 & FeP 04 & Euronorm 32-66 \\
Al51ST & Al MgSi 1 Mg & DIN 1746/1747 \\
\hline
\end{tabular}

\subsection{Results for different metals}

In section 6.3.1 the material parameters associated to elasto-plastic deformation are determined assuming the elasto-plastic constitutive model using Von Mises plasticity to be valid for all metals. Results for tensile testing, in which criteria will be characterised for the second approach, are presented in section 6.3.2. For the blanking process three different kinds of verification are outlined in section 6.3.3:

- the resulting maximum blanking forces are evaluated for all materials;

- results for the punch displacements at fracture initiation for the first approach (characterisation in blanking);

- results for the punch displacements at fracture initiation for the second approach (characterisation in tensile testing).

For Al51ST both procedures are applied with both criteria of equations (6.1) in section 6.3.4.

\subsubsection{Material characterisation}

All metals are assumed to behave according the elasto-plastic model using Von Mises plasticity with isotropic hardening. The elastic properties (Young's modulus $E$ and Poisson's ratio $v$ ) are adopted from the material supplier. For the determination of the plastic material parameters, the procedure of section 2.2.1 is applied, where a number of pre-rolled specimens are tested to give yield stress information for large strains. The results are plotted in figure 2.1 for $\mathrm{X} 30 \mathrm{Cr} 13$ and in figure 6.1 for the other metals. The triangles represent the maxima of the separate tensile tests. The circles are extra points, taken from the tensile test of the as-received material, which are needed to obtain information for the yield stress in the region of small strains. 

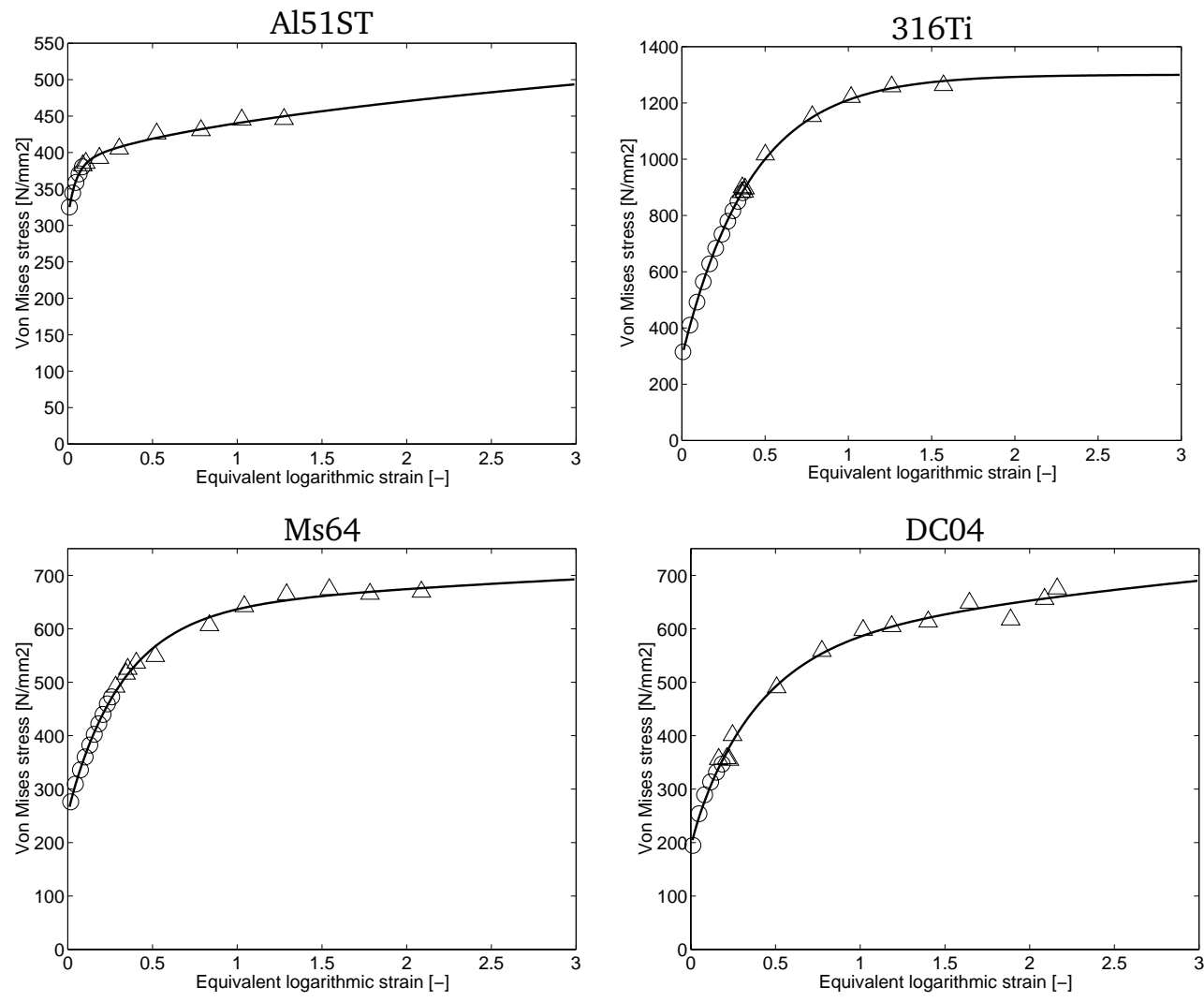

Figure 6.1: Fitting procedures for four different metals. The triangles represent the maxima of the separate (pre-rolled) tensile curves and the circles denote some points of the tensile tests on the as-received material. The curves are fitted on equation (2.21).

Through all markers a mastercurve is fitted using the formulation of equation (2.21). The parameters resulting from the fitting procedures are summarised in table 6.2 together with the elastic constants.

As it can be noticed in table 6.2 some parameters are fitted to be zero. This is due to the fact that in the fitting procedure, employing equation (2.21), the parameters $M_{3}$ and $M_{4}$ are not allowed to become negative. If this happens in the fitting routine, the parameter is put zero and fitting is repeated, keeping the concerned parameter zero. ( $M_{3}$ and $M_{4}$ are not allowed to become negative because an extrapolation of the mastercurve with negative parameters $M_{3}$ or $M_{4}$ may introduce intrinsic softening for large strains, which is not realistic for metals.) 
Table 6.2: Material parameters of five different metals for the elasto-plastic model with Von Mises plasticity, with hardening according to equation (2.21).

\begin{tabular}{|l|c|c|c|c|c|c|c|}
\hline & $E[\mathrm{MPa}]$ & $v[-]$ & $\sigma_{y 0}[\mathrm{MPa}]$ & $M_{1}[\mathrm{MPa}]$ & $M_{2}[-]$ & $M_{3}[\mathrm{MPa}]$ & $M_{4}[\mathrm{MPa}]$ \\
\hline X30Cr13 & $187 \cdot 10^{3}$ & 0.28 & 420 & 133 & 0.0567 & 406 & 70.7 \\
$316 \mathrm{Ti}$ & $200 \cdot 10^{3}$ & 0.28 & 298 & 1003 & 0.414 & 0 & 0 \\
Ms64 & $100 \cdot 10^{3}$ & 0.35 & 251 & 345 & 0.320 & 56.0 & 0 \\
DC04 & $210 \cdot 10^{3}$ & 0.29 & 185 & 309 & 0.378 & 113 & 0 \\
Al51ST & $70 \cdot 10^{3}$ & 0.33 & 306 & 61.0 & 0.0476 & 73.0 & 0 \\
\hline
\end{tabular}

The number of circles, taken from the as-received tensile curve, to be used during fitting, can be utilised as a weighing function in the fitting procedure. When the mastercurve is desired to describe the yield stress for small strains very accurately, the number of circles must be increased. When an optimum description is wanted for large strains the number of circles should be chosen small. Because an adequate description is desired over a large range of strains, a compromise is made and the number of circles is chosen such, that the fitted curve describes the yield stress satisfactorily. As it is shown in figures 2.1 and 6.1, the fitted mastercurves describe the yield stress data well, for both small and large strains, for all five metals.

\subsubsection{Tensile testing}

To perform ductile fracture characterisation according to the second approach with the criterion in equation (6.1b), tensile tests are performed using tensile specimens with dimensions as specified in figure 4.6. Next, for all five metals, 3D simulations of these tensile tests are performed with the FEM-model that is explained previously in section 4.4.2 using the material parameters of table 6.2. The deformed mesh and the fractured specimen are shown in figure 4.9 for X30Cr13. This figure shows that the FEM-model predicts the deformation of the tensile specimen well. Also the wedge-like shape of the specimen at fracture is predicted correctly.

Besides this verification on the deformation behaviour of X30Cr13, the FEM-simulation is also checked on the force - displacement curve for all metals. The experimental and numerical force - displacement curves are depicted in figure 6.2. Overall, numerical predictions agree fairly well with experiments. The largest deviations occur for Al51ST and for DC04. For these two metals only a few 'circular' data points were employed in the fitting procedure (figure 6.1), because otherwise deviations become too large for large strains. Consequently, the stress - strain relationship is not described accurately in the small strain region. (Another possibility is that the function of equation (2.21) can not accurately describe the yield curve for these two metals.) The shape of the curves for the other metals is well predicted. The only deviation is found in the final clamp displacement, which is sometimes somewhat underpredicted numerically. 


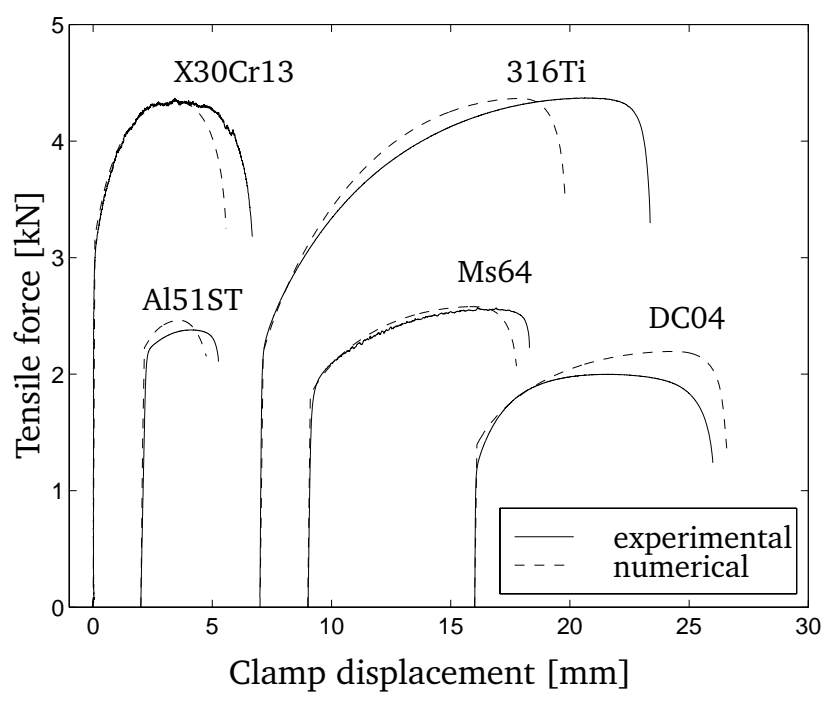

Figure 6.2: Experimental and numerical comparison of the tensile force versus clamp displacement for the tensile tests of all metals. (Zero points are shifted.)

\subsubsection{Blanking}

Axisymmetric blanking experiments are performed for the five metals selected, with five different clearances using the experimental setup described in section 2.3.3. The maximum blanking forces are measured, as well as the dimensions of the blanked edge (section 2.3.4), from which the punch displacement at fracture initiation is determined. Using the material parameters, characterised in section 6.3.1, axisymmetric FEM-simulations are performed for all clearances for the five different metals.

The numerical and experimental maximum blanking forces are presented in figure 6.3, scaled at the left axes. For X30Cr13, Al51ST and Ms64, deviations are observed in the order of 5\% or smaller. For 316Ti and DC04 the predictions deviate approximately $10 \%$ from the experiments. The stresses in the shear zone, where strains occur of approximately 3 , largely determine the numerical maximum blanking force. An error in the material description for large strains will, consequently, result in a corresponding error in the maximum blanking force. Therefore, the results and deviations for the maximum blanking force provide information about the performance for large strains of the material model, including its characterisation method and the assumption of the applicability of Von Mises plasticity modelling with isotropic hardening.

Two approaches are employed to predict the punch displacement at fracture initiation for all metals. The first approach utilises the adapted Rice \& Tracey criterion of equation (6.1a). The value of $C_{R T}$ is determined in the blanking experiment with the 

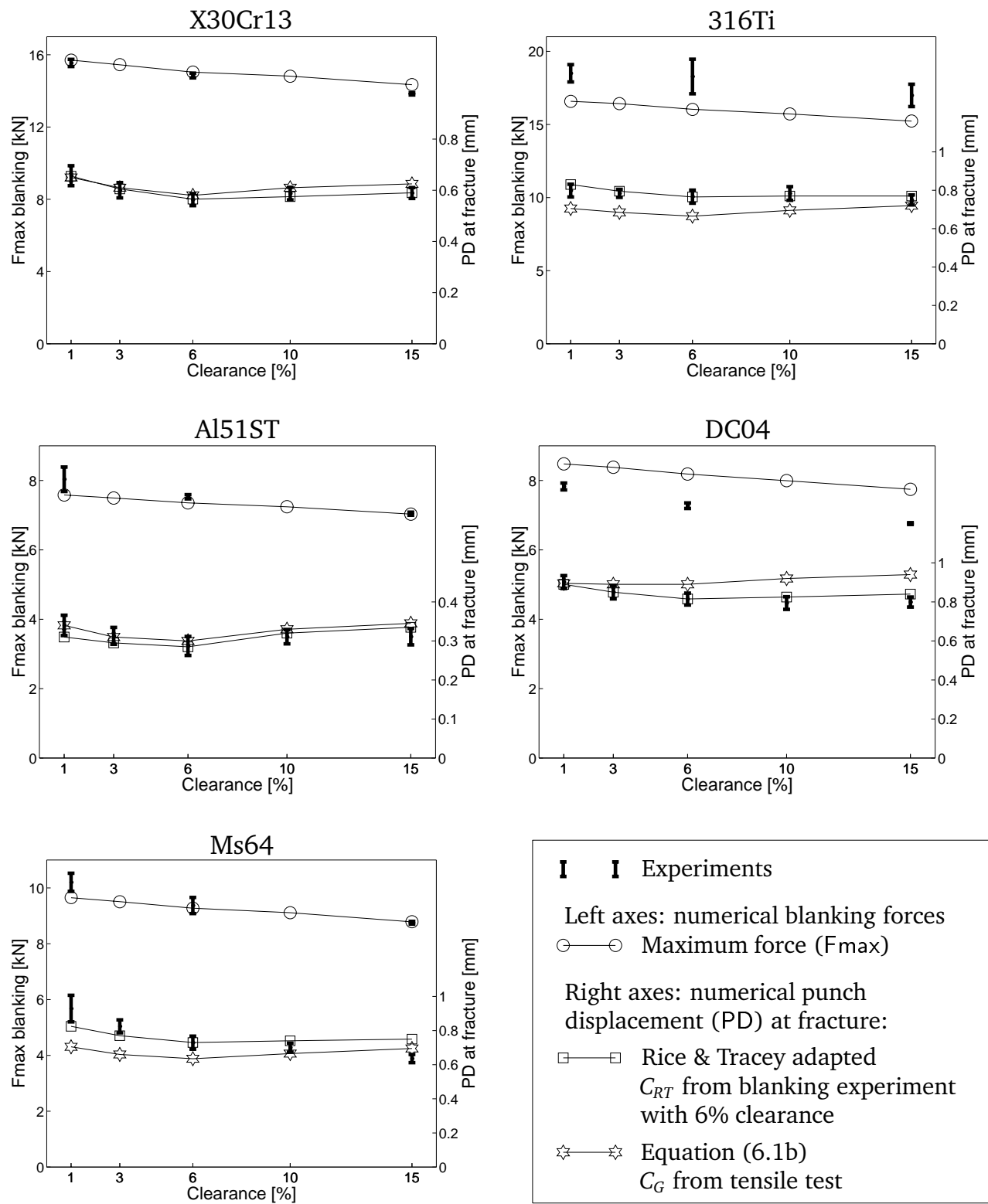
I I Experiments
Left axes: numerical blanking forces $\odot \quad \bigcirc$ Maximum force (Fmax)
Right axes: numerical punch displacement (PD) at fracture:
$\square \quad \square$ Rice \& Tracey adapted $C_{R T}$ from blanking experiment with $6 \%$ clearance
is Equation (6.1b) $C_{G}$ from tensile test

Figure 6.3: Comparison of blanking experiments (99\% interval) and numerical predictions for 5 different metals. Results are presented for the maximum blanking force at the left axes. For the prediction of punch displacement at fracture initiation (right axes), the adapted Rice \& Tracey criterion (equation 6.1a, $C_{R T}$ characterised in blanking) and the criterion in equation $(6.1 b)\left(C_{G}\right.$ characterised in tensile testing) are considered. 
6\% clearance and with this value of $C_{R T}$ the punch displacement at ductile fracture initiation is predicted for all other clearances. Results for the quantified values $C_{R T}$ are given in table 6.3 and the predictions are presented in figure 6.3. For the approach based on tensile testing, the thicknesses at fracture initiation in the tensile tests are measured and the critical values $C_{G}$ for the criterion of equation (6.1b) are determined in the 3D FEM-simulations of the tensile tests for all five metals (table 6.3). Predictions for the punch displacements at fracture initiation in the blanking process for all clearances, using the second procedure, are also presented in figure 6.3 for all metals.

Pursuing the first approach, the predictions fall within the experimental errors or in a very close range, for all metals. The maximum deviation from an experiment is $15 \%$ for Ms64 for the blanking geometry with the 15\% clearance. All other predictions deviate in the range of $10 \%$ or smaller. For the second approach, with characterisation based on the tensile tests, predictions for X30Cr13 and Al51ST maximally deviate 6\% and $10 \%$ from the experiments, respectively. For 316Ti and DC04, the maximum deviations are $12 \%$ and $15 \%$ and the maximum deviation for Ms64 is $24 \%$. In global terms, the first approach performs better for all metals.

Table 6.3: For five selected metals the experimentally determined critical C's are presented for both criteria employed. For the adapted Rice \& Tracey criterion, $C_{R T}$ is quantified in the blanking experiment with the $6 \%$ clearance. For the criterion of equation (6.1b), $C_{G}$ is resolved from the presented experimental thicknesses at fracture initiation using the $3 D$ FEM-simulations of the tensile tests.

\begin{tabular}{|l|c|c|c|}
\hline material & $C_{R T}$ (blanking) $[-]$ & $C_{G}$ (tensile test) [-] & thickness at fracture $[\mathrm{mm}]$ \\
\hline X30Cr13 & 2.70 & 3.53 & 0.448 \\
316Ti & 7.42 & 6.53 & 0.329 \\
Ms64 & 7.27 & 6.39 & 0.342 \\
DC04 & 8.70 & 14.8 & 0.132 \\
Al51ST & 1.49 & 1.45 & 0.642 \\
\hline
\end{tabular}

\subsubsection{Application of criteria to both characterisation approaches}

In chapter 4 as well as in this chapter up to this point, the adapted Rice \& Tracey criterion of equation (6.1a) is only used in the first approach (characterisation in blanking), and the criterion of equation (6.1b) is only utilised for the second strategy (characterisation in tensile testing). To check their application area, both criteria are applied in both procedures for Al51ST. Results are presented in figure 6.4. As it can be observed, the newly proposed criterion of equation (6.1b) performs well for both procedures. In table 6.3 it can be noticed that, for Al51ST, $C_{G}$ is determined to be 1.45 

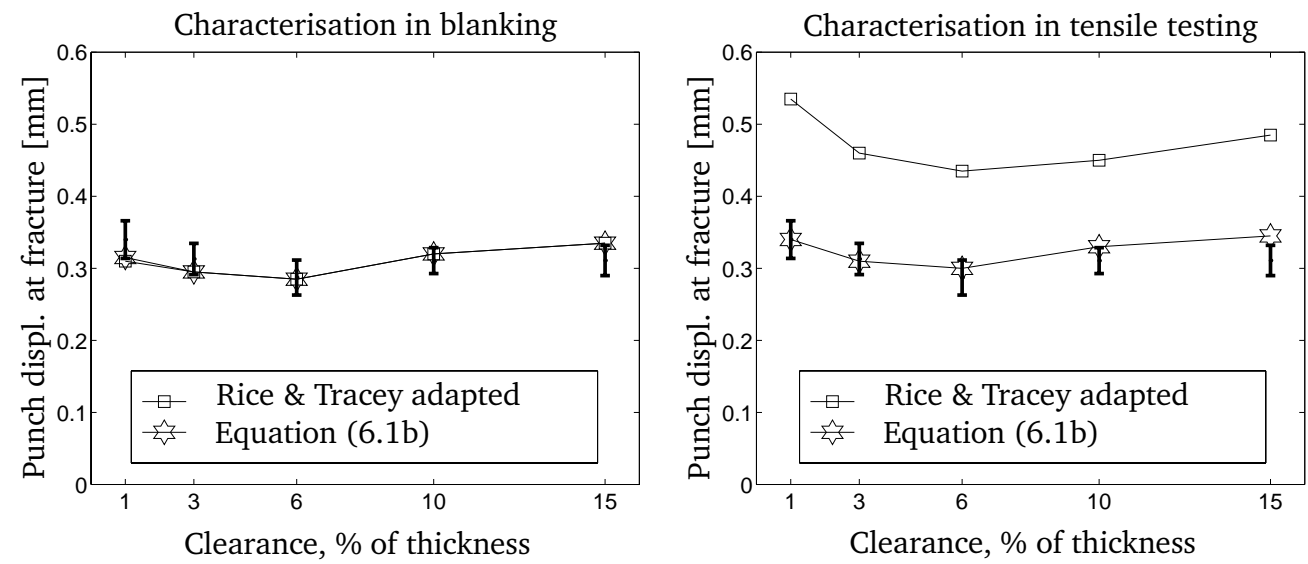

Figure 6.4: Experimental and numerical results of the punch displacement at fracture for both procedures utilising both criteria. Left, the first approach: characterisation in blanking. Right, the second strategy: characterisation in tensile testing.

in the tensile test. In blanking it is quantified quite close to that value: $C_{G}=1.29$, which reveals that the criterion may be valid for both tensile testing and blanking. In contrast, the adapted Rice \& Tracey criterion performs badly when characterised in tensile testing $\left(C_{R T}=3.18\right.$ determined in tensile testing compared to $C_{R T}=1.49$ quantified in blanking, table 6.3). This result shows that this criterion is highly process dependent.

\subsection{Discussion}

Strategies to predict ductile fracture initiation in the blanking process, which result in a complete blanking model, have been presented for one metal in chapter 4. Evaluation of these methods, including the identification of the material behaviour, are performed for four other metals in this chapter. For all five metals, experimental and numerical results are presented concerning maximum process force and punch displacement at ductile fracture initiation. The maximum process force, occurring in blanking, is valuable for engineering practice when wear and duration of life of the tools is considered. The punch displacement at fracture initiation is important because it largely determines the shape of the blanked edge and thus the geometry and dimensional accuracy of the product.

Material characterisation is a significant issue in the modelling of the blanking process. Because very large strains occur in the localised shear zone it is important to accurately determine the stress - strain relation for large strains, which is not straightforward. Tensile tests are performed on pre-rolled specimens to retrieve this 
relation up to large strains. The calculated force - clamp displacement curves for the tensile tests and the predicted maximum blanking forces suggest that the plastic material behaviour is characterised successfully over the entire strain range for all metals.

Predictions for maximum blanking forces are satisfactory for all metals, with maximum deviations from experimental data of approximately $10 \%$. For the prediction of punch displacement at ductile fracture initiation two procedures have been evaluated. The strategy where the adapted Rice \& Tracey criterion is characterised in a blanking experiment performs well for all metals. The second procedure, which utilises a much more accessible tensile test to characterise ductile fracture with the newly proposed criterion of equation (6.1b), yields very useful results. The advantage of the first approach is the higher accuracy. The second strategy, however, has the advantage of a much simpler experiment that is needed for the characterisation of ductile fracture. Moreover, the ductile fracture initiation criterion of the latter is not only valid for blanking (as is the adapted Rice \& Tracey criterion, section 6.3.4) but also for tensile testing under different pressures and it may be applicable for more forming processes.

For the newly proposed criterion of equation (6.1b) as well as for both the Rice \& Tracey criterion of equation 6.1a and the Oyane criterion in table 4.2 (which shows similar results), it is concluded that the only material parameter is the critical parameter $C$. 


\section{Chapter 7}

\section{Investigation of the blanking process for different grain sizes}

\subsection{Introduction}

In industrial practice a trend is recognised to process continuously thinner sheets, down to thicknesses of $40[\mu \mathrm{m}]$ (present) to $10[\mu \mathrm{m}]$ (near future). Given the average grain size areas in the order of $25 \cdot 10^{-6}\left[\mathrm{~mm}^{2}\right]$, this leads to sheet morphologies with only a few grains over the thickness.

As was already mentioned by Armstrong (1961), Miyazaki et al. (1979), Yuan et al. (1994) and Geiger et al. (1996), so-called size effects occur along with the miniaturisation of forming processes, where materials can no longer be assumed to behave as an isotropic continuum. This is, because separate grains have strong anisotropic behaviour due to their orientation. The behaviour of a specimen or sheet can only be isotropic if a representative volume element contains a large number of grains. Therefore, the predictive value of FEM-models, developed for isotropic continuum materials, as well as the experimental reproducibility of the process, become questionable with a decreasing number of grains (or increasing grain size). However, as was suggested by Kals \& Eckstein (1998) these effects are larger in tensile testing and free bending than in blanking. This is due to the fact that the deformations in the blanking process are much more constrained by the boundary conditions from all the different tool components than in tensile testing and free bending.

In this chapter a preliminary investigation is performed into the effect of grain size on the blanking process in order to explore a limitation of the FEM-model that is validated earlier in this thesis. Instead of decreasing the sheet thickness, the grain

The content of this chapter corresponds to:

Goijaerts, A.M., Răulea, L.V., Govaert, L.E., and Baaijens F.P.T., 1999, Investigation of the blanking process for different grain sizes. In preparation for publication. 
size is increased using a recrystallisation procedure on aluminium sheet (A199, DIN 1747, Werkstoffnr. 3.0205). This scaling up of the experiments for thinner sheets with constant grain size to experiments on equally sized sheets with larger grains, is performed in order to be able to use the same experimental setup. The planar experimental setup of section 2.3.1, using the tools of table 2.4 with relatively large cutting radii and a clearance of $0.10[\mathrm{~mm}]$, is employed to perform all experiments in this chapter. The blanking process will be examined for sheets with different grain sizes, especially relatively large grain sizes. Effects on process force, deformation fields and product dimensions will be considered.

In the next section, the recrystallisation procedure will be explained that is applied to obtain sheets with different grain sizes. In section 7.3, the results will be shown for aluminium sheet with approximately 6 grains over the thickness as well as the results for larger grain sizes. The mutual comparison will show differences in process forces, deformation fields and product shapes. This chapter is concluded with a discussion in section 7.4.

\subsection{Recrystallisation procedures}

In order to obtain different grain sizes, a recrystallisation procedure is applied. In this heat treatment procedure three consecutive steps can be distinguished. The first step is an annealing step. In this step the internal stresses in the as-received material, as a result of its production process, are reduced (actually, recrystallisation takes place). The next step is a deformation step in order to store a certain amount of energy in the material. Uniaxial extension is used for this purpose. The final step is recrystallisation, where discrete locations of concentrated internal energy, e.g. dislocation pile-ups, form so-called nuclei, which are the nucleation points for recrystallisation. The size of the resulting grains can be controlled by the amount of deformation and the recrystallisation temperature: with smaller deformation in the second step, less nuclei and thus larger grains will be formed in the final step; with a higher temperature the growth rate of the crystals is larger and thus the grains will become

Table 7.1: Recrystallisation procedures to obtain specimens with four different grain sizes.

\begin{tabular}{|c|c|c|c|}
\hline \multicolumn{3}{|c|}{ Subsequent procedures } & Resulting \\
\hline Annealing & Extension & Recrystallisation & Grain size $\left[\mathrm{mm}^{2}\right]$ \\
\hline $600\left[{ }^{\circ} \mathrm{C}\right]$ (1 hour) & $10 \%$ & $300\left[{ }^{\circ} \mathrm{C}\right]$ (1 hour) & 0.025 \\
\hline $600\left[{ }^{\circ} \mathrm{C}\right]$ (1 hour) & $10 \%$ & $600\left[{ }^{\circ} \mathrm{C}\right]$ (1 hour) & 1 \\
\hline $600\left[^{\circ} \mathrm{C}\right]$ (1 hour) & $6 \%$ & $600\left[^{\circ} \mathrm{C}\right]$ (1 hour) & 6 \\
\hline $600\left[{ }^{\circ} \mathrm{C}\right]$ (1 hour) & $1.5 \%$ & $600\left[{ }^{\circ} \mathrm{C}\right]$ (1 hour) & 250 \\
\hline
\end{tabular}


larger. Eventually, four different grain sizes are used in the experimental investigations; specimens with small crystals, specimens consisting of only one grain, and two intermediate grain sizes. The different sizes as well as the procedures to realise them, are given in table 7.1. For more detailed information on recrystallisation, reference is made to general material science literature (e.g., Callister, 1997).

\subsection{Results for different grain sizes}

In this section, the blanking process is performed using specimens with different grain sizes, obtained by the recrystallisation procedures in table 7.1. Specimen dimensions are according to figure 2.5 , with thicknesses of approximately $1[\mathrm{~mm}]$ (small deviations may occur due to the elongation step in the recrystallisation procedures). Differences in the process forces are considered in section 7.3.1; deviations in the deformation fields are presented in section 7.3.2; variations in the characteristics of the blanked edge are displayed in section 7.3.3.

\subsubsection{Process forces}

To show the reproducibility of the punch displacement versus punch force relation for different grain sizes, the force - displacement curves for both the smallest and the largest grain sizes are given in figure 7.1. It can be observed that for the smallest grain sizes (at the left-hand side of figure 7.1) small variations occur, not only in the maximum process force but also in the shape of the force - displacement curves. However, the variations are only slightly larger than the experimental error.
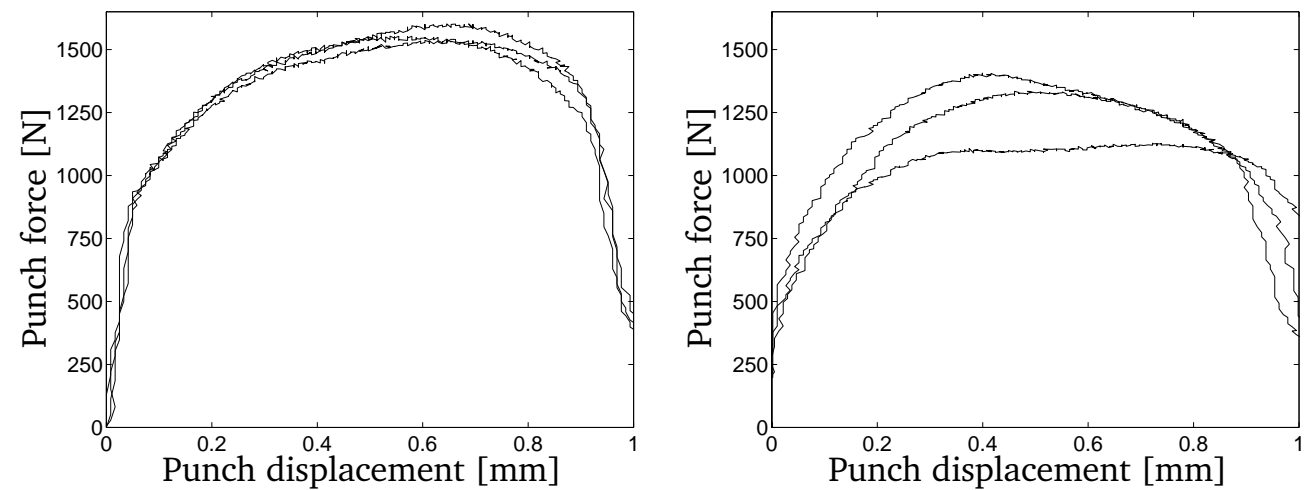

Figure 7.1: Experimental force - displacement curves for three specimens with approximately 6 grains over the thickness (left) and for three specimens consisting of only one grain with random orientation (right). 


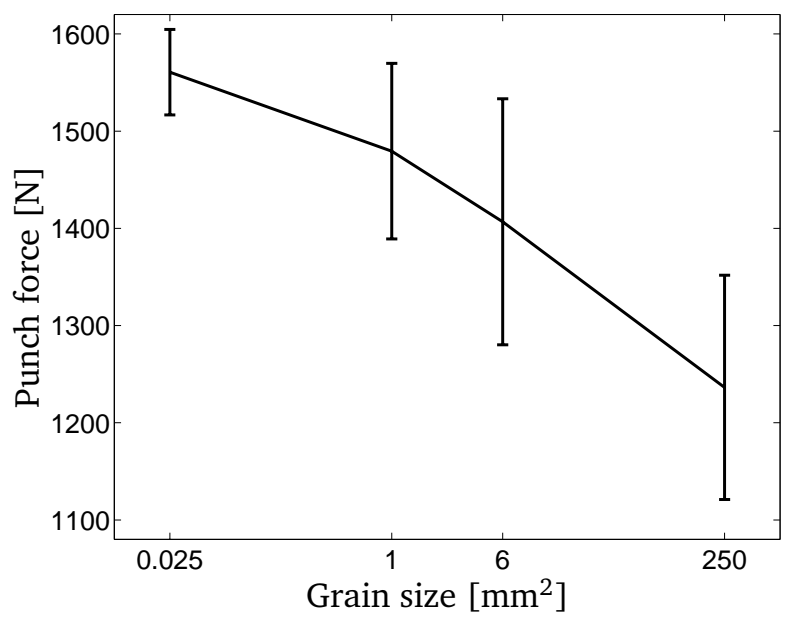

Figure 7.2: Decreasing blanking force with larger standard-deviation for increasing grain size (or equivalently thinner sheets) on a logarithmic axis.

At the right-hand side of figure 7.1 three force - displacement curves are presented for three specimens consisting of only one grain with random orientation. Deviations occur of about $25 \%$ in the maximum force. Moreover, striking differences are presented in the shape of the force - displacement curves. It can also be noticed that the average process force is significantly smaller for the specimens consisting of only one single grain.

To confirm this observation, eight specimens are blanked for four grain sizes and the maximum force for each specimen is measured during the process. The averages and standard-deviations are presented in figure 7.2 for all different grain sizes, displayed at a logarithmic scale. After the recrystallisation process the thicknesses vary for different grain sizes because of the different amounts of elongation. In figure 7.2 all force levels are scaled to a specimen thickness of $1.00[\mathrm{~mm}]$.

The explanation for the increasing standard-deviation for increasing grain size is of course the diminishing reproducibility for larger grains, which is a reflection of the randomly anisotropic behaviour. The larger the grains, the larger the influence of the separate orientations of the grains. The decreasing average force level for increasing grain size can be explained by grain boundary strengthening or the Hall-Petch effect: grain boundaries act as obstacles for dislocations and thus for plastic deformation and will increase the process force; smaller grains will result in more grain boundaries, which enlarge the force. Considering figure 7.2, the difference in forces for singlegrain specimens and specimens with approximately 6 grains in thickness direction appears to be less than $25 \%$. 

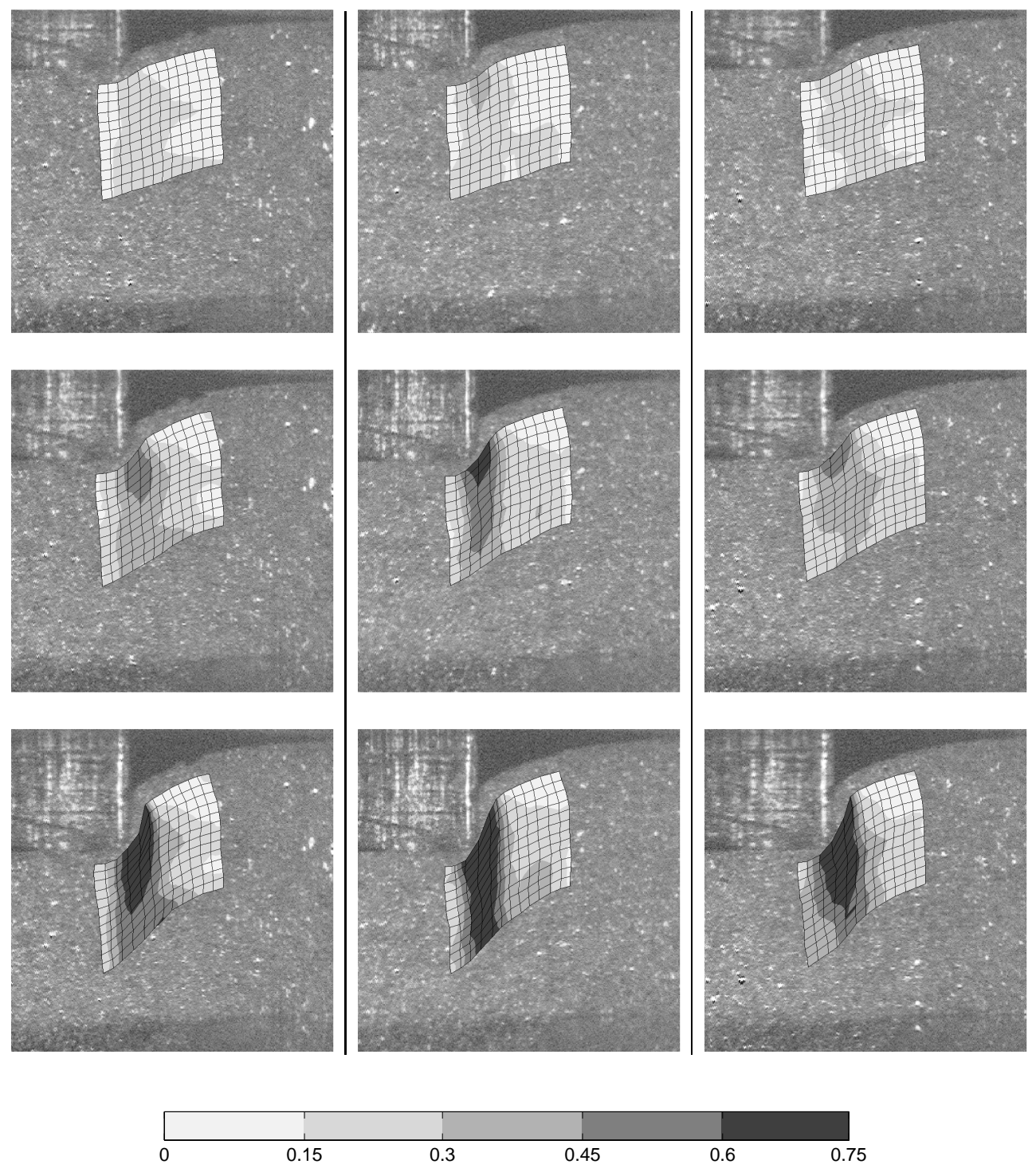

Figure 7.3: Experimental results for the equivalent strain fields of initially rectangular grids for three blanking specimens (left, centre and right) consisting of approximately 6 grains over the thickness. Three stages are presented (top, middle and bottom) corresponding to punch displacements of approximately 0.18, 0.29 and $0.40[\mathrm{~mm}]$. Notice that the roll-over zones next to the punch show close resemblance. 

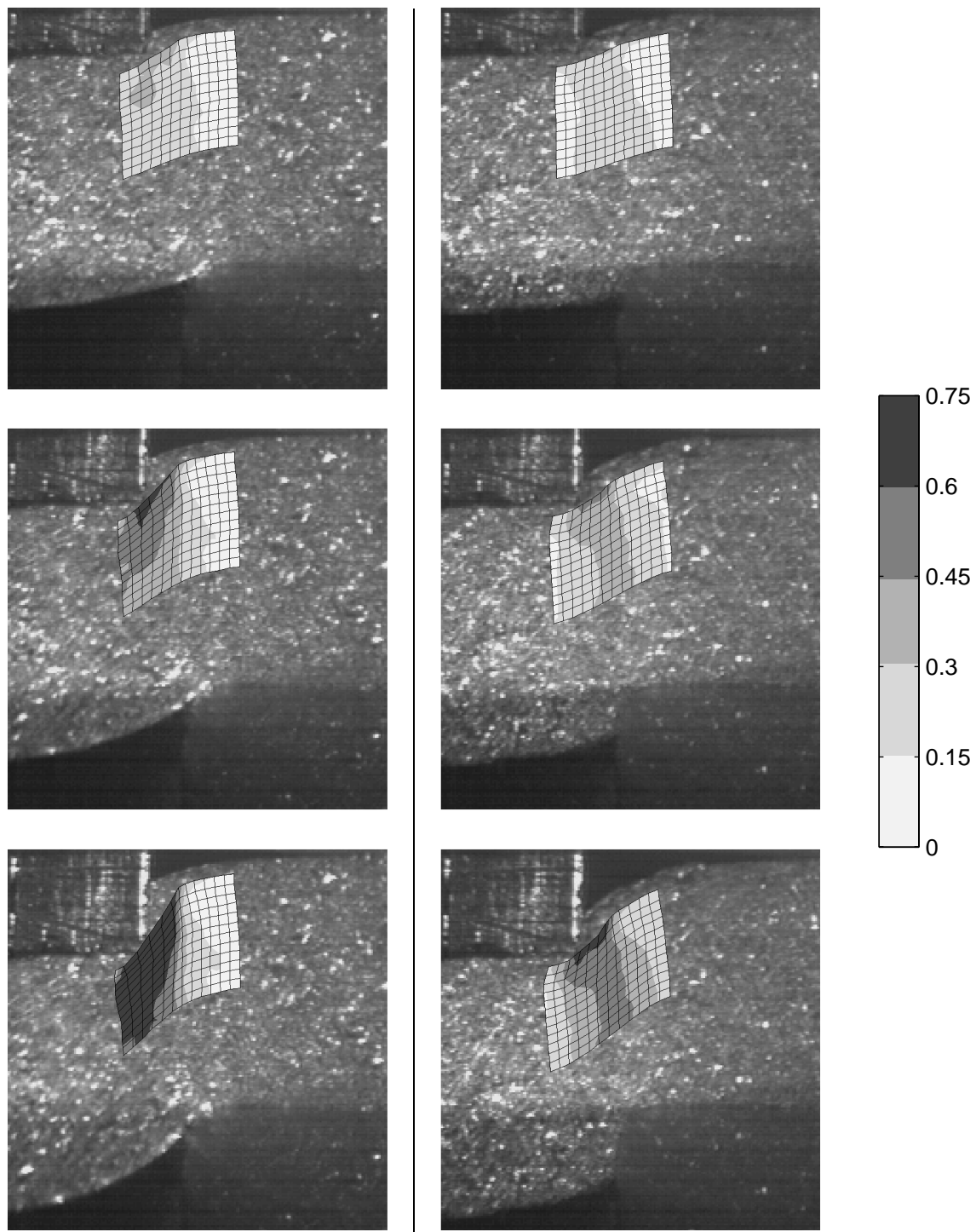

Figure 7.4: Experimental results for the equivalent strain fields of initially rectangular grids for two blanking specimens (left and right), each consisting of only one grain, with a different orientation. Three stages are presented (top, middle and bottom) corresponding to punch displacements of approximately $0.18,0.29$ and $0.40[\mathrm{~mm}]$. Notice that the roll-over zones next to both the punch and the die differ considerably. 


\subsubsection{Deformation fields}

To monitor deformation fields of the different specimens during blanking, the experimental setup of figure 2.4 is employed with use of a digital camera (as was also applied in chapter 3). Equivalent strains are calculated from the displacements that are measured with the Digital Image Correlation technique (with windows and search areas of $31 \times 31$ and $47 \times 47$ pixels, respectively) as it has been explained in section 2.3.2.

In figure 7.3 deformation fields are shown for three different specimens, consisting of approximately 6 grains over the thickness. Three stages during the blanking process are presented and it can be observed that the strain fields agree reasonably well. The occurring differences are explained by the relatively large grain sizes and the corresponding local anisotropic behaviour. It is also shown that the roll-over zones next to the punch are hardly different.

To demonstrate the extreme differences that may occur for single-grain specimens, results for two single-grain specimens with different grain orientation are shown in figure 7.4. The specimen at the left shows an extremely large roll-over at the die and a small roll-over at the punch. The strains below the punch are larger than in the samples of figure 7.3. The specimen at the right exhibits a larger roll-over at the punch which results in a smaller strain level because the deformation is less localised.

\subsubsection{Characteristics of blanked edges}

In figure 7.5 three pictures are presented that show the different zones of the blanked edge for different specimens. The left picture shows the blanked edge of a specimen with approximately 6 grains over the thickness. The surface of the roll-over appears to be hilly (orange-skin). This is caused by the different orientations of the grains on
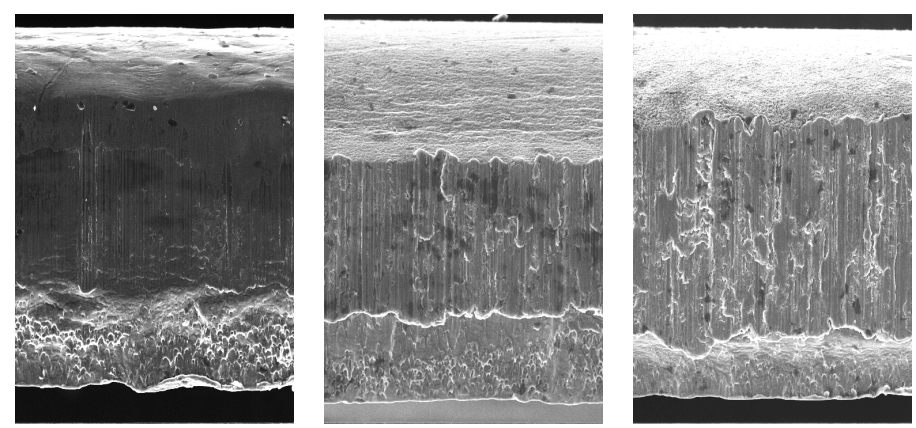

Figure 7.5: Blanked edges of one specimen with approximately 6 grains over the thickness (left) and two single-grain specimens. The top part is the roll-over zone, in the middle the shear zone can be distinguished and the fracture zone is at the bottom. 


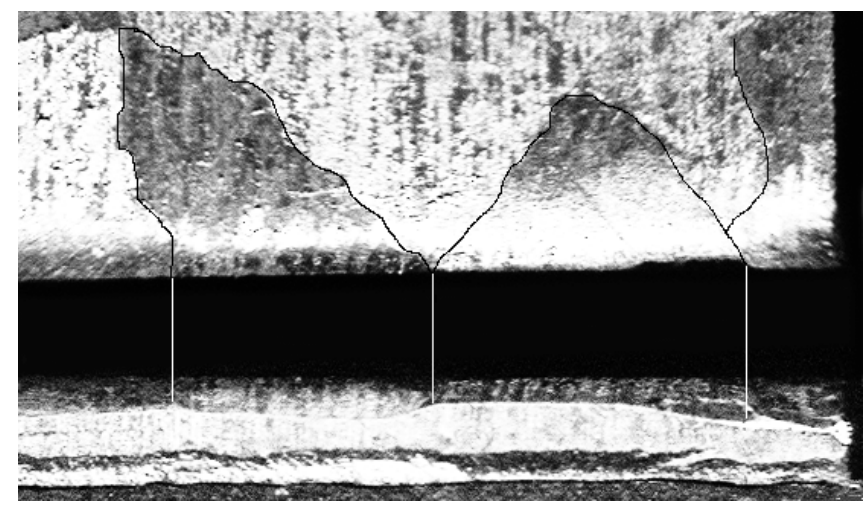

Figure 7.6: An example exposing the differences that may exist in the blanked edge due to different orientations. At the bottom, the blanked edge is recognisable and on top, the view from above is shown where the separate crystals can be distinguished. Over the thickness there is only one grain.

top of the specimen and the phenomenon becomes specifically manifest at the free surface (it is not constrained by any tool).

The two pictures at the right of figure 7.5 represent blanked edges of single-grain specimens. The dissimilarities in the different zones for these specimens are quite large, but in blanking this could be expected when the sheet consists of only one grain. The problems involved become even more pronounced when a specimen is blanked that consists of several grains over the width, but only one grain over the thickness (figure 7.6).

\subsection{Discussion}

The reproducibility of the blanking process for the material consisting of approximately 6 grains over the thickness is reasonably good. When grains become larger the mutual deviations increase, both in process force and deformation field. In the experiments discussed, the process force decreases with larger grains, which is mainly explained by the diminishing grain boundary strengthening. The decreasing process force could be considered to be an advantage for the wear of tools, however, for larger grains the variations in deformations and blanked edges increase.

Considerably deviating results in process force, deformation field and product shape (blanked edge) are presented for blanked specimens, consisting of only one grain. 


\section{Chapter 8}

\section{Conclusions and recommendations}

In this thesis the attention has been focused on the modelling of ductile fracture initiation in metal blanking. To arrive at an adequate fracture initiation characterisation, firstly a numerical model has been validated that describes the deformation and loading history of the process prior to fracture correctly. With a modification of existing fracture models, ductile fracture initiation could be successfully predicted using one blanking experiment. With the formulation of a new criterion, the prediction has been achieved by performing only a tensile test. Also strain rate effects have been investigated and only a minor influence on the blanking process up to punch speeds of $10[\mathrm{~mm} / \mathrm{s}]$ has been observed. Finally, an investigation was performed into the effect of grain size on the blanking process, because of the current miniaturisation of blanked products.

In section 8.1 the conclusions of this thesis are recapitulated, ordered by subject, and recommendations for future research are formulated in section 8.2.

\subsection{Conclusions}

The importance of material characterisation at large strains

For an accurate simulation of the blanking process, material characterisation at large strains is considered to be crucial, because very large strains (in the order of 3) occur in this process. Extrapolation of the stress - strain information obtained from a single tensile test introduces inadmissible errors.

The measurement of displacements with Digital Image Correlation

The Digital Image Correlation technique, described in this thesis (section 2.3.2), 
is not based on the application of markers but instead uses the contrast information of the surface, and provides the possibility of accurate displacement measurements in the highly strained, localised deformation zone of the blanking process with an accuracy of approximately $1[\mu \mathrm{m}]$. In combination with the second order method to calculate the strain field (Geers et al., 1996), an excellent method to experimentally record deformation data is obtained.

Validation of FEM-model prior to fracture

Employing the elasto-plastic Von Mises model, assuming isotropic hardening, the numerical finite element model of the blanking process (Brokken, 1999) is validated for $\mathrm{X} 30 \mathrm{Cr} 13$ with respect to process force and deformation field prior to fracture (deviations are in the order of 5\%). The FEM-approach also accurately predicts the roll-over for X30Cr13. Furthermore, this numerical tool provides the loading and deformation history essential for the modelling of ductile fracture initiation.

Application of existing fracture models

In general, existing fracture criteria only describe ductile fracture initiation if they are characterised under similar loading conditions. When some of these criteria are slightly modified, they can predict ductile fracture initiation during blanking very accurately for five different metals over a range of geometries, by performing one blanking experiment (for each metal). A criterion that can be used for this application is e.g. the Oyane et al. (1980) criterion $\left(A_{O}=3.9\right)$ :

$$
\int_{\bar{\varepsilon}_{p}}\left\lfloor 1+3.9 \cdot \sigma_{h} / \bar{\sigma}\right\rfloor d \bar{\varepsilon}_{p}=C_{O}
$$

However, this criterion fails to describe ductile fracture initiation in both blanking and tensile testing for the same parameter set.

A new ductile fracture criterion that is applicable for different loading conditions To extend the application area, considering loading conditions, an extra strain contribution is inserted in the expression mentioned above:

$$
\int_{\bar{\varepsilon}_{p}}\left\lfloor 1+3.9 \cdot \sigma_{h} / \bar{\sigma}\right\rfloor \bar{\varepsilon}_{p}^{0.63} d \bar{\varepsilon}_{p}=C_{G}
$$

This newly proposed criterion can predict ductile fracture initiation in the blanking process as well as in tensile testing for five different metals. This criterion also appears to be applicable for fracture initiation in pressurised tensile tests, implying that the influence of the triaxiality is adequately accounted for. Consequently, the experimental characterisation procedure only involves a tensile test instead of a complicated blanking experiment. Good results are achieved for predictions of the punch displacement at ductile fracture initiation. 
Prediction of the shape of blanked edges

Accurate predictions of punch displacement at ductile fracture initiation are made using data obtained from a complicated blanking experiment. Results are promising when a standard tensile test is employed to characterise the newly proposed, more generally valid criterion. The correct prediction of the punch displacement at ductile fracture initiation provides, together with the validated description of the roll-over, a reliable estimation of the shape of the blanked edge.

Influence of blanking speed

The effect of the process speed on the blanking process is investigated using the elasto-viscoplastic model with Bodner-Partom viscosity. For X30Cr13 the magnitude of the blanking speed (in the industrially relevant range) has a minor influence on the process force and has no significant influence on the punch displacement at ductile fracture initiation. For larger speeds (beyond the applicable area in practice) temperature effects, decreasing the yield stress, have to be taken into account.

The effect of grain size

For larger grains or, equivalently, thinner sheets, the blanking experiments are not reproducible anymore. Process forces tend to decrease with the increase of grain size.

\subsection{Recommendations}

Material characterisation at large strains

The method using tensile specimens rolled to different thicknesses is very timeconsuming and obstructs the easy characterisation of different materials. Therefore, the search for a simpler method to determine the material behaviour at large strains is highly recommended.

Further application of the new criterion

The newly proposed criterion shows to perform adequately for blanking as well as tensile testing under different superposed pressures. This implies that the influence of the most important parameters on ductile fracture initiation (plastic strain and triaxiality) is incorporated. Now, the more general applicability of the newly proposed criterion for other forming processes should be examined.

Microstructural modelling of ductile fracture

Microstructural modelling of void growth (during the blanking process), may lead to more insight in the physical phenomena, and may result in a ductile fracture initiation model based on physical understanding, in contrast with the phenomenological criterion proposed in this thesis. 
Crack propagation and crack interaction

An investigation is proposed into the physics of crack propagation and crack interaction. These phenomena may cause some specific problems in industrial practice. Experimental verification procedures monitoring the local fracture evolution need to be developed for this purpose.

Extension to three dimensions

Before the complete numerical blanking model is confronted with industrial applications, an extension of the model into three dimensions is recommended. Then, it can provide more insight into the variations over the blanked edge of geometrically complicated products. This extension becomes feasible in the near future with the growing computational power and improving numerical techniques. 


\section{Bibliography}

van der Aa, M. A. H., 1999, Wall ironing of polymer coated sheet metal, Ph.D. thesis, Eindhoven University of Technology, The Netherlands.

van Alphen, C. J., 1996, Turbostampen, In Dutch, internal report CTB 591-96-3745, Philips Electronics B.V.

Anderson, T. L., 1995, Fracture mechanics, fundamentals and applications, CRC Press, Boca Raton, Florida.

Armstrong, R. W., 1961, On size effects in polycrystal plasticity, Journal of the Mechanics and Physics of Solids, vol. 9, pp. 196-199.

Atkins, A. G., 1996, Fracture in forming, Journal of Materials Processing Technology, vol. 56, pp. 609-618.

Atkins, A. G. \& Mai, Y. W., 1985, Elastic and plastic fracture mechanics; metals, polymers, ceramics, composites, biological materials, Ellis Horwood Limited, Chichester.

Baaijens, F. P. T., 1991, Calculation of residual stresses in injection molded products, Rheologica Acta, vol. 30, pp. 284-299.

Baaijens, F. P. T., 1993, An U-ALE formulation of 3-D unsteady viscoelastic flow, International Journal for Numerical Methods in Engineering, vol. 36, pp. 1115-1143.

Balendra, R. \& Travis, F. W., 1969, Static and dynamic blanking of steel of varying hardness, International Journal of Machine Tool Design and Research, vol. 10, pp. 249-271.

Bodner, S. R. \& Partom, Y., 1975, Constitutive equations for elasto-viscoplastic strain-hardening materials, Journal of Applied Mechanics, vol. 42, pp. 385-389.

Bolt, P. J., 1989, Prediction of ductile failure, Ph.D. thesis, Eindhoven University of Technology, The Netherlands.

de Borst, R., Carmeliet, J., Pamin, J., \& Sluys, L. J., 1994, New horizons in computer analysis of damage and fracture in quasi-brittle materials., Fracture and damage in quasi-brittle structures - experiment, modelling and computer analysis, Z. Bažant, Z. Bittnar, M. Jirásek, \& J. Mazars, eds., E\&FN Spon, London, pp. 359-372, Proceedings of the US-Europe workshop, Prague, Czech Republic.

Boudeau, N. \& Gelin, J. C., 1992, Finite element simulation of the ductile fracture in 3-D sheet metal forming process, Journal of Materials Processing Technology, vol. 32, pp. 521-530.

Broek, D., 1971, A study on ductile failure, Ph.D. thesis, Delft University of Technology, The Netherlands.

Broek, D., 1989, The practical use of fracture mechanics, Kluwer Academic Publishers, Dordrecht. 
Brokken, D., 1995, Towards the analysis of the metal punching process, Master's thesis, Eindhoven University of Technology, The Netherlands, WFW report 95.021.

Brokken, D., 1999, Numerical modelling of ductile fracture in blanking, Ph.D. thesis, Eindhoven University of Technology, The Netherlands.

Brokken, D., Brekelmans, W. A. M., \& Baaijens, F. P. T., 1996, Numerical analysis of the metal blanking process, Advanced Technology of Plasticity 1996 - Proceedings of the 5th International Conference on Technology of Plasticity, T. Altan, ed., Columbus, Ohio, U.S.A., pp. 665-668.

Brokken, D., Brekelmans, W. A. M., \& Baaijens, F. P. T., 1998, Numerical modelling of the metal blanking process, Journal of Materials Processing Technology, vol. 83, pp. 192-199.

Brokken, D., Goijaerts, A. M., Brekelmans, W. A. M., Oomens, C. W. J., \& Baaijens, F. P. T., 1997, Modelling of the blanking process, Computational Plasticity, Fundamentals and Applications, D. R. J. Owen, E. Oñate, \& E. Hinton, eds., vol. 2, CIMNE, Barcelona, pp. 1417-1424.

Bruck, H. A., McNeill, S. R., Sutton, M. A., \& Peters, W. H., 1989, Digital image correlation using Newton-Raphson method of partial differential correction, Experimental Mechanics, vol. 29, pp. 261-267.

Callister, W. D., 1997, Materials science and engineering; an introduction, John Wiley \& Sons, Inc., New York.

Chang, T. M., 1951, Shearing of metal blanks, Journal of the Institute of Metals, vol. 78, pp. 393414.

Chang, T. M. \& Swift, H. W., 1950, Shearing of metal bars, Journal of the Institute of Metals, vol. 78, pp. 119-146.

Clift, S. E., Hartley, P., Sturgess, C. E. N., \& Rowe, G. W., 1990, Fracture prediction in plastic deformation processes, International Journal of Mechanical Science, vol. 32, pp. 1-17.

Cockroft, M. G. \& Latham, D. J., 1968, Ductility and the workability of metals, Journal of the Institute of Metals, vol. 96, pp. 33-39.

Dodd, B. \& Bai, Y., 1987, Ductile fracture and ductility - with applications to metalworking, Academic Press, London.

Faura, F., Garcia, A., \& Estrems, M., 1998, Finite element analysis of optimum clearance in the blanking process, Journal of Materials Processing Technology, vol. 80-81, pp. 121-125.

Freudenthal, A. M., 1950, The inelastic behaviour of solids, Wiley, New York.

Fukui, S., Konda, K., \& Maeda, K., 1971, Smooth shearing by stepped profile tool, Annals of the CIRP, vol. 20, pp. 57-58.

Gdoutos, E. E., 1993, Fracture mechanics; an introduction, Kluwer Academic Publishers, Dordrecht.

Geers, M. G. D., de Borst, R., \& Brekelmans, W. A. M., 1996, Computing strain fields from discrete displacement fields in 2D-solids, International Journal of Solids and Structures, vol. 33, pp. 4293-4307.

Geiger, M., Vollertsen, F., \& Kals, R., 1996, Fundamentals on the manufacturing of sheet metal microparts, Annals of the CIRP, vol. 45, pp. 277-282.

Goijaerts, A. M., Govaert, L. E., \& Baaijens, F. P. T., 1999a, Characterisation of ductile fracture in metal blanking, Proceedings of the International Conference on Technology of Plasticity, M. Geiger, ed., Springer-Verlag, Berlin, Heidelberg, pp. 2225-2230.

Goijaerts, A. M., Govaert, L. E., \& Baaijens, F. P. T., 1999b, Evaluation of ductile fracture models for different metals in blanking, submitted to Journal of Materials Processing Technology. 
Goijaerts, A. M., Govaert, L. E., \& Baaijens, F. P. T., 1999c, Experimental and numerical investigation on the influence of process speed on the blanking process, In preparation for publication.

Goijaerts, A. M., Govaert, L. E., \& Baaijens, F. P. T., 1999d, Modelling ductile fracture to improve metal blanking, Fourth International Conference on Constitutive Laws for Engineering Materials, R. C. Picu \& E. Krempl, eds., ISBN: 0-9609992-1-3, Rensselaer Polytechnic Institute, Troy, NY, USA, pp. 209-212.

Goijaerts, A. M., Govaert, L. E., \& Baaijens, F. P. T., 1999e, Modelvorming van het stansproces om sneller tot een goed procesontwerp te komen, Materialen, vol. 15, no. 4, pp. 25-28.

Goijaerts, A. M., Govaert, L. E., \& Baaijens, F. P. T., 1999f, Prediction of ductile fracture in metal blanking, Accepted for publication in Journal of Manufacturing Science and Engineering, transactions of the ASME.

Goijaerts, A. M., Govaert, L. E., \& Baaijens, F. P. T., 1999g, Prediction of ductile fracture in metal blanking, Proceedings of the International Conference on Sheet Metal Forming, M. Geiger, H. J. J. Kals, B. Shirvani, \& U. P. Singh, eds., Meisenbach, Bamberg, pp. 465-472.

Goijaerts, A. M., Răulea, L. V., Govaert, L. E., \& Baaijens, F. P. T., 1999h, Investigation of the blanking process for different grain sizes, In preparation for publication.

Goijaerts, A. M., Stegeman, Y. W., Govaert, L. E., Brokken, D., Brekelmans, W. A. M., \& Baaijens, F. P. T., 1998a, Modelling of the metal blanking process, First Esaform Conference on Material Forming, J. L. Chenot, J. F. Agassant, P. Montmitonnet, B. Vergnes, \& N. Billon, eds., SophiaAntipolis, France, pp. 239-242.

Goijaerts, A. M., Stegeman, Y. W., Govaert, L. E., Brokken, D., Brekelmans, W. A. M., \& Baaijens, F. P. T., 1998b, Can a new and experimental and numerical study improve metal blanking?, Proceedings of the International Sheet Metal Conference, volume I, H. J. J. Kals, M. Geiger, B. Shirvani, \& U. P. Singh, eds., Twente University Printers, The Netherlands, pp. 185-194.

Goijaerts, A. M., Stegeman, Y. W., Govaert, L. E., Brokken, D., Brekelmans, W. A. M., \& Baaijens, F. P. T., 1998c, A validated FEM model to improve metal blanking, Simulation of Materials Processing: Theory, Methods and Applications, J. Huétink \& F. P. T. Baaijens, eds., A.A. Balkema, Rotterdam, pp. 979-984.

Gonzalez, R. C. \& Wintz, P., 1983, Digital image processing, Addison-Wesley Publishing Company, Amsterdam.

Goodwin, G. M., 1968, Application of strain analysis to sheet metal forming problems in the press shop, SAE Automative Engineering Congress, SAE paper No. 680093, Detroit, MI, USA.

Gouveia, B. P. P. A., Rodrigues, M. C., \& Martins, P. A. F., 1996, Fracture prediction in bulk metal forming, International Journal of Mechanical Science, vol. 38, pp. 361-372.

Gronostajski, J. \& Zimniak, Z., 1995, A few methods of analytical calculation of forming-limit curves, Journal of Materials Processing Technology, vol. 55, pp. 213-217.

Gurson, A. L., 1977, Continuum theory of ductile rupture by void nucleation and growth: part I - yield criteria and flow rules for porous ductile media, Journal of Engineering Materials and Technology, Transactions of the ASME, vol. 99, pp. 1-15.

Habraken, F., 1996, Consolidation, plastic yield and formability of rapidly solidified Al-Si-X alloys, Ph.D. thesis, Eindhoven University of Technology, The Netherlands.

Hancock, J. W. \& MacKenzie, A. C., 1975, On the mechanics of ductile failure in high strength steels subjected to multi-axial stress-states, Journal of the Mechanics and Physics of Solids, vol. 24, pp. 147-169. 
Hartley, P., Clift, S. E., Salimi-Namin, J., Sturgess, C. E. N., \& Pillinger, I., 1989, The prediction of ductile fracture initiation in metalforming using a finite element method and various fracture criteria, Res Mechanica, vol. 28, pp. 269-293.

Hilbert, H. L., 1972, Stanzereitechnik, Band I, Carl Hanser Verlag, München.

Huétink, J., Vreede, P. T., \& van der Lugt, J., 1990, Progress in mixed Eulerian-Lagrangian finite element simulation of forming processes, International Journal for Numerical Methods in Engineering, vol. 30, pp. 1441-1457.

Hwang, J. T. \& Chang, R. G., 1990, Comparing the image matching methods of the two stage and FFT, Close range photogrammetry meets machine vision, SPIE, Vol.1395.

Iliescu, C., 1990, Cold-Pressing Technology, Number 9 in Studies in mechanical engineering, Elsevier, Amsterdam.

Jeong, S. H., Kang, J. J., \& Oh, S. I., 1996, A study on shearing mechanism by FEM simulation, Advanced Technology of Plasticity, Columbus, Ohio, USA, pp. 631-634.

Johnson, W. \& Slater, R. A. C., 1967, A survey of the slow and fast blanking of metals at ambient and high temperatures, Proceedings of the International Conference of Manufacturing Technology, Michigan, pp. 773-851.

Johnston, R., Fogg, B., \& Chisholm, A. W. J., 1968, An investigation into the fine blanking process, Proceedings of the 9th Machine Tool Design Conference, Birmingham, pp. 397-410.

Kachanov, L. M., 1986, Introduction to Continuum Damage Mechanics, Martinus Nijhoff Publishers, Dordrecht.

Kals, R. T. A. \& Eckstein, R., 1998, Miniaturization in sheet metal working, Proceedings of the International Sheet Metal Conference, volume II, H. J. J. Kals, M. Geiger, B. Shirvani, \& U. P. Singh, eds., Twente University Printers, The Netherlands, pp. 15-24.

Kanninen, M. F. \& Popelar, C. H., 1985, Advanced fracture mechanics, Oxford University Press, New York.

Keeler, S. P., 1965, Determination of forming limits in automative stampings, Sheet Met. Ind., vol. 42, pp. 683-691.

Klocke, F. \& Sweeney, K., 1998, Crack prediction and prevention in the fine blanking process: FEM simulations and experimental results, Proceedings of the International Sheet Metal Conference, volume I, H. J. J. Kals, M. Geiger, B. Shirvani, \& U. P. Singh, eds., Twente University Printers, The Netherlands, pp. 215-222.

Kolkailah, F. A. \& McPhate, A. J., 1990, Bodner-Partom constitutive model and non-linear finite element analysis, Journal of Engineering Materials and Technology, vol. 112, pp. 287-291.

Kondo, K. \& Suzuki, H., 1996, Research on the accuracy of sheared products by different working principles in precision shearing, Journal of Materials Processing Technology, vol. 56, pp. 70-77.

Lemaitre, J., 1996, A Course on Damage Mechanics, Springer-Verlag, Berlin, Heidelberg, New York.

Leonov, A. I., 1976, Non-equilibrium thermodynamics and rheology of viscoelastic polymer media, Rheologica Acta, vol. 15, pp. 85-98.

MARC, 1997, MARC Manuals: Volume A to F, Version K7, Palo Alto, California, U.S.A.

MATLAB, 1996, MATLAB reference guide, version 4, Natick, Mass., U.S.A.

McClintock, F. A., 1968, A criterion for ductile fracture by the growth of holes subjected to multi-axial stress-states, Journal of Applied Mechanics, vol. 35, pp. 363-371. 
Meuwissen, M. H. H., 1998, An inverse method for the mechanical characterisation of metals, Ph.D. thesis, Eindhoven University of Technology, The Netherlands.

Miyazaki, S., Fujita, H., \& Hiraoka, H., 1979, Effect of specimen size on the flow stress of rod specimens of polycrystalline Cu-Al alloy, Scripta Metallurgica, vol. 13, pp. 447-449.

Nakagawa, T. \& Maeda, T., 1968, Experimental investigation on fine blanking, Sci. Papers, vol. 62, pp. 65-80.

Needleman, A., Tvergaard, V., \& Hutchinson, J. W., 1992, Void growth in plastic solids, Springer Verlag, New York.

Noble, C. F. \& Oxley, P. L. B., 1963, Crack formation in blanking and piercing, The International Journal of Production Research, vol. 2, pp. 265-274.

Oyane, M., Sato, T., Okimoto, K., \& Shima, S., 1980, Criteria for ductile fracture and their applications, Journal of Mechanical Working Technology, vol. 4, pp. 65-81.

Post, J. \& Voncken, R., 1996, FEM analysis of the punching process, Proceedings of the 4th International Conference on Sheet Metal, Volume I, H. J. J. Kals, B. Shirvani, U. P. Singh, \& M. Geiger, eds., Twente University Printers, The Netherlands, pp. 159-169.

Rank, E., Schweingruber, M., \& Sommer, M., 1993, Adaptive mesh generation and transformation of triangular to quadrilateral meshes., Communications on Numerical Methods in Engineering, vol. 9, pp. 121-129.

Rice, J. R. \& Tracey, D. M., 1969, On the ductile enlargement of voids in triaxial stress fields, Journal of the Mechanics and Physics of Solids, vol. 17, pp. 201-217.

Rubin, M. B., 1987, An elasto-viscoplastic model exhibiting continuity of solid and fluid states, International Journal of Engineering Sciences, vol. 25, pp. 1175-1191.

Rubin, M. B., 1989, A time integration procedure for plastic deformation in elasto-viscoplastic metals, Journal of Applied Mathematics and Physics, vol. 40, pp. 846-871.

Răulea, L. V., 1998, Blanking of aluminium with different grain sizes, Internal report MT98.008, Eindhoven University of Technology, The Netherlands.

Răulea, L. V., Goijaerts, A. M., Govaert, L. E., \& Baaijens, F. P. T., 1999, Size effects in the processing of thin metal sheets, Proceedings of the 7th International Conference on Sheet Metal, M. Geiger, H. J. J. Kals, B. Shirvani, \& U. P. Singh, eds., Meisenbach, Bamberg, pp. 521-528.

Samuel, M., 1998, FEM simulations and experimental analysis of parameters of influence in the blanking process, Journal of Materials Processing Technology, vol. 84, pp. 97-106.

Schreurs, P. J. G., Veldpaus, F. E., \& Brekelmans, W. A. M., 1986, Simulation of forming processes using the arbitrary Eulerian-Lagrangian formulation, Computer Methods in Applied Mechanics and Engineering, vol. 58, pp. 19-36.

Smit, R. J. M., Brekelmans, W. A. M., \& Baaijens, F. P. T., 1999, Flexible, consistent and fully implicit finite element implementation of the generalised compressible Leonov model., Submitted to International Journal for Numerical Methods in Engineering.

Spur, G. \& Stöferle, T., 1985, Handbuch der Fertigungstechnik, Band 2/3, Carl Hanser Verlag, München, Wien.

Stegeman, Y. W., Goijaerts, A. M., Brokken, D., Brekelmans, W. A. M., Govaert, L. E., \& Baaijens, F. P. T., 1999, An experimental and numerical study of a planar blanking process, Journal of Materials Processing Technology, vol. 87, pp. 266-276.

Sutton, M. A., Cheng, M., Peters, W. H., Chao, Y. J., \& McNeill, S. R., 1986, Application of an optimized digital correlation method to planar deformation analysis, Image and Vision Computing, vol. 4, pp. 143-150. 


\section{BIBLIOGRAPHY}

Swinden, T. \& Bolsover, G. R., 1927, Some notes on cold-rolled strip steel, Journal of the Iron and Steel Institute, vol. 115, pp. 569-602.

Taupin, E., Breitling, J., Wu, W.-T., \& Altan, T., 1996, Materials fracture and burr formation in blanking; results of FEM simulations and comparison with experiments, Journal of Materials Processing Technology, vol. 59, pp. 68-78.

Tervoort, T. A., Smit, R. J. M., Brekelmans, W. A. M., \& Govaert, L. E., 1998, A constitutive equation for the elasto-viscoplastic deformation of glassy polymers, Mechanics of Time Dependent Materials, vol. 1, pp. 269-291.

Tilsley, R. \& Howard, F., 1958, Recent investigations into the blanking and piercing of sheet materials, Machinery, vol. 93, pp. 151-158.

Tvergaard, V., 1990, Material failure by void growth to coalescence, Advances in Applied Mechanics, vol. 27, pp. 83-151.

Walsh, R. A., 1994, McGraw-Hill machining and metalworking handbook, McGraw-Hill, Inc.

Yuan, Z. J., Lee, W. B., Yao, Y. X., \& Zhou, M., 1994, Effect of crystallographic orientation on cutting forces and surface quality in diamond cutting of single crystal, Annals of the CIRP, vol. 43, pp. 39-42.

Zhou, Q. \& Wierzbicki, T., 1996, A tension zone model of blanking and tearing of ductile metal plates, International Journal of Mechanical Science, vol. 38, pp. 303-324.

Zienkiewicz, O. C. \& Zhu, J. Z., 1992, The Superconvergent Patch Recovery (SPR) and adaptive finite element refinement, Computer Methods in Applied Mechanics and Engineering, vol. 101, pp. 207-224.

Zienkiewicz, O. C. \& Zhu, J. Z., 1995, Superconvergence and the Superconvergent Patch Recovery, Finite Elements in Analysis and Design, vol. 19, pp. 11-24.

Zuidema, P., 1998, Grain size dependence in the punching process using recrystallised aluminium, Internal report MT98.031, Eindhoven University of Technology, The Netherlands. 


\section{Samenvatting}

Het ponsproces is een veel gebruikte produktietechniek voor het fabriceren van grote aantallen, metalen componenten. De bestaande algemene richtlijnen voor dit produktieproces kunnen niet voorkomen dat in de praktijk een 'trial-and-error' procedure nodig blijkt, dit terwijl de eisen aan doorlooptijd en produktvorm steeds hoger worden. Daarom is er een duidelijke behoefte aan een nieuw ontwerpgereedschap dat in staat is de vorm en dimensies van de geponste rand van een produkt te voorspellen (de intrekzone, de afschuifzone en de breukzone). Een op de eindige-elementenmethode gebaseerd numeriek gereedschap is weliswaar beschikbaar, maar een belangrijk probleem om tot een volledig ponsmodel te komen is nog niet opgelost: de nauwkeurige voorspelling van de initiatie van taaie breuk.

Dit proefschrift richt zich op de ontwikkeling van methodes om een volledig ponsmodel op te stellen dat in staat is om nauwkeurig de vorm van een geponste rand te beschrijven. Een goede voorspelling van de intrekzone hangt vooral af van de kwaliteit van de mechanische materiaalbeschrijving. Initiatie van taaie breuk markeert de overgang van afschuifzone naar breukzone. Aldus bepalen de betrouwbaarheid van zowel de materiaalbeschrijving als van het te gebruiken breukcriterium de voorspellende kwaliteit voor de geponste rand.

Een nauwkeurige beschrijving van het materiaalgedrag voor een ferritisch roestvrij staal is verkregen met behulp van een elasto-plastisch model met Von Mises plasticiteit onder de veronderstelling van isotrope versteviging. De materiaalparameters zijn experimenteel bepaald voor logaritmische rekken tot 3 met behulp van trekproeven aan voorgewalst materiaal. Voor de verificatie is een vlakke-rek ponsopstelling gebruikt waarmee zowel de materiaalvervorming (met een digitale beeldverwerkingstechniek) als de stempelkracht, in-situ gemeten kunnen worden. Het numerieke model blijkt het ponsproces nauwkeurig te beschrijven tot aan breuk.

Van taaie breukinitiatie is bekend dat het sterk afhangt van de vervormings- en belastingsgeschiedenis. De beschrijving hiervan is gerealiseerd met behulp van een algemene klasse van breukmodellen waarbij taaie breuk wordt verondersteld te initiëren wanneer een integraal over de plastische rek, als functie van de genoemde geschiedenis, een kritieke waarde bereikt, gegeven door de materiaalparameter $C$. De experimentele bepaling van deze parameter vormt het voornaamste aandachtspunt. Uit 
literatuuronderzoek is gebleken dat het vrijwel onmogelijk is met een bestaand criterium breuk te voorspellen in sterk verschillende belastingssituaties. Deze kritieke parameter wordt dan ook meestal bepaald in een experiment dat qua belastingstoestand erg lijkt op de gewenste toepassing.

In eerste instantie is daarom een procedure gebruikt waarbij de kritieke parameter $C$ bepaald wordt in een ponsexperiment met één bepaalde snijspleet. Het blijkt dat, met een geringe aanpassing van het Rice \& Tracey criterium, breukinitiatie nauwkeurig voorspeld kan worden voor een brede klasse van procesparameters (snijspleet en snijradius van de stempel) voor het roestvrij staal.

Een eenvoudige proef verdient echter de voorkeur. Daarom wordt in de tweede procedure een trekproef gebruikt om de kritieke materiaalparameter $C$ te bepalen. Hierbij is dan een criterium nodig dat in verschillende belastingstoestanden geldig is. Omdat de bekende criteria hier niet aan voldoen is een nieuw criterium voorgesteld dat tevens is gecontroleerd in trekproeven onder verschillende hydrostatische drukken. Voor verschillende procesparameters worden goede resultaten behaald met betrekking tot de voorspelling van taaie breuk voor het roestvrij staal.

Het effect van stempelsnelheid is onderzocht met behulp van een elasto-viscoplastisch materiaalmodel dat de reksnelheidsinvloeden beschrijft. Voor industriële stempelsnelheden, tot ongeveer $10[\mathrm{~mm} / \mathrm{s}]$, wordt de maximale stempelkracht beïnvloed door de processnelheid. Tot aan diezelfde snelheid is echter geen verandering waargenomen in het moment van breukinitiatie voor verschillende snelheden. De simulaties komen hierin goed overeen met de experimenten. Voor de correcte beschrijving van ponsprocessen met hogere snelheden is een thermo-mechanische koppeling nodig, inclusief de bijbehorende materiaalparameters.

De twee procedures, die zijn ontwikkeld voor het roestvrij staal - karakterisatie van breuk enerzijds in een ponsexperiment en anderzijds in een trekproef - zijn vervolgens geverifieerd voor vier andere metalen. Goede resultaten zijn verkregen met behulp van het ponsexperiment in combinatie met het aangepaste Rice \& Tracey criterium. De bepaling van de kritieke waarde in een relatief eenvoudige trekproef geeft bevredigende resultaten in combinatie met het nieuwe criterium. Deze laatste procedure verschaft de industrie een snelle en goedkope methode om de geponste rand van een produkt te voorspellen. In tegenstelling tot bestaande criteria kan het nieuwe criterium taaie breuk voorspellen in zowel het ponsproces als in trekproeven onder verschillende hydrostatische drukken. Extra onderzoek is nodig om de geldigheid van dit nieuwe criterium voor andere omvormprocessen te testen.

Tot slot is de invloed van korrelgrootte op de reproduceerbaarheid van het ponsproces onderzocht. Er zijn experimenten uitgevoerd met zes en minder korrels over de dikte van de plaat, welke zijn verkregen met een rekristallisatie proces. Bij het ponsen van een-kristallen heeft de kristaloriëntatie een grote invloed op de vervormingen en grote onderlinge verschillen worden waargenomen. Het ponsproces is nog redelijk reproduceerbaar bij een plaat met ongeveer zes korrels over de dikte, omdat de randvoorwaarden van het gereedschap de vervormingen in grote mate beperken. 


\section{Dankwoord}

Graag wil ik iedereen bedanken die een bijdrage heeft geleverd aan het tot stand komen van dit proefschrift, met name de hieronder genoemde personen.

Frank Baaijens en Leon Govaert hebben met hun begeleiding de basis gecreëerd om dit werk uit te kunnen voeren. Het enthousiasme van Leon heeft mij goed gedaan.

Grote dank gaat uit naar Dirk Brokken. Zonder zijn numerieke vernuft en collegialiteit was er niets van het hele ponsproject terecht gekomen. Yvonne Stegeman heeft met haar afstudeerproject een enorme bijdrage geleverd aan de experimentele verificatie van het numeriek model. Liviu Răulea en Patrick Zuidema hebben geholpen bij de bereiding van het toetje.

Zonder de hulp van Han Meijer, Marc Geers, Cees Oomens, Rob Petterson, Luc Tillie, Jan Faessen, Theo van Duppen, Leo Wouters, Patrick van Brakel, Rob van de Berg, Toon van Gils, 'professor' Sjef Garenfeld en de GTD was dit project een fiasco geworden. Speciale dank treft Marcel Brekelmans voor alle waardevolle gedachtewisselingen.

De ondersteuning en industriële terugkoppeling vanuit Philips is ook van belang geweest. In het bijzonder wil ik Kees Donkers en Jan Post bedanken.

Mijn (ex-)kamergenoten Nathan van de Wouw, Niels Geerts, Marco Moens en Harold van Melick hebben gezorgd voor de plezierige afleiding. Ook het zesde ('Never shoot a winning horse!' ) heeft hier aan bijgedragen.

Van mijn vrienden wil ik speciaal de Seize Bouteilles bedanken. Daarbij wil ik nog kwijt dat de volgende verloren dag ruimschoots wordt gecompenseerd door de intensiteit van een SB-avond.

Mijn ouders en ook Fred en Enky wil ik bedanken voor hun vertrouwen.

Last but not least: Pien. Ik had nooit gedacht dat een beetje gerommel om me heen zo belangrijk kon zijn voor het voltooien van een proefschrift.

Ad Goijaerts,

15 december 1999 
98 Dankwoord 


\section{Curriculum Vitae}

27 december 1970

september 1983 - juni 1989

september 1989 - juni 1990

september 1990 - augustus 1995

november 1995 - december 1999
Geboren te Schijndel.

Gymnasium $\beta$, Gymnasium Bernrode, Heeswijk-Dinther.

Propedeuse Werktuigbouwkunde, Technische Universiteit Eindhoven.

Werktuigkundige Medische Technologie, Technische Universiteit Eindhoven.

Assistent in Opleiding,

Sectie Materials Technology,

Technische Universiteit Eindhoven. 